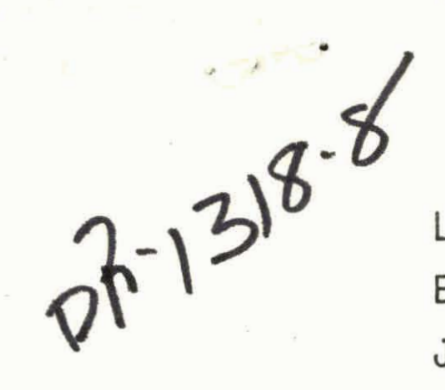

Mmกตร

NOTICE

THIS REPORT IS ILLEGIBLE TO A DEGREIE

THAT PRECLUDES SATISFACTORY REPRODUCIION

FLOW-INDUCED VIBRATION STUDY

IN THE LOFT STEAM GENERATOR

C. F. Carmichael
LOFT TECHNICAL REPORT LTR 1141-30

EG\&G REPORT NUMBER RE-A-77-045

JULY 21, 1977

EGG/LTR--11
DE85 015471

$141-30$ 


\section{DISCLAIMER}

This report was prepared as an account of work sponsored by an agency of the United States Government. Neither the United States Government nor any agency Thereof, nor any of their employees, makes any warranty, express or implied, or assumes any legal liability or responsibility for the accuracy, completeness, or usefulness of any information, apparatus, product, or process disclosed, or represents that its use would not infringe privately owned rights. Reference herein to any specific commercial product, process, or service by trade name, trademark, manufacturer, or otherwise does not necessarily constitute or imply its endorsement, recommendation, or favoring by the United States Government or any agency thereof. The views and opinions of authors expressed herein do not necessarily state or reflect those of the United States Government or any agency thereof. 


\section{DISCLAIMER}

Portions of this document may be illegible in electronic image products. Images are produced from the best available original document. 
WORK REQUEST NO. 52151-543-382

LTR \# 1741-30

Date Published by CDCS 10ct. 18, $1977^{\square}$

NOTES<smiles>C[14CH2]</smiles>

\title{
MAN ONLS
}

PORTIONS OF THIS REPQPRT ARE II ER:GE. F

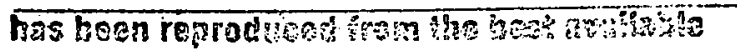
cory to permit the troades prssible avaiàishy

\section{RESEARCH, ENGINEERING AND CONSTRUCTION REPORT ENGINEERING ANALYSIS DIVISION}

\author{
THERMAL ANALYSIS \\ FLOW-INDUCED VIBRATION STUDY \\ IN THE I.DFT STEAM GENERATOR
}

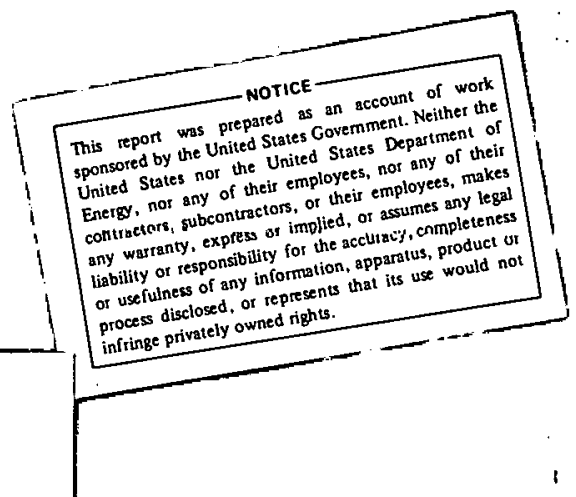

This report was prepared as an account of work sponsored by an agency of the United States Government. Neither the United States Government nor any agency thereof, nor any of their employees, makes any warranty, express or implicd, or assumes any legal liability or responsibility for the accuracy, completencss, or usefulness of any information, apparatus, product, or process disclosed, or represents that its use would not infringe privately owned rights. Reference herein to any specific commercial product, process, or service by trade name, trademark, manufacturer, or otherwise does not necessarily constitute or imply its endorsement, recommendation, or favoring by the United States Government or any agency thereof. The views and opinions of authors expressed herein do not necessarily state or reflect those of the United States Government or any agency thereof.

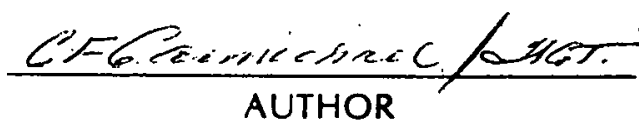

C. F. Carmichael

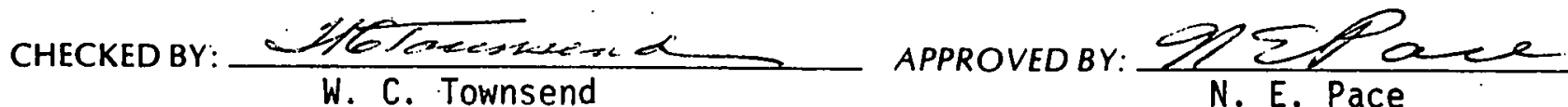
W. C. Townsend

N. E. Pace

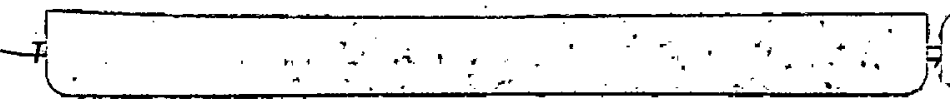
$\therefore+$

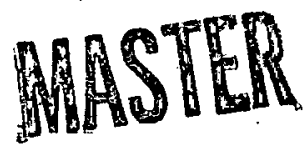




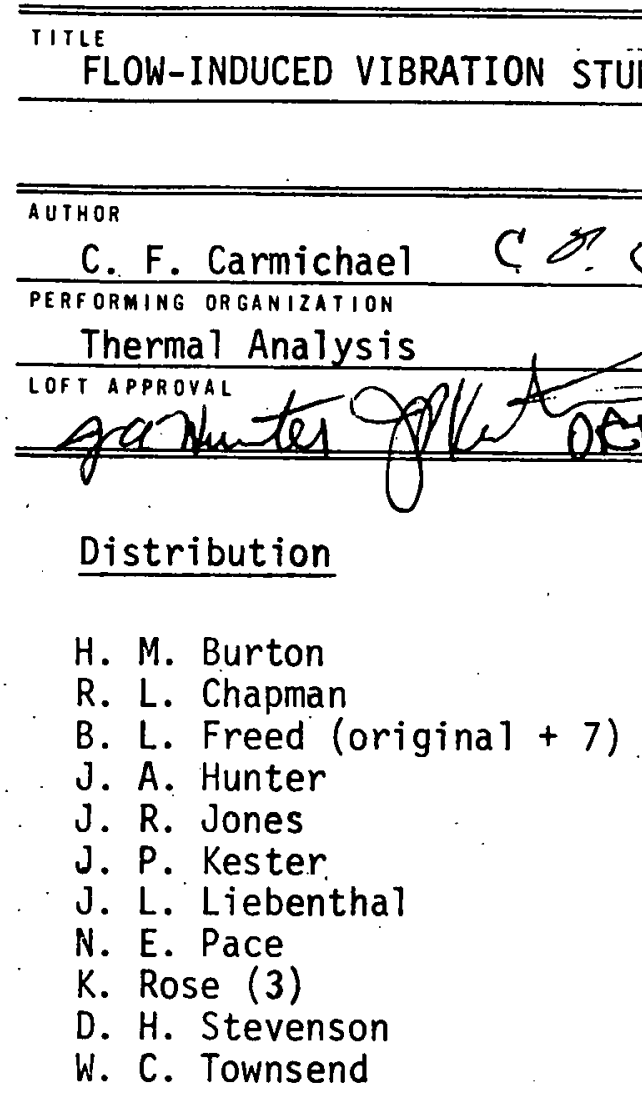


SUMMARY

The consequences of flow induced vibration in the LOFT steam generator were studied. Tube-baffle contact and fretting wear are expected to occur while tube-tube contact is not predicted. The LOFT steam generator is, in all probability adequate from a fluid induced viewpoint for the scheduled service of the LOFT facility at power. 
TABLE OF CONTENTS

Page

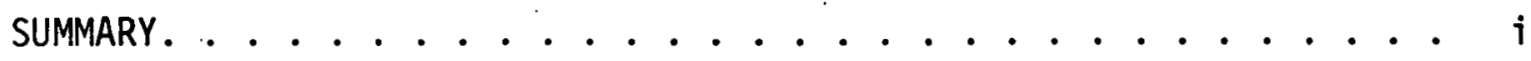

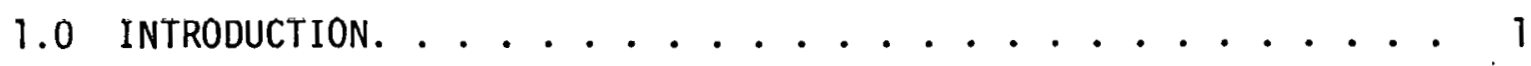

1.1 Description of System. . . . . . . . . . 1

1.2 Purpose of the Analysis.............. 1

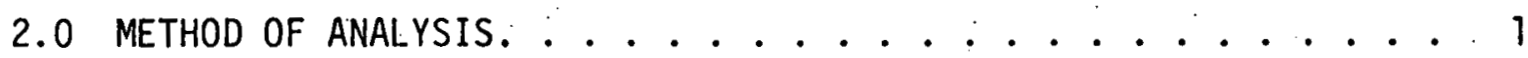

3.0 DISCUSSION. .......................... 10

3.1 Previous Related Flow-Induced Vibration Studies. . . . 10

Assumptions Made In The Present Flow-Induced $\ldots \ldots \ldots$
Vibration Study. . . . . . . . . . 12

4.0 RESULTS ............................ 14

5.0 CONCLUSIONS .......................... 17

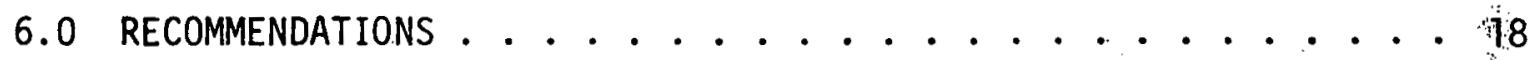

7.0 REFERENCES. . . . . . . . . . . . . . . . . 19

APPENDIX A - von Karman Vortex (Vortex-Sthedding) Excitation
Mechanism for Flow-Induced Vibration (FIV). . . . . A-i

APPENDIX B - Turbulent-Buffeting Excitation Mechanism for

Flow-Induced Vibration (FIV). .......... B-i

APPENDIX C - Fluidelastic Instability (Whirling) Excitation Mechanism for Flow-Induced Vibration (FIV). . . . . C C-i

APPENDIX D - Tube Natural Frequencies and Damping Ratios ..... D-i APPENDIX E - Physical Properties and Geometric Details . . . . . E-i APPENDIX F - U-Tube Bend Region. ................. F-i

APPENDIX G - SAP-IV Models for Vibration Response of U-Tubes in the Bend Region of the LOFT Steam Generator. . . . . G-i

APPENDIX H - Flow Parameters for LOFT Steam Generator Straight-Tube Sections............H-i 


\section{LIST OF TABLES AND FIGURES}

Page

TABLE I. LOFT Steam Generator Thermal-Hydraulic Parameters. . . . 2

TABLE II. Natural Frequencies of Straight-Tube Sections of LOFT Steam Generator Bundle . . . . . . . 15

TABLE III. Natural Frequencies of U-Tube Bend for Out-ofPlane Motion of the Largest U-Bend ......... 16

Figure 1. Schematic of LOFT Steam Generator Tube Bundle Assembly ................. 3

Figure 2. LOFT Steam Generator Shell Side Flow Velocities And Dynamic Pressures. . . . . . . . . . . 6

Figure 3. Velocity Distribution in U-Tube Bundle Region At Top of LOFT Steam Generator . . . . . . . . . 7

Figure 4. Critical Gap Velocity for Onset of Fluidelastic Whitiling.............. 8

Figure 5. Vortex Shedding Frequency for Straight Tube Region ... 9 
1.0 INTRODUCTION

\subsection{Description of System}

The LOFT Steam Generator $(1-10)(11)$ is a vertical U-tube type heat exchanger which transfers heat generated in the reactor core, from the primary to the secondary coolant system. Thermal-hydraulic design parameters of the steam generator are given in Table I. A sketch of the tube-bundle dimensions, based on the referenced drawings, appears in Figure 1.

\subsection{Purpose of the Analysis}

Vibration of the straight sections as well as the U-bends of the steam generator tubes, results from transient forces due to steam-water flow past the tubes. The purpose of the analys is is to identify the important fluid-induced vibration (FIV) mechanisms and the resulting forces acting on the tubes, to determine those regions of the tube bundle which have the largest-amplitude motions in response to FIV forces, and to decide whether tube-baffle contact or tube-tube collision occurs under the given flow conditions.

\subsection{METHOD OF ANALYSIS}

The consequences of flow-induced vibrations (FIV) for the LOFT Steam Generator, were investigated for a 1 imited number of cases that were considered to be likely or potential problem areas. The assumptions and general basis for developing these cases are covered below in the Discussion. Due to the extremely large number of possible combinations of physical parameters that could be investigated, no attempt was made to provide an exhaustive study of all combinations; nor wä such an exhaustive study con-sidered necessary, especialiy in view of the many uncertainties that still exist in this field. 


\section{TABLE I}

\section{LOFT Steam Generator}

\section{Therma 1-Hydraul ic Parameters}

Totàl Number of U-Tubes (2 straight sections each) - 1845

Tube Side (Prïmary Coolant System) Nominal Pressure - 2250 DS

Shell Side (Secondary Coolant System) Nominal Pressure - 850 psia

Tube Side Nominal Mass Flowrate

$2.1 \times 10^{6} \mathrm{lbm} / \mathrm{hr}$.

Tube Side Maximum Mass Flowrate

$3.9 \times 10^{6} \mathrm{lbm} / \mathrm{hr}$.

Shell Side Minimum Mass Flowrate

$4.39 \times 10^{5} \mathrm{lbm} / \mathrm{hr}$. (34)

Shell Side Maximum Mass Flowrate

$6.59 \times 10^{5} \mathrm{ibm} / \mathrm{hr}$. (34)

Tübe Material

Inconel -600

Spacing

Equilateral Triangle

Tube ID $/ 00$

$0.402 / 0.500$ inches

Tube Wa11 Thickness

0.049 inches (\#18 BWG)

Tube Pitch

0.75 inches

Length of Straight Section, Up to but not including II-Rend

84 inches (ineludes tubesheet)

U-Bend Maximum Diameter (Between Centers)

49.5 inches

U-Bend Minimum Diameter (Between Centers)

3.0 inches

Number of Shell-Side Baffles

3 (not including. End Support Plate Baffle)

Baffle Spacing

17.375 inches (evenly spaced) 


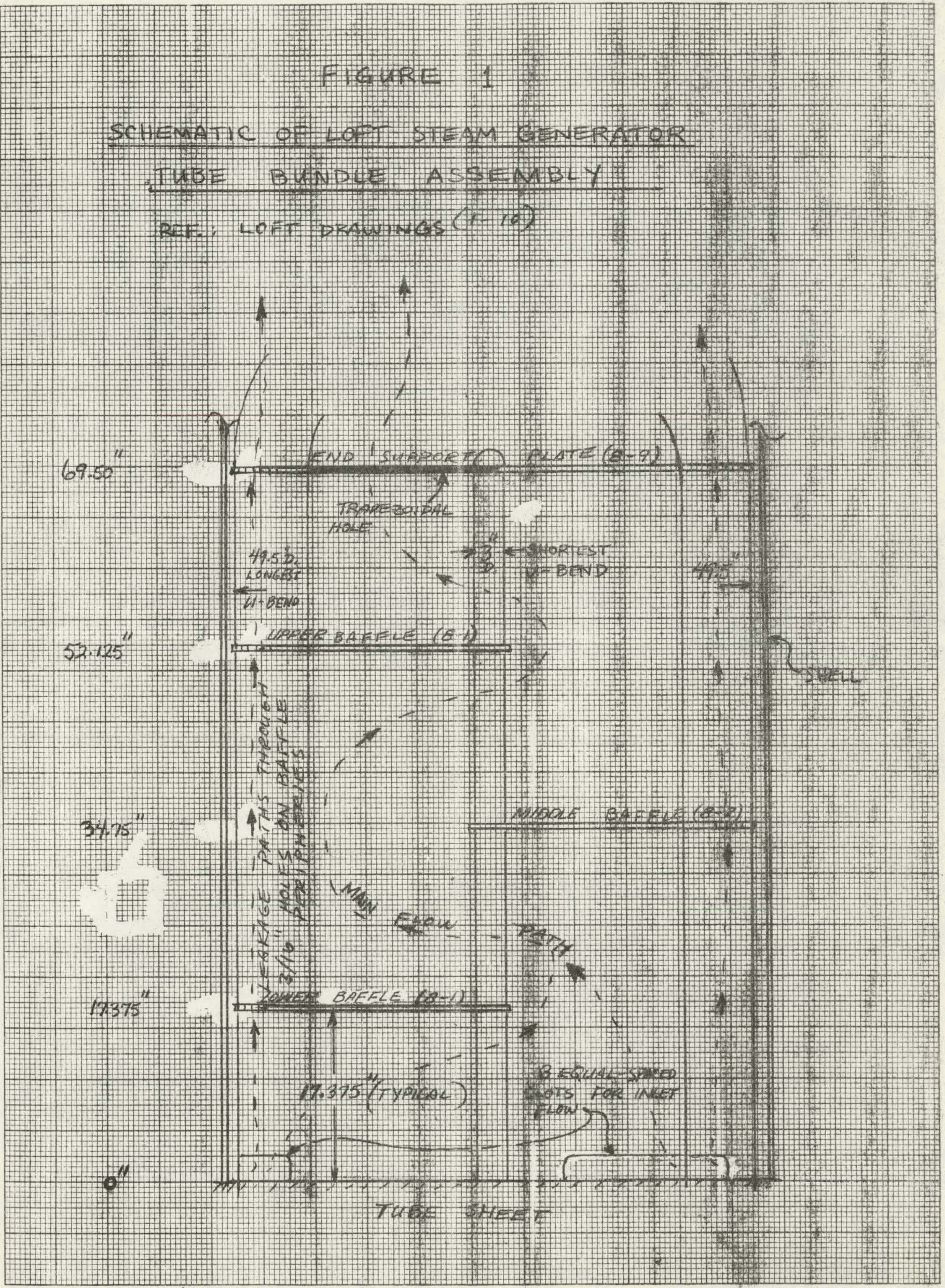


The method of analysis which evolved, was as follows:

1. The three most important probable FIV excitation mechanisms were identified (von Karman vortex shedding, turbulent buffeting, and fluidelastic excitation). The first two mechanisms were considered separately, since they interfere with ach other, and the third was assumed to originate from either one of the others, so that it also could be considered separately.

2. Shell-side flow velocities for the expected operating conditions were estimated for each tube bay in the straight-tube baffle sections (Appendix $\mathrm{H}$ ), and the U-tube bend region (Appendix F). These velocities are presented in Figures 2 and 3, respectively.

3. Critical flow velocities for the onset of fluidelastic instability were calculated (Appendix C) and are presented in Figure 4. Tube damping ratios in the ranges measured by Halle et al ${ }_{9}^{(23)}$ were used to scope the expected results.

4. Forcing-function frequencies and amplitudes were estimated for the vortex-shedding mechanisms (Appendix A), based on the work of Y. N. Chen $(14)(15)(16)$ and the flow velocities estimated previously.

5. Turbulent-buffeting mechanism estimated forcing frequencies and amplitudes were based on the flow velocities, and on the work of P. R. Owen ${ }^{(17)}$ and A. A. Townsend (18).

6. Tube natural frequencies were estimated, based on the developments summarized in Shin and Wambsgenss, (12) and in Thomson (31).

7. Tube-baffle contact was predicted by assuming several cases for the longest possible unsupported tube spans and comparing forcing 
frequency, tube natural frequency, tube amplification factor (consider as a single-degree-of-freedom system), and tube deflection, with baffle clearance. These results are summarized in Figure 5 and Appendix A.

8. Tube-to-tube collision in the straight-tube section was predicted not to occur from either mechanism (vortex shedding or turbulent buffeting).

9. The longest remaining unsupported tube spans of interest at this point, were located in the U-tube bend region at the top of the steam generator. Two structural models then were generated with the SAP4 code, in order to study the maximum deflection responses of the $U$-tube bends in this region (summarized in Appendix $G$ ). These results show that small finite tube motions do exist resulting in fretting wear on the tubes, baffles and tube support spaces; however, tube-to-tube collision does not occur here for the given operating conditions. 


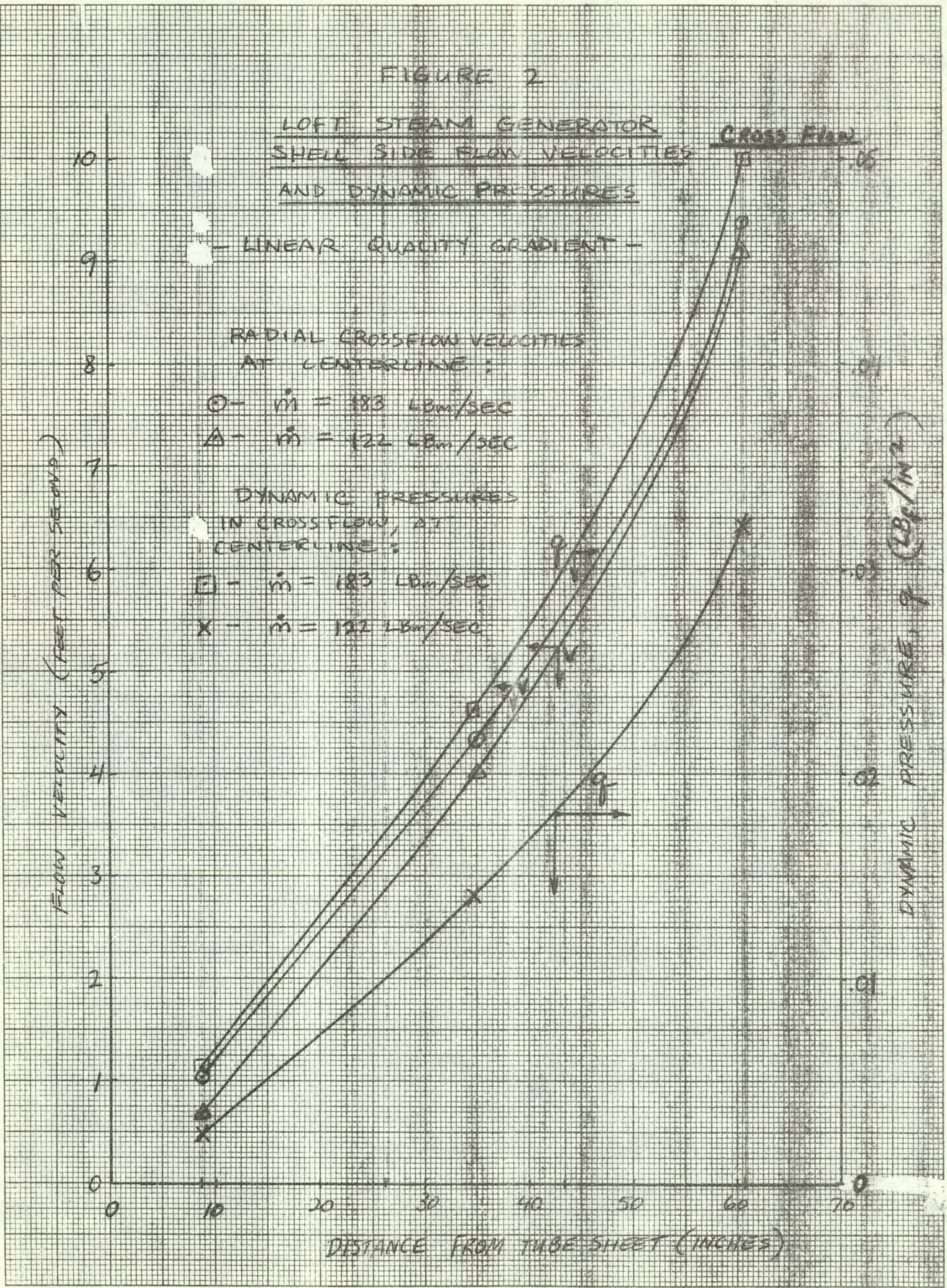




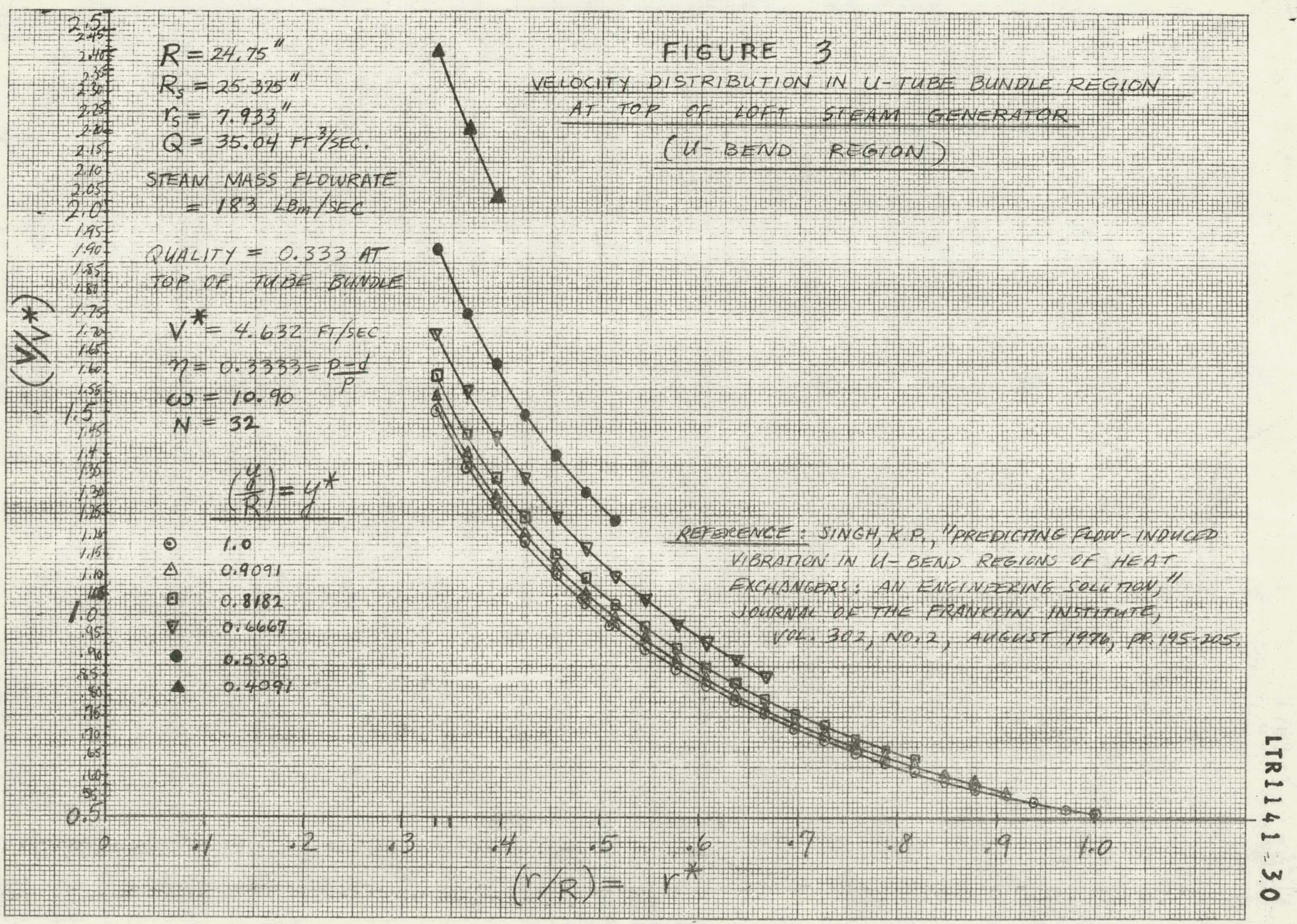


Mre1141 30

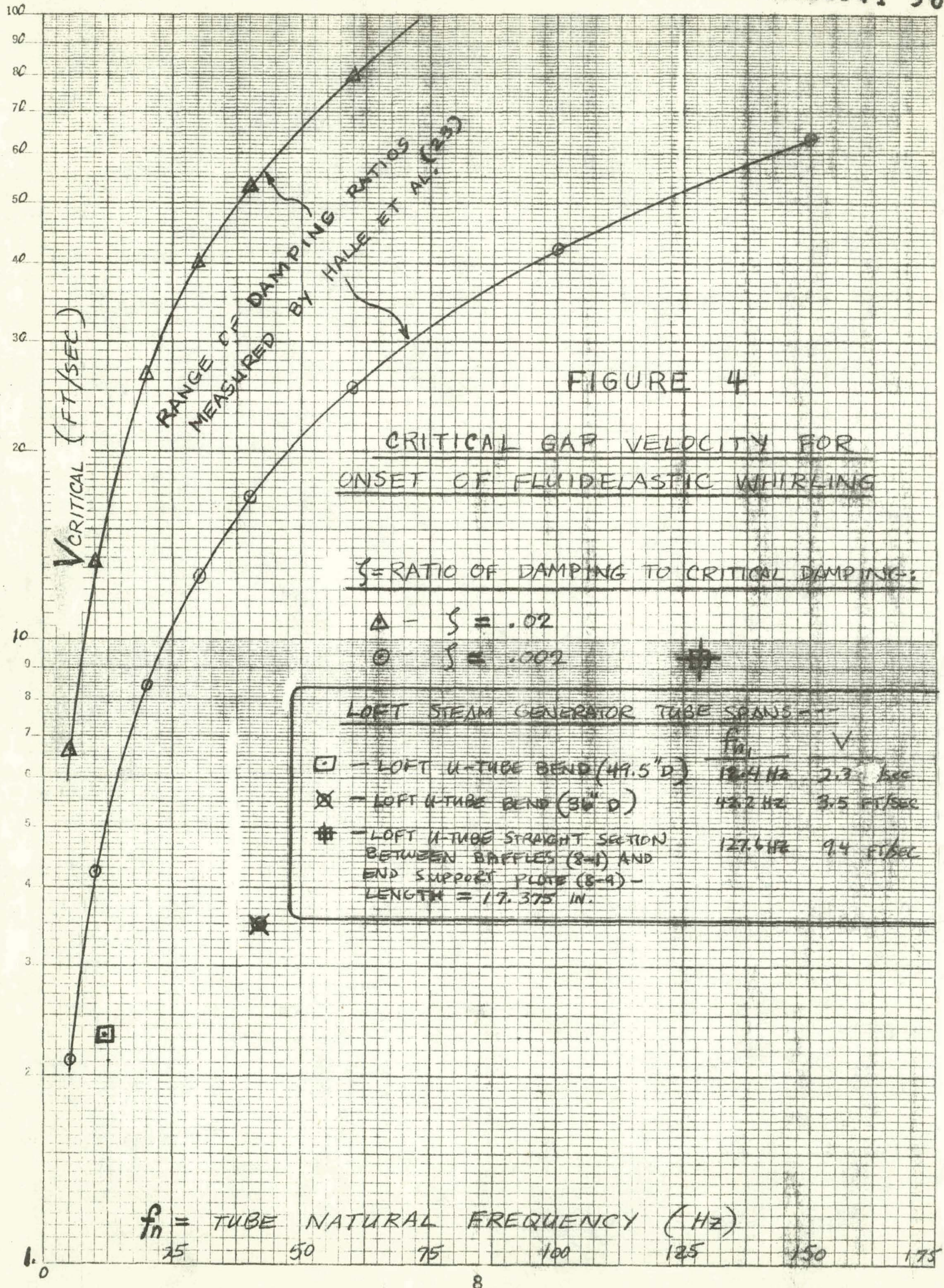




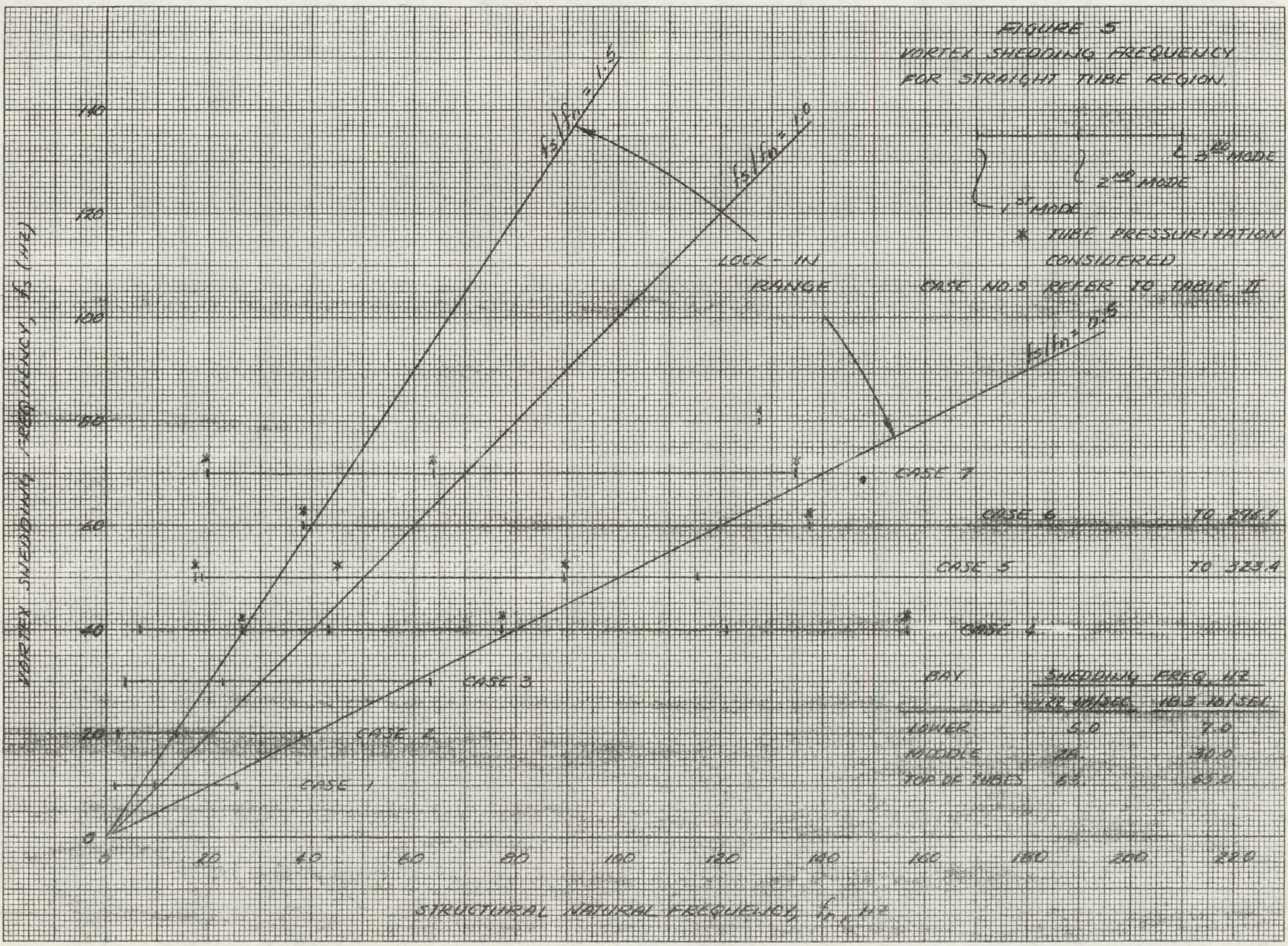




\subsection{DISCUSSION}

\subsection{Previous Related Flow-Induced Vibration Studies}

Messrs. Shin and Wambsganss ${ }^{(12)}$ have published a state-of-the-art review of flow-induced vibration (FIV) in LMFBR steam generators, which has influenced this analys is to a considerable extent.

Some of their more important findings were as follows:

(a) crossflow has a much higher potential than parallel flow for causing tube vibration damage;

(b) an increase of tube-baffle hole clearance causes decreased tube natural frequency;

(c) shell-side flow represents the primary source of flow-induced vibration;

(d) anti-vibration bar regions and U-tube bend regions are vulnerable to FIV damage:

(e) FIV forcing mechanisms include vortex shedding, turbulent buffeting, fluidelastic whirling, jet switching, and systemdependent sources (structural-borne noise and flow oscillae. tions);

(f) the state of the art is inadequate to predict accurate shel1side flow velocity distributions;

(g) added mass of fluid, internal pressurization of tubes, and $U$ tube bend curvature all affect tube natural frequency and must be accounted for;

(h) tube natural frequencies should be separated from shedding frequencies by a factor of 3 if flow velocities cannot be predicted accurately; 
(i) dominant turbulent-buffeting frequency should be separated from the tube natural frequencies,

(j) tube natural frequencies must be greater than the vortex shedding frequency, dominant turbulent-buffeting frequency, and fluidelastic critical whirling frequency;

(k) maximum expected tube displacement must be less than half the tube gap in order to avoid tube-to-tube contact;

(1) maximum combined stresses due to FIV loads plus thermal and gravity loads, must not exceed the tube fatigue-endurance limits, and

(m) sufficient cycles should be available to avoid tube fallure due to wear at baffle support points.

Savkar ${ }^{(13)}$ studied the effects of added mass, vortex shedding, turbulent buffeting, and motion-dependent instabilities. He concluded that several unresolved issues sti.l1 exist:

(a) the effect of separated crossflow on added mass,

(b) the effect of ignoring the Reynolds Number in unsteady fluid motion, and

(c) the'explanation of vortex-shedding. "lock-in" at resonance. In addition, Savkar shows that the added mass corrections due to Fritz ${ }^{(14)}$ ignore the effect of frequency-dependent drag force on the tube. The value of the fluctuating vortex-shedding drag coefficient at twice the Strohhal frequency is given as the order of 0.2 (comparable to the values given by Shin and Wambsganss). Vortex-shedding lift force measurements are shown to mutually repel neighboring cylinders, opposite to the predictions of potential flow theory. 
Y. N. Chen $(14)(15)(16)$ reported vortex-shedding lift coefficient and Strouhal Number values for tube bundles with both staggered and in-line spacing. There is apparently disagreement between Chen and Owen (17) as to whether the predominant fluid forcing mechanism deep within a tube bundle is vortex-shedding or turbulent-buffeting (or perhaps fluidelastic instability). The vortex-shedding calculations on the LOFT Steam Generator were based on Chen's work.

P. R. Owen ${ }^{(17)}$ derived an expression for the dominant turbulentbuffeting mechanism frequency in crossflow. A. A. Townsend ${ }^{(18)}$ measured turbulence intensity levels in air flow downstream of a transvierse circular cylinder; his results were also reported by J. 0. Hinze ${ }^{(19)}$.

Fluidelastic mechanisms in tube arrays (whirling instabilities) were investigated by H. J. Connors, ${ }^{(20)}$ R. D. Blevins, (21) and S. S. Chen:

U-tuhe critical damping ratios were measured by Halle et al. (23)

K. P. Singh ${ }^{(24)}$ developed a model for flow velocities in the U-bend region of a tube bundle. Kays and London ${ }^{(25)}$ reported pressure drop information for tube bundles which was used in this analysis. Tinker $(26)$ investigated the shell-side flow characteristics of heat exhcangers. The work of Gerlach and Dodge; (27) Chen, Rosenberg and Wambsganss; ${ }^{(28)}$ and Chen and Weber, (29) provided additional background for the present study.

\subsection{Assumptions Made in The Present Flow-Induced Vibration Study}

There are an almost infinite number of possible combinations of fluid forcing mechanisms, flow conditions, baffle misalignments, critical damping ratios, turbulence intensities, and tube natural frequencies, that could be investigated in a flow-induced vibration study of the LOFT Steam Generator. In order to reduce the number of cases to be studied in detail to a manageable level, the findings of Shin and Wambsganss, (12) and Savkar (13) were 
used as a guide. The major assumptions that were made for this study, were as follows:

(a) the effects of tube-side flow (parallel flow) could be ignored;

(b) system-dependent excitation mechanisms (structural-borne: noise and unsteady-state flow oscillations) were neglected;

(c) the excitation mechanisms of von Karman vortex shedding and turbulent-buffeting were considered to interfere with one another and therefore could be considered separately;

(d) the important FIV exciting mechanisms were considered to be (1) von Karman vortex shedding, (2) turbulent buffeting, and (3) fluidelàstïc excitation resulting from (1) and (2);

(e) acoustic resonance of the heat exchanger shell with the exciting mechanisms could be ignored, due to the relatively small shell diameter in the region of gas (steam) flow, and low flow veloes ities; and

(f) the U-tube bend region was a critical location for FIV. 


\subsection{RESULTS}

Results of this study indicate the existence of general tube-baffle contact throughout the LOFT Steam Generator, except for the lowest baffle. Tube-to-tube collision, accoustic resonance, and fluidelastic instability are not predicted.

Estimated cross-flow shell-side velocities in the straight tube sections of the bundle at the centerline are presented in f1gure 2\% Straighttube sections on the bundle periphery are expected to see lower cross-flow velocities than these, due to the combined effects of the $3 / 16^{\prime \prime}$ diameter. baffle-perforation leakages and turning of the flow at the outer edges of the bundle.

Estimated flow velocities are given in Figure 3 for the U-tube region. Selected tube natural frequencies are given in Tables II (straight sections) and III (U-bend region), as well as Appendix D. 


\section{TABLE II*}

Natural Frequencies of Straight-Tube Sections

of LOFT Steam Generator Bundle

(Beam No.) and

Assumed Tube-Section

Boundary Conditions

(1) U-Tube Cantilivered from Tube Sheet

(2) Contact Between $\mathrm{U}$-Tube and Lower Baffle (Plate $8-1) \star \star ~$

(3) Contact Between $U$-Tube and Middle Baffle (Plate 8-2)

(4) Contact Between U-Tube and Upper Baffle (Plate 8-1)

(5) Contact Between $U$-Tube and End Support Baffle (Plate 8-9)

(6) Contact Between U-Tube and both the Upper and Lower Baffles (8-1)

(7) Contact Between U-Tube, End Support. Baffle (8-9), and Lower Support Baffle $(8-1)$.
Unsupported Span
Description ..

No Baffle Contact-Entire U-Tube Cantilevered

U-Tube Cantilevered

from Lower Baffle

(P1ate 8-1)

Cantilever U-Tube

Trom Middle Baffle

(P1ate 8-2)

(a) Cantilever U-Tube from Upper Baffle (Plate 8-7)

(b) Clamped-Hinged U-Tube below Upper Baffle (Plate 8-1)

(a) Cantilever U-Tube Above End Support Plate (8-9)

(b) Clamped-Hinged U-Tube Beiuw End Supporte Baffie:-:

Simply Supported Tube Between Both $(8 \div 1)$ Baffles (Hinged-Hinged)

Simply Supported Tube from End Support Baffle (PIate 8-9) to Lower Support Baffle (P1ate 8-1) (Hinged-Hinged)

\begin{tabular}{|c|c|}
\hline $\begin{array}{l}\text { Unsupported } \\
\text { Span (tin.) }\end{array}$ & $\begin{array}{c}f n= \\
\text { Natural } \\
\text { Frequency } \\
(\mathrm{Hz})\end{array}$ \\
\hline $96.77 \mathrm{in.}$ & $\begin{array}{l}1.5 \mathrm{~Hz} \\
9.2 \\
25.7\end{array}$ \\
\hline $79.40 \mathrm{in.}$ & $\begin{array}{r}2.2 \\
13.6 \\
38.1\end{array}$ \\
\hline $62.03 \mathrm{in.}$ & $\begin{array}{r}3.6 \\
22.6 \\
63.3\end{array}$ \\
\hline
\end{tabular}

44.66 in.

6.9

43.3

121.3

$52.125 \mathrm{in.}$

26.50 77.40
156.80

$27.285 \mathrm{in}$.

56.80

69

69.50 in

115.5

323.4

17.40

45.00

89.50

$34.75: t n$.

38.30

137.40

296.90

52.125 in.

19.90

64.00

$13 \% .80$

\section{1}

1

2

3 
TABLE III*

Natural Frequencies of U-Tube Bend for Out-of-Plane. Motion of the

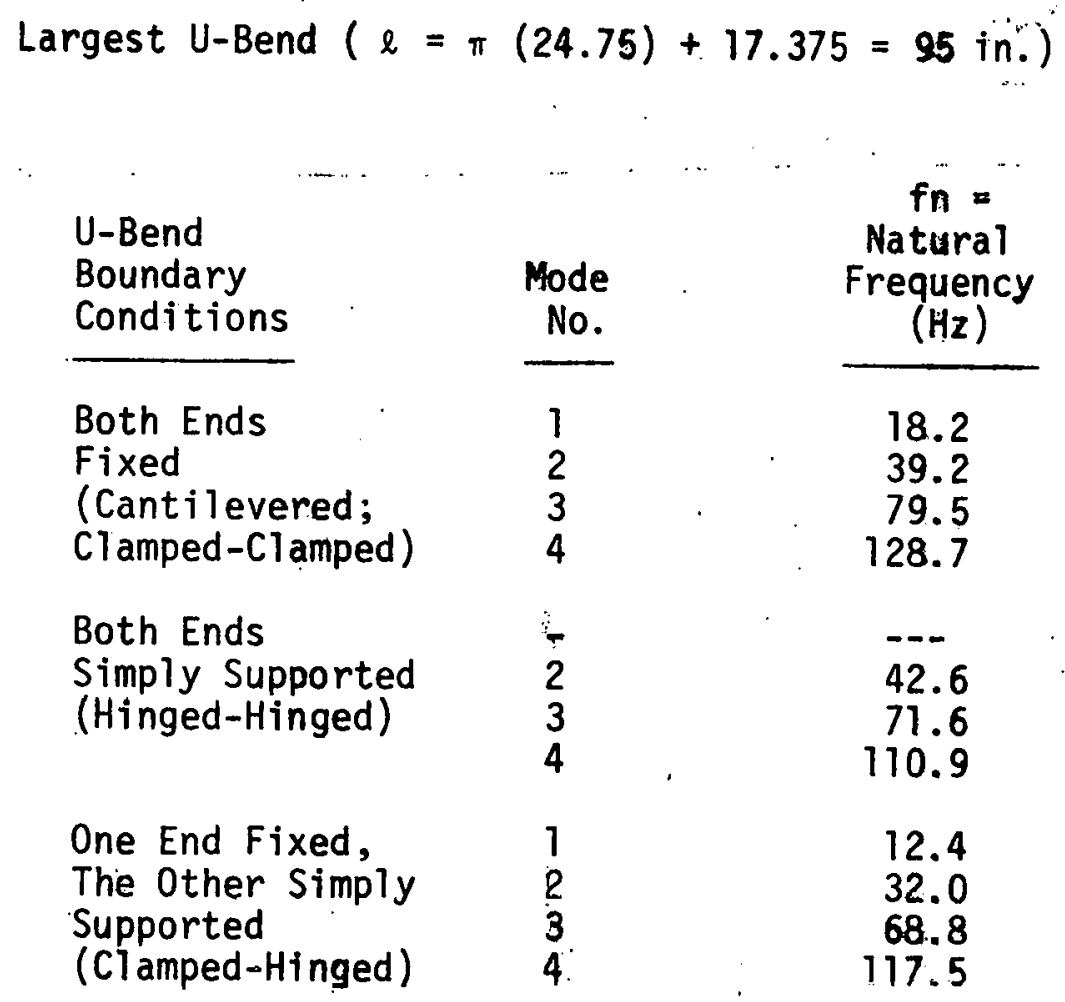

* - See also Appendix D. 


\subsection{CONCLUSIONS}

1. Tube-baffle contact due to flow-induced vibration exists in the LOFT Steam Generator for all baffles except the lowest one, for the given operating conditions.

2. Fretting is expected to occur at those tube-baffle locations considered in this study. Fretting is the only result of concern at power operation and can result in baffle hole enlargement and/or tube damage; however, fretting is not expected to be significant in the LOFT Steam Generator because (1) similar steam generators operating at higher power revels and flow apparently do not have serious fretting problems, and (2) the scheduled operation time at power is short.

3. Tube-to-tube collision is not predicted in the LOFT Steam Generator, for the given operating conditions.

4. Fluidelastic instability is not predicted in the LOFT Steam Generator for the given operation conditions.

5. Acoustic resonance of the LOFT Steam Generator shell with one of the flow exciting mechanism, is not predicted. 


\subsection{RECOMMENDATIONS}

Additional structural and hydraulic analyses are not recommended (1) because of the inadequacy of accurately predicting the required forcing function in the two-phase fluid regime, and (2) the short operation times the steam generator will be operating at power. (The LOFT steam generator should not suffer failure due to tube vibration during its intended operational life unless caused by gross flow instability within the steam generator. Gross flow instability would cause more severe problems in operating the plant and should not occur wi thout beting detect.) 


\subsection{REFERENCES}

1. ANC Drawing No. 206161, "LOFT Steam Generator Outline," October 29, 1973.

2. ANC Drawing No. 206162, "LOFT Steam Generator General Assenbity," October 29, 1973.

3. ANC Drawing No. 206163, "LOFT Steam Generator Channel Head and Connections," October 29, 1973.

4. ANC Drawing No. 206164, "LOFT Steam Generator Lower Shell SubAssembly," October 29, 1973.

5. ANC Drawing No, 206165, "LOFT Steam Generator Upper Shel1 SubAssembly," October 29, 1973.

6. ANC Drawing No. 206166, "LOFT Steam Generator Shell Side Nozzles and Openings,". October 29, 1973.

7. ANC Drawing No. 206167, "LOFT Steam Generator Primary Steam Separation Equipment and Details," October 29, 1973.

8. ANC Drawing No. 206168, "LOFT Steam Generator Tube Bundle Détailsit" October 29, 1973.

9. ANC Drawing No. 206169, "LOFT Steam Generator Tube Sheet Detạils," October 29, 1973.

10. ANC Drawing No. 206170, "LOFT Steam Generator Channel Partition Details," October 29; 1973.

11. D. H: Stevenson, Private Communication.

12. Shin, Y. S., and Wambsganss, M. W., "Flow-Induced Vibration in LMFBR Steam Generators: A State-of-the-Art Review," Nuclear Engi-neering and Design, Vol. 40 (1977) pp 235-284, North Holland Publishing Co., 1977.

13. Savlear, S. D., "A Survey of Flow-Induced Vibrations of Cylindrical Arrays in Crossflow," ASME Paper 76-WA/FE-21, Winter Annual Meeting, N.Y., December 5, 1976.

14. Chen, Y. N., "Flow-Induced Vibration and Noise in Tube-Bank Heat Exchangers Due to von Karman Streets," ASME Paper 67-Vibr-48, Boston, Mass., March 29-31, 1967.

15. Chen, Y. N., "Fluctuating Lift Forces of the Karman Vortex Streets on Single Circular Cylinders and in Tube Bundles, Part 3-ifift Forces in Tube Bundles," Journal of Engineering for Industry., May 1972, pp. 623-628.

16. Chen, Y. N., "Karman Vortex Streets and Flow-Induced Vibrations in Tube Banks," Journal of Engineering for Industry., February 1973, pp. $410-414$. 
17. Owen, P. R., "Buffeting Excitation of Boiler Tube Vibration," Journal of Mechanical Engineering Science, Vo1. 7, No. 4, 1965, pp. 431-439.

18. Townsend, A. A., "The Fully Developed Wake of a Circular Cylinder," Australian Journal of Scientific Research, Series A, Physical Sciences, Vol. 2, No. 4, December 1949, pp. 451-468.

19. Hinze, J. 0., Turbulence, McGraw-Hil1, 1959, New York, p. 397.

20. Connors, H. J., Jr., "Fluidelastic Vibration of Tube Arrays Excited by Cross Flow," ASME Symposium, Flow-Induced Vibration in Heat Exchangers, New York, December 1970, pp. 42-56.

21. Blevins, R. D., "Fluid Elastic Whirling of Tube Rows and Tube Arrays," ASME Paper 76-QA/FE-26, December 5, 1976/

22. Chen, S. S., Vibrations of a Row of Circular Cylinders in a Liquid, Argonne National Laboratory, ANL-CT-75-34, April 1975.

23. Halle, H., Boers, B. L., Jendrzejczyk, J. A., Lawrence, W. P., and Wambsganss, M. W., Flow-Induced Vibration Testing of Finned RFTEHTS/DHX U-Tubes, Argonne National Laboratory, ANL-75-6, December 1975.

24. Singh, K. P., "Predicting Flow-Induced Vibration in U-Bend Regions of Heat Exchangers: An Engineering Solution," Journal of the Frankl in Instittue, Vo1. 302, No. 2, August 1976, pp. 195-205.

25. Kays, W. M., and London, A.L., Compact Heat Exchangers, McGraw-Hill, New York, 1955, p. 21.

26. Tinker, T., "Shell-Side Characteristics of She11-and-Tube Heat Exchangers," ASME Transactions, Vol. 80, New York, November 25, 1956,", pp. 36-52.

27. Gerlach, C. R., and Dodge, F. T., "An Engineering Approach to Tube.. Flow-Induced Vibrations," ASME Symposium on Flow-Induced Vibration in Heat Exchangers, New York, December 1, 1970, pp. 18-26.

28. Ibid., pp. 27-35.

29. Ibid., pp. 57-77.

30. Spanner, J. C., Editor, Nuclear Systems Materials Handbook, Vol. Y: Design Data, February 1976, TID-26666-1, Hanford Engineering Devefopment Laboratory, Richland, Washington.

31. Thomson, W. T., Vibration Theory and Applications, Prentice-Halke: Englewood Cliffs, N.Y., 1965.

32. Bathe, K. J., Wilson, E. L., and Peterson, F. E., SAP IV--A Structural Analys is Program for Static and Dynamic Response of Linear Systeis. University of California, Berkeley, Californta, 1973. 
33. Rahl, R. G., Private Communication.

34. Townsend, W. C., Private Communication.

35. Fritz, R. J., "The Effect of Liquids on the Dynamic Motions of Immersed Solids," ASME Paper 71-Vibr-100, presented at the Vibrations Conference, Toronto, Canada, September 8-10, 1971.

36. Standards of Tubular Exchangers Manufdeturer's Association, $\therefore$ Tubular Exchanger Manufacturer's Association, New York, p. 120.

37. Spitzglass, J. M., "Orifice Coefficients--Data and Results of Tests," ASME Transactions, Vo1. 44, 1922, pp. 919-974. 


\author{
APPENDIX A \\ von Karman Vortex (Vortex-Shedding) Excitation \\ Mechanism for Flow-Induced Vibration (FIV)
}




\section{TABLE A-I}

SUMMARY OF LOCK-IN MATCHES BETWEEN 'KARMAN VORTICES AND'. TUBE NATURAL FREQUENCIES IN CROSS FLOW

A. Top of Bundle $\left(63<f_{S}<\mathrm{Hz}\right)$, centerline Case No. Beam No.

T. 3-3 Cantilevered U-Tube from Middle. Plate $8-2$

$$
\begin{aligned}
& (l=62.03 \text { in. }) \\
& f_{n_{3}}=63.3 \mathrm{~Hz}
\end{aligned}
$$

2.

$$
\begin{array}{ll}
\text { 4a-2 } & \text { Cantilevered U-Tube from Upper Plate } 8-1(l=44.66 \text { in. }) \\
4 a-3 & f_{n_{2}}=43.3 \mathrm{~Hz} \\
& f_{n_{3}}=121.3 \mathrm{~Hz}
\end{array}
$$

3. 5b-3 (Clamped-Hinged) Tube Below End Sypport.Plate

$$
\begin{aligned}
& (\ell=69.50 \text { in. }) \\
& f_{n_{3}}=89.5 \mathrm{~Hz}
\end{aligned}
$$

4. $5 b-2$ (Clamped-Hinged) Tube Below End Support Plate

$$
\begin{aligned}
& (l=69.50) \\
& f_{n_{2}}=45.0 \mathrm{~Hz}
\end{aligned}
$$

5. 7-2 Simply-Supported, (Hinged-Hinged) Tube from ESP

$$
\text { 8-9 to Lower SP 8-1 }
$$

$$
\begin{aligned}
& \left(\ell=52.125^{\prime \prime}\right) \\
& f_{n_{2}}=64 \mathrm{~Hz} \\
& f_{n_{3}}=138 \mathrm{~Hz}
\end{aligned}
$$


B. Middle Bay, $\&\left(27.9<f_{s}<30.3 \mathrm{~Hz}\right)$

Case No. Beam No.

6.

1-3 Entire U-Tube Cantilevered from. Tube Sheet

$(\ell=96.77$ in. $)$

$f_{n_{3}}=25.7 \mathrm{~Hz}$

7. 2-3 Cantilevered U-Tube from Lower Plate 8-1.

$(\ell=79.40 \mathrm{in.})$

$f_{n_{3}}=38.1 \mathrm{~Hz}$

8. 3-2 Cantilevered U-Tube from Middle Plate 8-2

$(\ell=62.03$ inc. $)$

$f_{n_{2}}=22.6 \mathrm{~Hz}$.

9. $4 b-1$ Clamped-Hinged Tube Below Upper Plate 8-1

$(\ell=52.125$ in. $)$

$f_{n_{1}}=31.2 \mathrm{~Hz}$

10. $5 b-2$ Clamped-Hinged Tube Below ESP

$(\ell=69.50 \mathrm{in.})$

$f_{n_{2}}=45.0 \mathrm{~Hz}$.

11. 6-1 Simply-Supported, (Hinged-Hinged) Tube Between

Both 8-1 SP's

$(\ell=52.125$ in. $)$

$f_{n_{2}}=64 \mathrm{~Hz}$. 
C. Lower Bay, $€\left(4.8<f_{s}<7.2 \mathrm{~Hz}\right)$

13. 1-2 Entire U-Tube Cantilevered from Tube Sheet

$(l=96.77$ in. $)$

$f_{n_{2}}=9.2 \mathrm{~Hz}$.

14. $5 b-1$ Clamped-Hinged Tube Below ESP

$$
\begin{aligned}
& (l=69.50 \mathrm{in.}) \\
& f_{n_{1}}=17.4 \mathrm{~Hz} .
\end{aligned}
$$




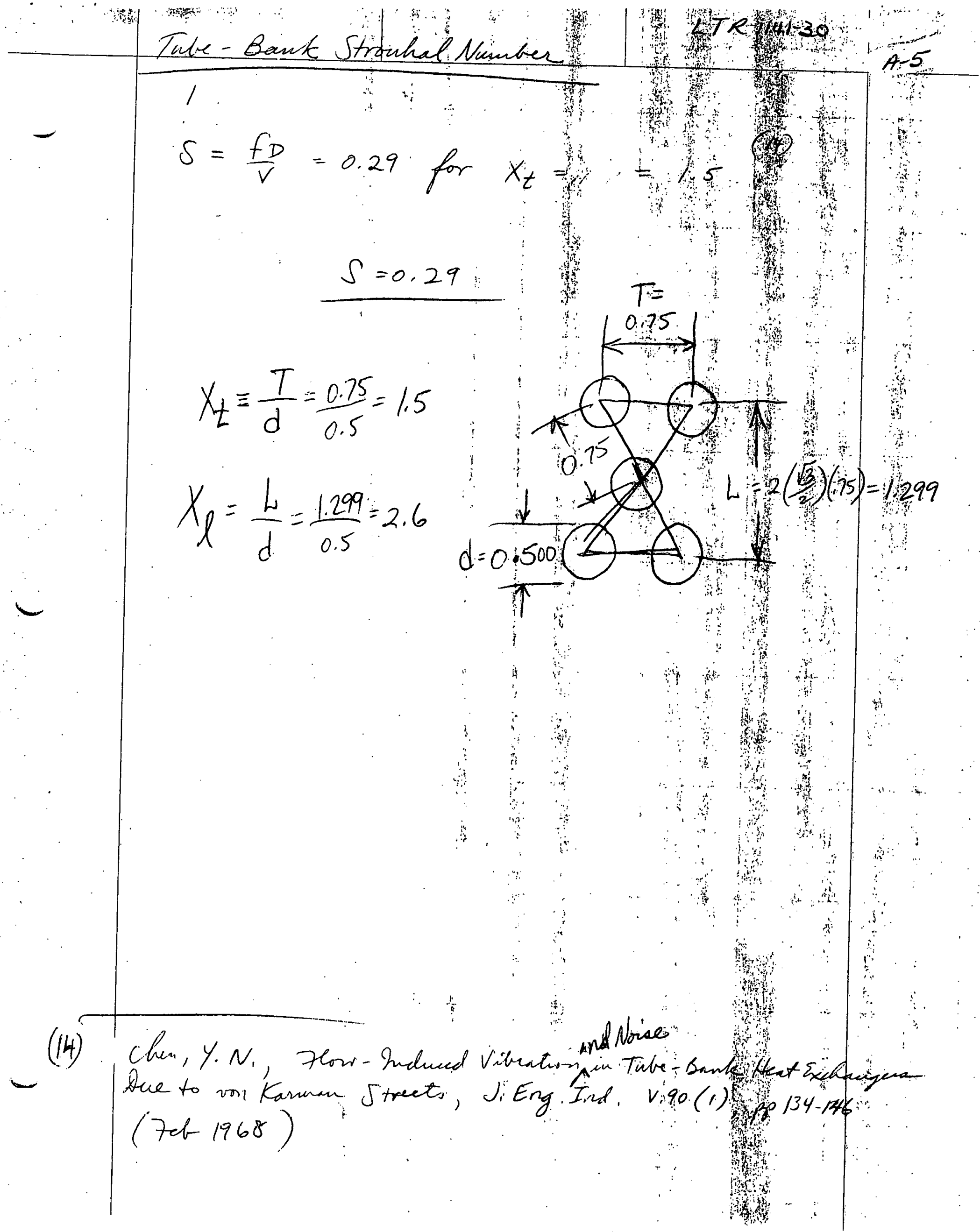




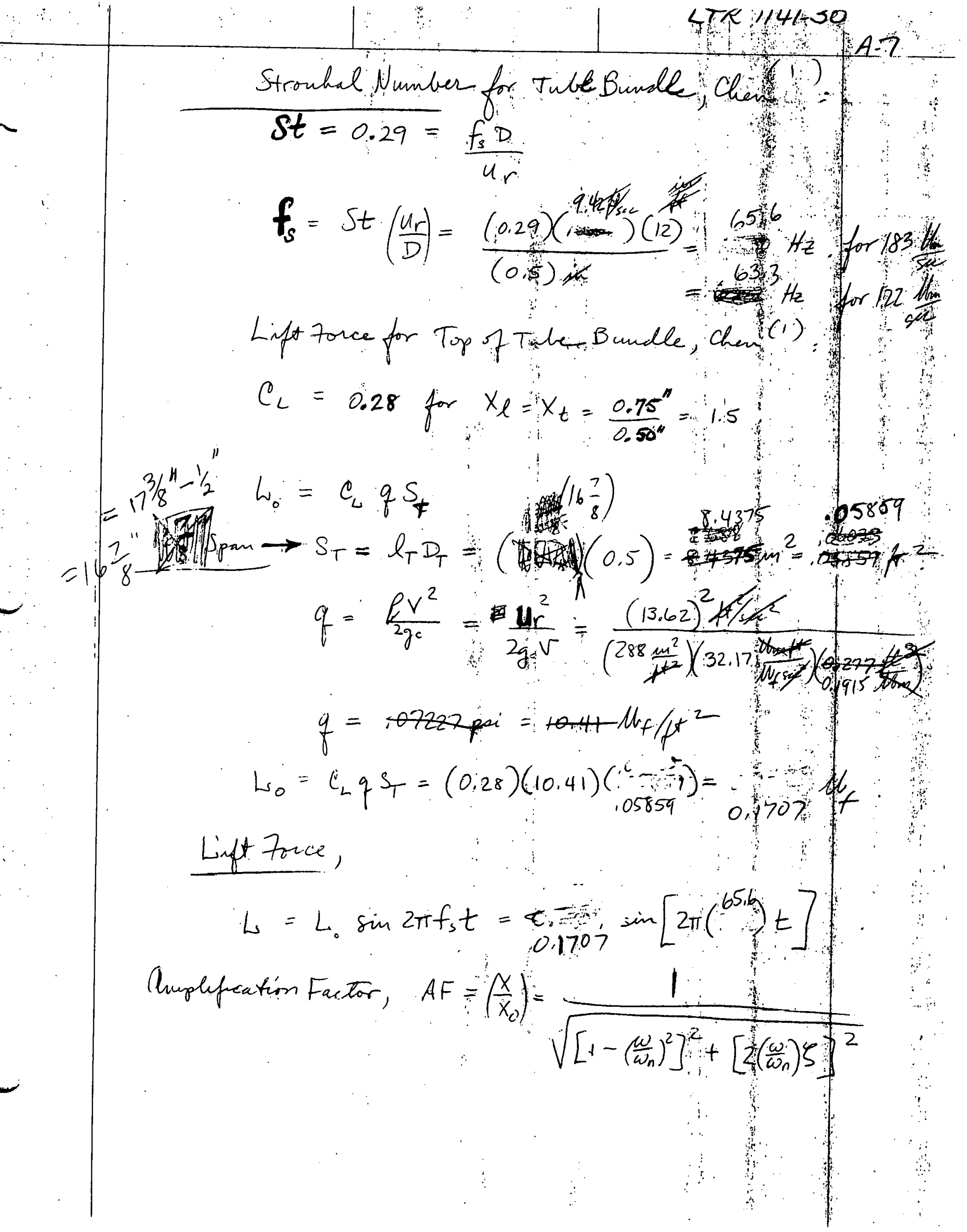


APPENDIX B

Turbulent-Buffeting Excitation Mechanism For

Flow-Induced Vibration (FIV) 


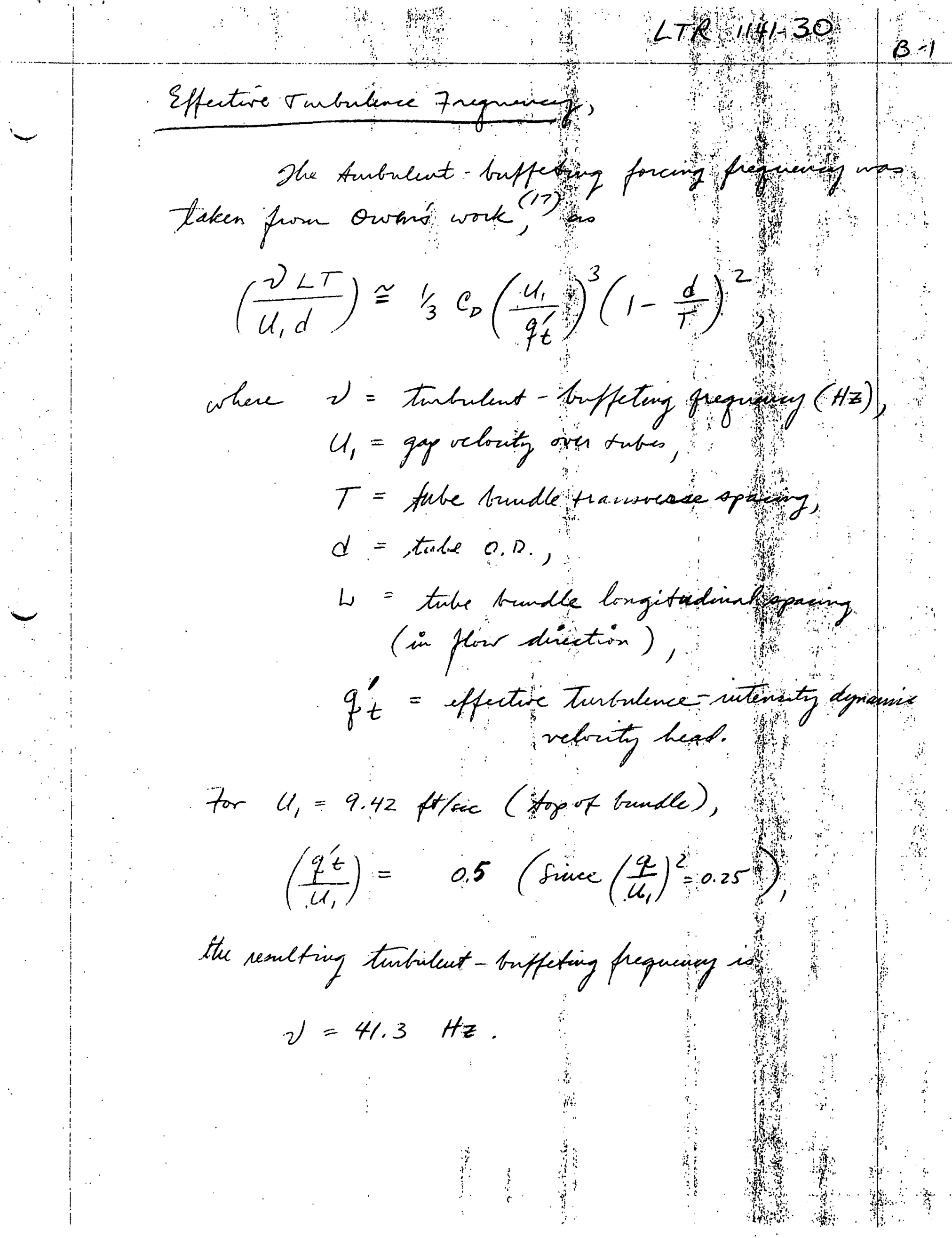


Turbulence Intensity

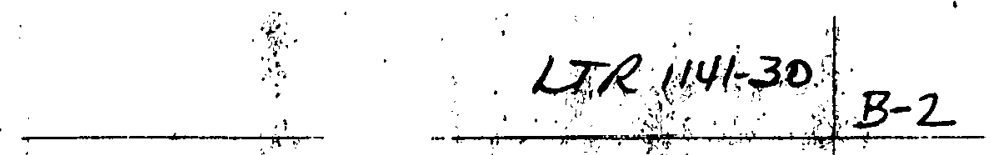

measured turbulence intercity for the fully-deveros water of a circular cylinder in airflow, on the order if $25 \%$ of the shamanic velocity head. (18) H his value was assumed for they LoFT

- Steam Generation tubes as well.

Turindent-Buffeting Drag Coefficient

The stiady-state drag coefficient value of 1.2 was accursed for the tiubulent-buffeting ding coefficient. Butter information for the force coefficient was not found the lifuatine. 


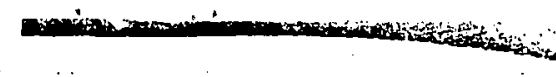

:CE

ery great, and sime.., n:.. •.

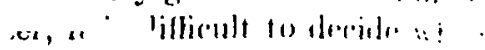
rome tratsport illenes. . ature velusity di-trilint:. . niil $\left(\xi_{2}\right)_{11}=0.48$.

-transport theory we take:

$\sqrt{2}$

ory, $c_{\gamma}=c_{\omega}$, the agremmit : :: er al large patrt of the withe. ... and the wake boumdary reno:

\section{Measured}

Momentum transport theory $c_{y}=c_{m}$

Momentum transport theory $c_{\gamma}=c_{m}, Z$ vorticity transport theory $c_{Y}=c_{w}$ $\left(\epsilon_{1}\right)_{22}=$ Constant

\section{रें.

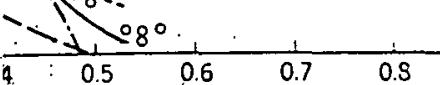 $\sqrt{d\left(x_{1}+a\right)}$}

ke of a circular cylinder. (Fn!" .l..." 35:4, 19:35.)

$\left(\boldsymbol{c}_{\gamma}\right)_{22}$ be calculated firm : ith the aid, of the relations ti li"

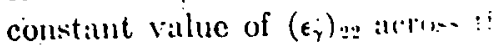
0.12liod. This is almosi $1: 1$ laylor's volticity-lramsisult lla.... $=2\left(\epsilon_{m}\right)_{11}$.

rest the best agreement, oulsil. " 5 value for $\left(\epsilon_{\gamma}\right)_{22}=0.119 C_{\text {irl }} \quad$ I)

Quantities in the Wake Flow of? of these quantities hase heren at: :-: vailable in a series of pulitiontin!-

\section{FIGURE B-1}

He measurements were made at varions sections in the wake at relation - 1:mese from $\xi_{1}=80$ up to 9:50. Most of the measurements refer te

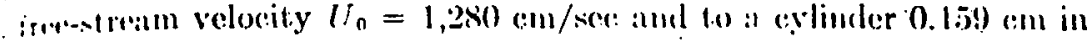

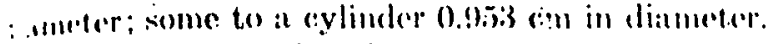

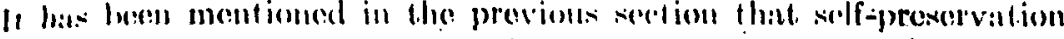
: he detail structure of the tubbulence at valrious soctions is attalined if at large distances downstreatm from the eytinder, say, beyond $\therefore$ : $\therefore$ However, not all the data that we wallt to show here refer as suh large distances. We shall comsider these data, anyhow, since

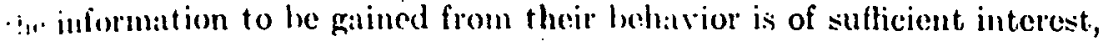
.newithstanding some latek in self-prescriation.

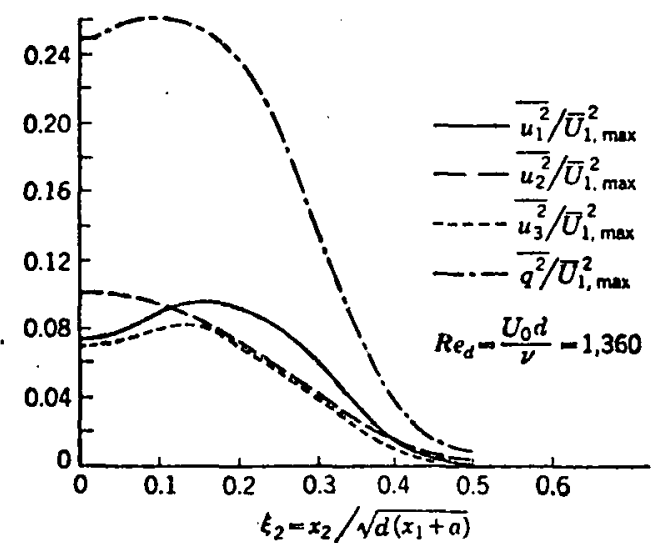

lin; (i-5. Relntive turbulence intensities at the soetions $\xi_{1}=500,650,800$, and $\mathbf{9 5 0}$ :s the wake of a circular sylinder. (I'ounernil, .1. A., Austratiun I. Sci. Research, $\cdots: 2.1,1 \% .+51,1944$.

- Figure $6-5$ shows the values of the squared relative turbulence intensi-

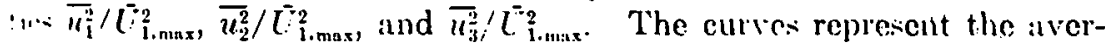
walues for the four sections at $\xi_{1}=500$, $3: 50,800$, and 950 , respecwy. The differences between the quantities at these sections are -mall and are within experimental scatter; so similarity among the $\therefore$ arious ourves is good indeed.

In lig. 6-6 are shown the courses of the shenr stress $\overline{\pi_{1} \|_{12}} / \bar{U}_{1, \max }^{2}$ and of :he eddy viscosity $\left(\epsilon_{m}\right)_{11} / U_{0 d}$, in Fig. $(i-7$ those of the lateral transport

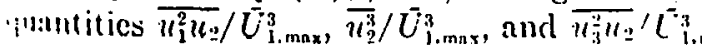

The distribution curves of $\overline{\left\|_{1}^{2}\right\|_{2}} / \bar{B}_{1, \max }^{3}$ and $\overline{\left\|_{3}^{2}\right\|_{y} / \bar{C}_{1, \max }^{3}}$ show negative f.urts in the center region of the wake, which means an inward transport in tho axis of the wake. This picture accords with the course of the :nlensity gradients shown in Fig. (1-5, though eloser observation of the reperetive curves reveals that the regions of inwand ransport and of insitive intensity gradients in the center of the wake do not entirely 
LIK :1141-SO

Tube-Baffe Conteat fiom Tusbulent-Buffeting Meibenom

1. Lower Bay

$$
\begin{aligned}
& J=\frac{\text { (cantiliver), } l=17.375^{\prime \prime} \text { assumed }}{\mathrm{ral} d=.015625^{\prime \prime}} \\
& f_{n_{1}}=127.6 \mathrm{cps} \\
& f_{t}=\left(\frac{1.04}{9.42}\right)(41.3)=4.6 \mathrm{~Hz} \\
& f_{s}=\frac{(0.29)(1.04)(12)}{(0.5)}=7.2 . \mathrm{Hz} \\
& a_{r}=1.04 \\
& \text { fpo } \\
& q=.00555, q_{t}=0.25 \mathrm{~g} \\
& \omega_{t}=(0.25)(.00555)(1.2)(0.5)=.000832 \frac{\mu_{f}}{i m} \\
& w_{s}=(.00555)(0.28)(0.5)=000777 \frac{\mu_{f}}{i_{\mu}}
\end{aligned}
$$

(a) Tubinleut - Buffet Mechaniman :

$$
\begin{aligned}
& \delta_{s s_{t}}=\frac{w_{t} l^{4}}{8 E I}=\frac{(.000832)\left(\frac{w_{t}}{2 t}\right)(17.375)^{4}}{(8)\left(29.4 \times 10^{6} \frac{\mu_{t}^{2}}{2 N^{2}}\right)(.001786)} \\
& \delta_{S S t}=.000181 \mathrm{in} . \\
& A F_{t}=\frac{1}{\sqrt{\left[1-\left(\frac{v_{t}}{\left.\omega_{v_{11}}\right)^{2}}\right]^{2}+\left[2.5\left(\frac{\omega_{t}}{\omega_{11}}\right)\right]^{2}\right.}} \\
& A F_{t}=\frac{1}{\sqrt{\left[1-\left(\frac{41.6}{127.6}\right)^{2}\right]^{2}+\left[(002)(2)\left(\frac{4.6}{127.6}\right)\right]^{2}}} \\
& A F_{t}=1.001 \\
& \delta_{t}=(1.001)(.000181)=.000181 \mathrm{in} \\
& \therefore \text { No baffer - iabe contad }
\end{aligned}
$$


Tube- Baffle Contact

2. Middle Bay

$$
\begin{aligned}
& q=.0232 \mathrm{psi} \\
& u_{r}=4.36 \mathrm{for}
\end{aligned}
$$

Tube considered as a

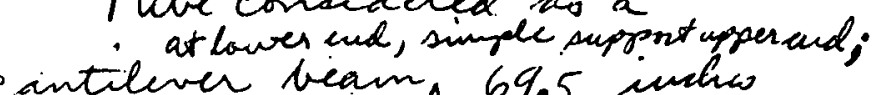
long. (4 spans of $17.375^{\prime \prime}$ each).

In general, the cuocaplow load in one direction will cancel that in the: other; hoverer, both Kansan vortex and tinboleut - buffeting loads can not at sight angles to the main flow, and that is the case that will be considered.

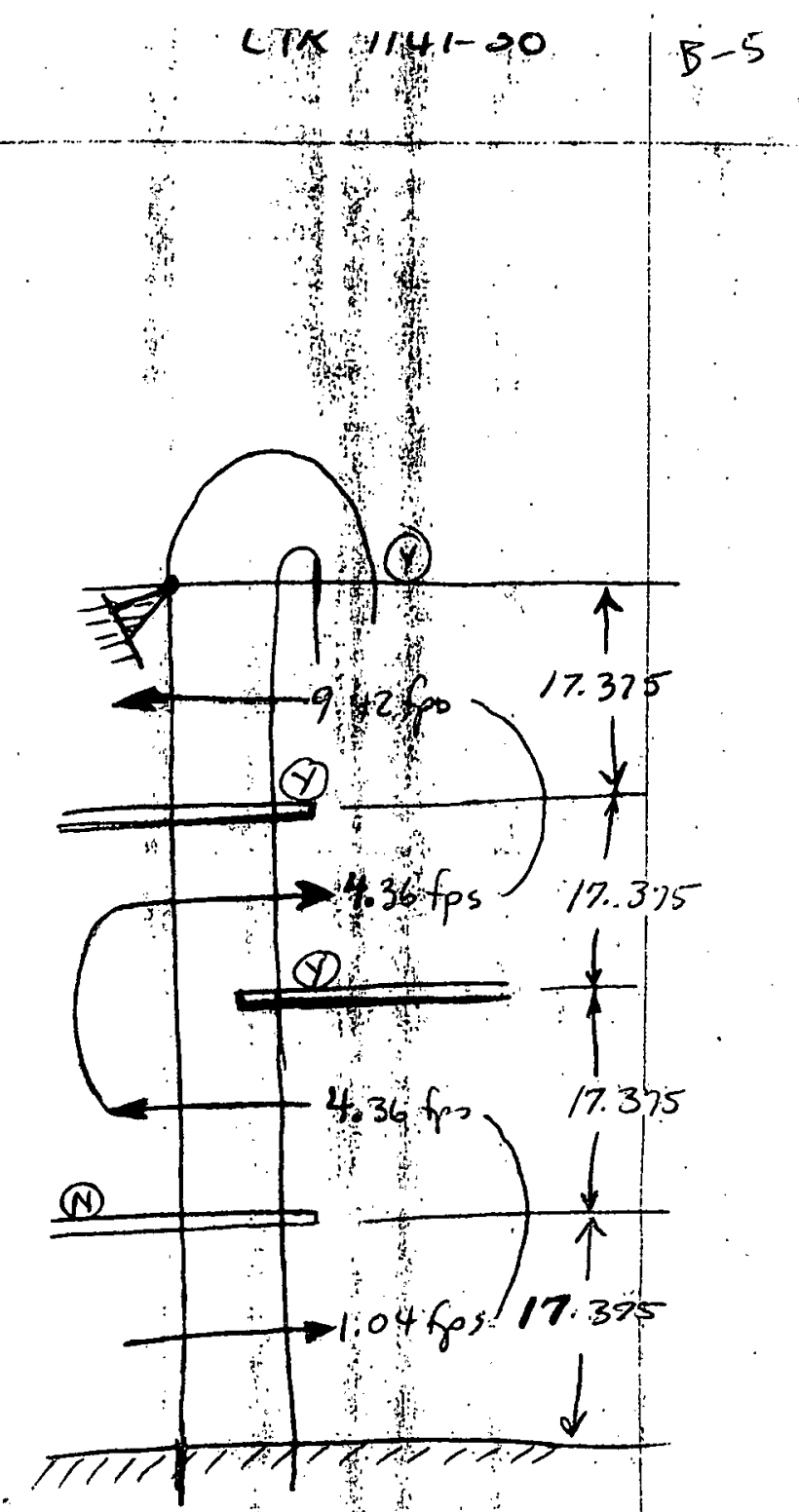

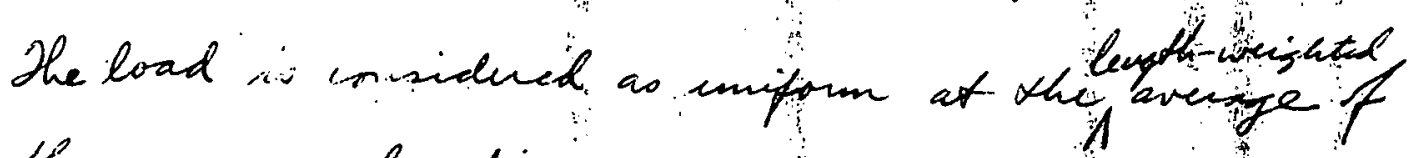
The three gran loading.

$$
\begin{aligned}
& w_{t_{1}}=\quad(1.2)(0.25)(.05)(.5)=.0075 \mu \mathrm{r} / \mathrm{sin} \\
& w_{t_{2}}=\quad(1.2)(0.25)(.0232)(.5)=.00348 \mathrm{lb} / \mathrm{sin} . \\
& w_{t_{3}}=(1.2)(0.25)(.00555)(.5)=.000833 \mathrm{H} / \mathrm{fm} \\
& \bar{w}=\left(w_{t_{1}}+2 w_{t_{2}}+w_{t_{3}}\right)\left(\frac{1}{4}\right)=.00383 \mu t / m \\
& f_{t}=\left(\frac{4.36}{9.42}\right)(41.3)=19.1 H_{z} \\
& f_{n_{1}}^{\prime}=17.4 \mathrm{~Hz}
\end{aligned}
$$


Tube-Baffle. Contract

WTR 1141-30

$$
\begin{aligned}
& f_{n_{1}}^{\prime}=17.4 \mathrm{~Hz} \\
& A F=\frac{1}{\sqrt{\left[1-\left(\frac{\omega}{\omega_{n}}\right)^{2}\right]^{2}+\left[2 \zeta\left(\frac{\omega}{\omega_{n}}\right)\right]^{2}}} \\
& A F=\frac{1}{\sqrt{\left[1-(191)^{2} 7^{2}\right.}} \\
& \sqrt{\left[1-\left(\frac{19.1}{17.4}\right)^{2}\right]^{2}+\left[2(.002)\left(\frac{19.1}{17.4}\right)\right]^{2}} \\
& A F=4.88 \\
& \delta_{S S}=\frac{\bar{w} l^{4}}{185 E}=\frac{\left(.00383 \frac{l_{f}}{\mathrm{~m}}\right)(69.5)^{4} \mathrm{in}^{4}}{(185)\left(29.4 \times 10^{6} \frac{l_{f}}{m_{m}}\right)(.001786)^{4} 4\left(\frac{2 l}{15}\right)^{2}} \\
& \delta_{S S}=.004693 \mathrm{in} \text {. } \\
& \delta_{t}=A F \delta_{S S}=(4.88)(.00469)=.0229 \mathrm{in} .>.015625 \mathrm{~m} .
\end{aligned}
$$

$\therefore$ Tube-baffle ingact occius on the uspoer 3 baffles. 


\section{APPENDIX C}

Fluidelastic Instability (Whirling) Excitation Mechanism for Flow-Induced Vibration (FIV) 


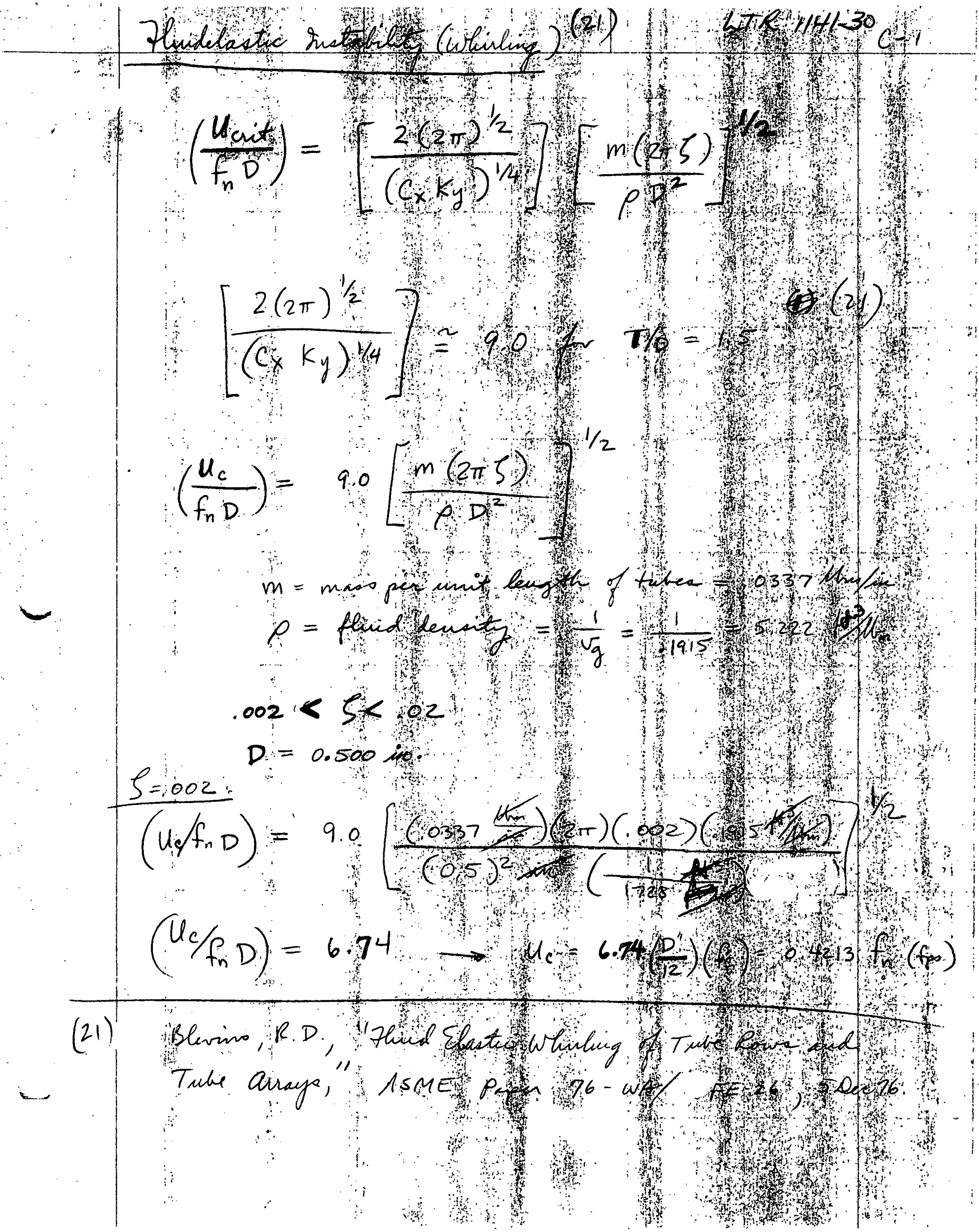




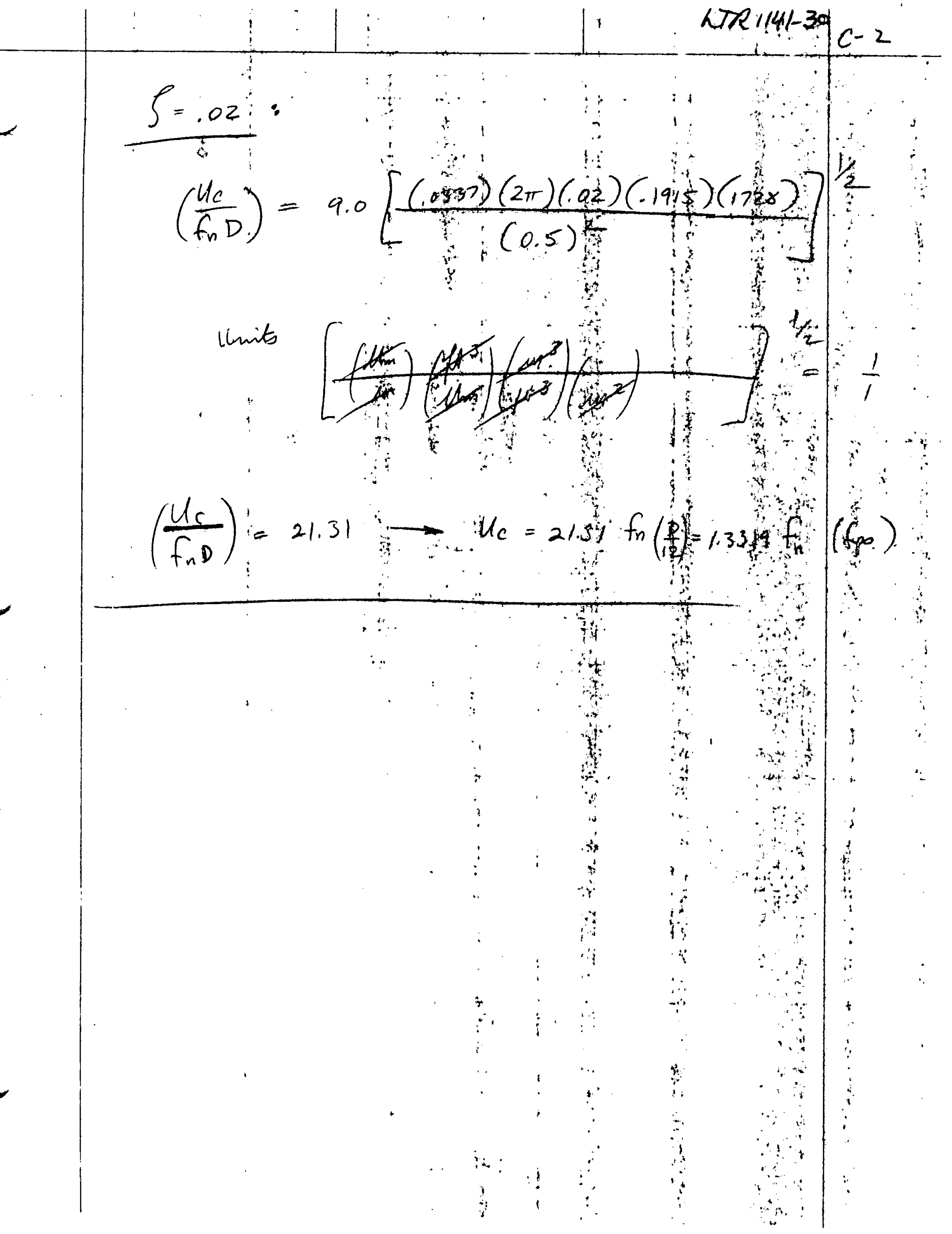




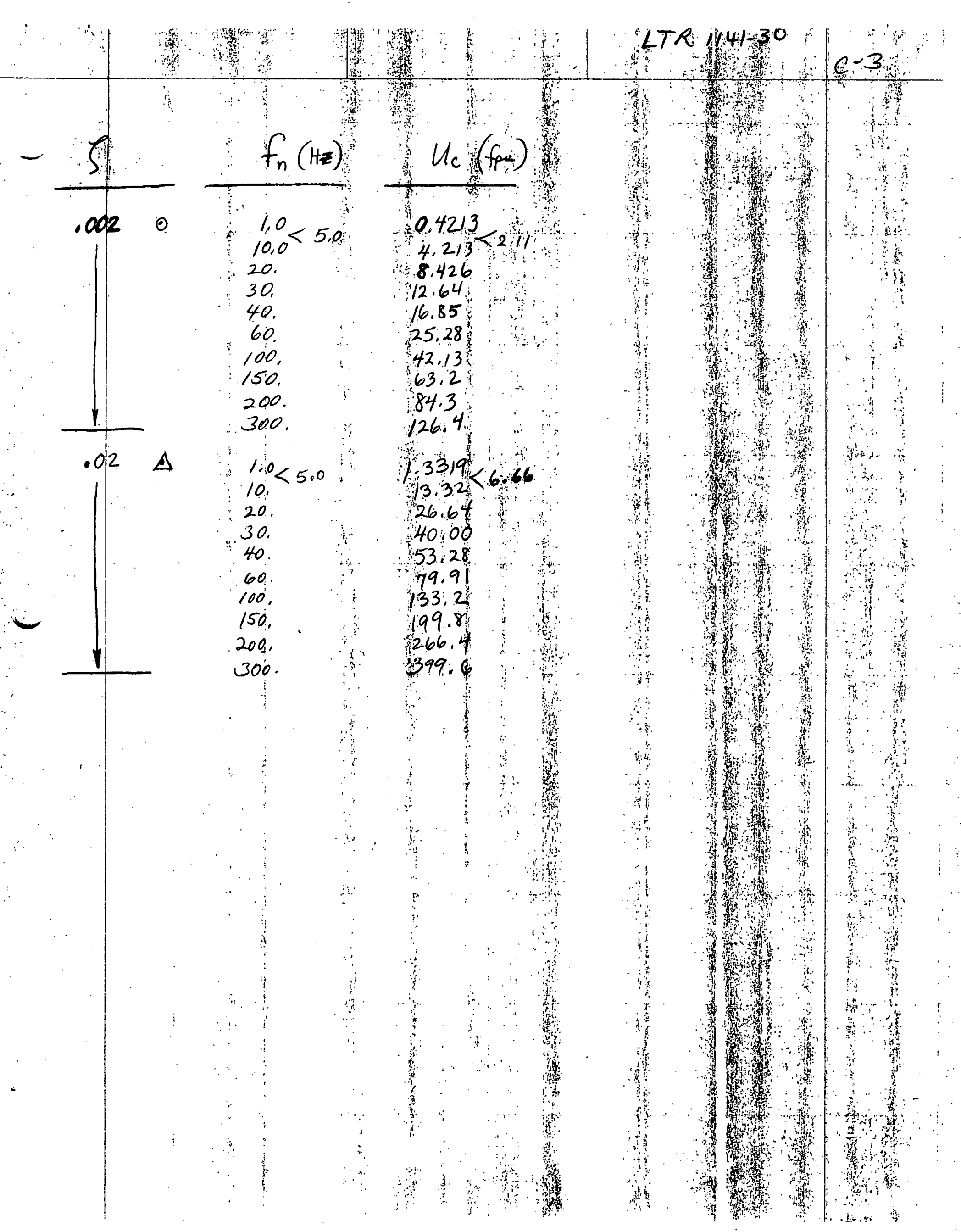




\section{APPENDIX D}

Tube Natural Frequencies and Damping Ratios 


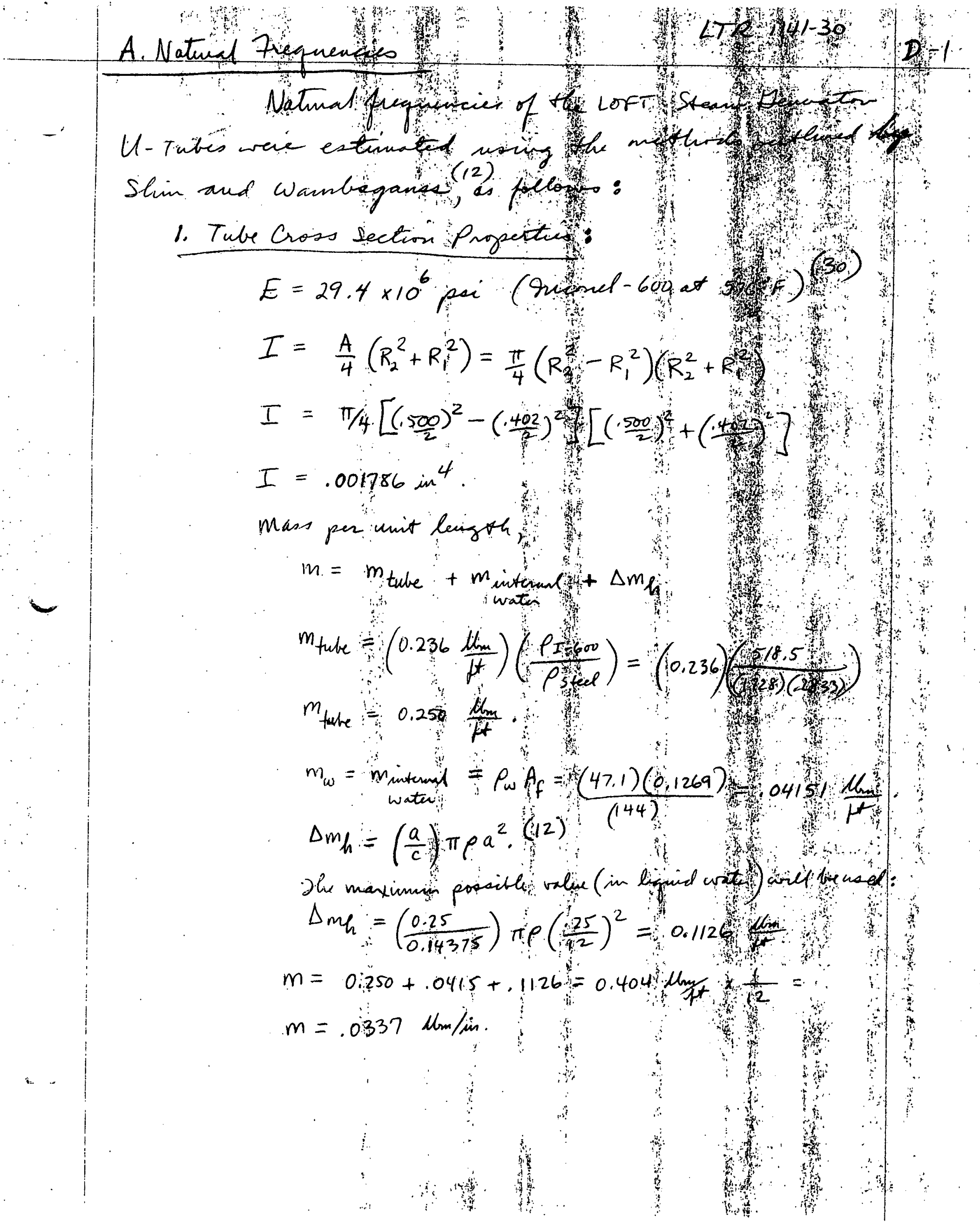


LTR $\quad \therefore 41-30]_{D-2}$

2. Base notunal fiequencice (cuicorrected for intemal pressunination ):

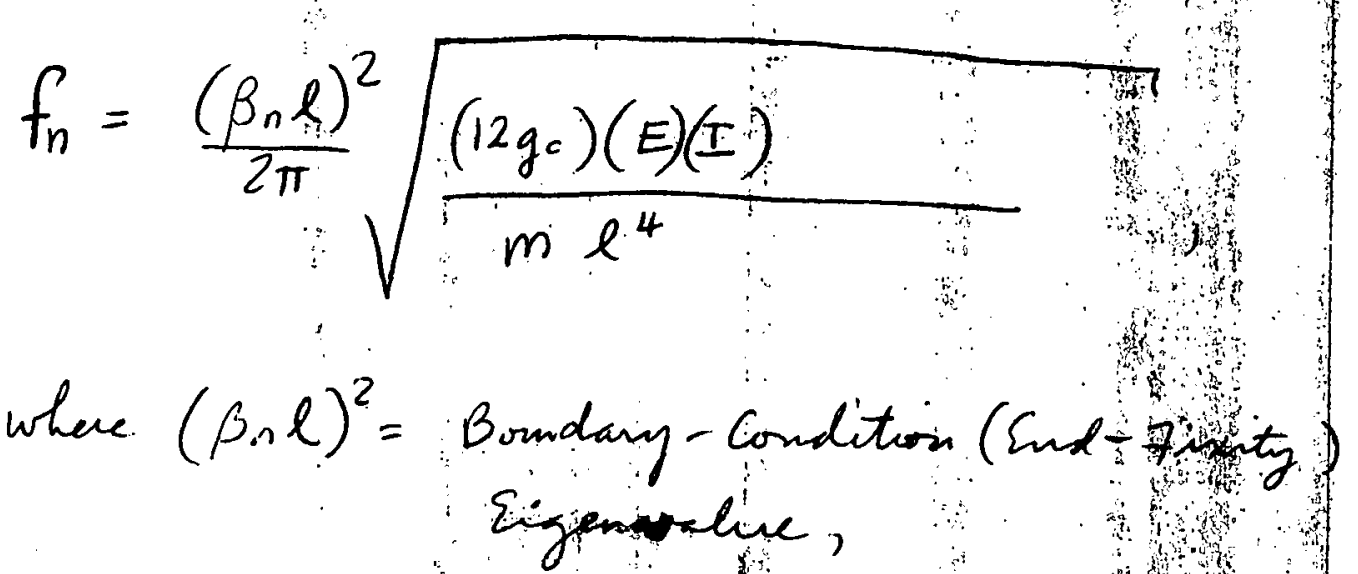

$$
\begin{aligned}
& f_{n}=\text { frequiency }(H z)
\end{aligned}
$$

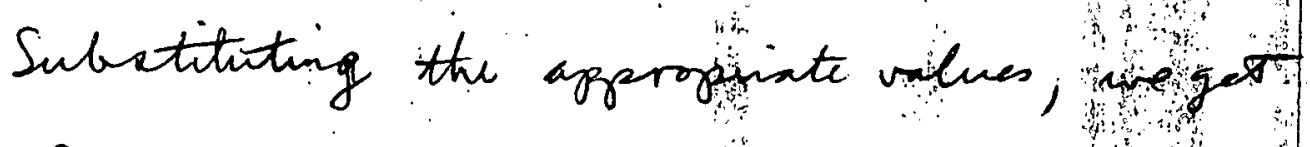

$$
f_{n}=(3903.6)\left(\beta_{n} l\right)^{2}\left(\frac{h}{7}\right) \mathrm{Hz} \text {. }
$$

3. Pressuingation Correction Irator:

$$
\begin{aligned}
& \Delta P=(2250-850)=1400 \mathrm{pai} \\
& \Gamma=\frac{F_{A} l^{2}}{E I}=\frac{A_{\mathrm{f}} \Delta P l^{2}}{E I}=\frac{(1400)(.1269)\left(l^{2}\right)}{\left(294 \times 10^{6}\right)(001786)} \\
& \left.\Gamma=.003383 l^{2}\right)
\end{aligned}
$$

where $l=$ unimporited opan of tho

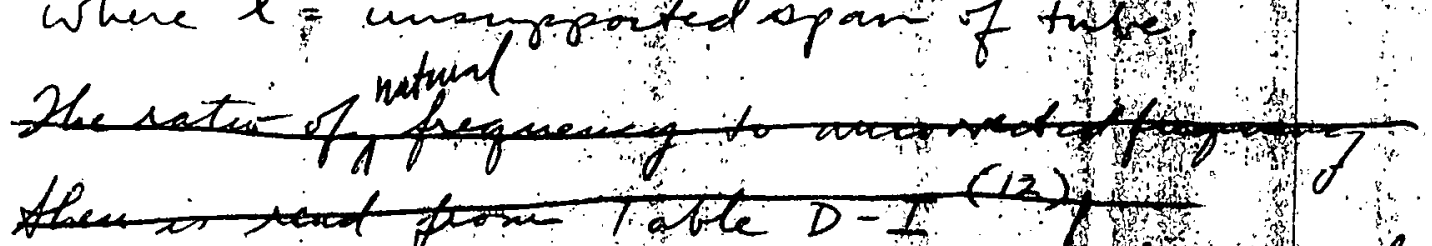

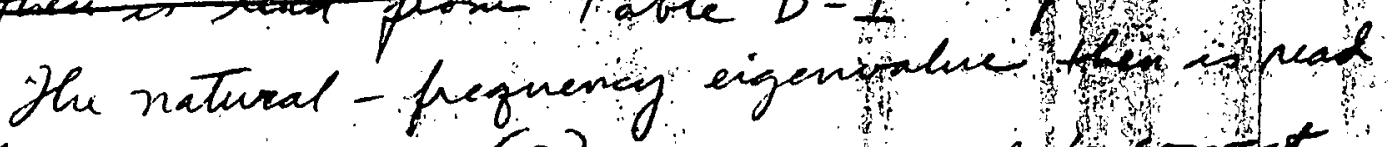
from Table D-I (12), and is used to toritat

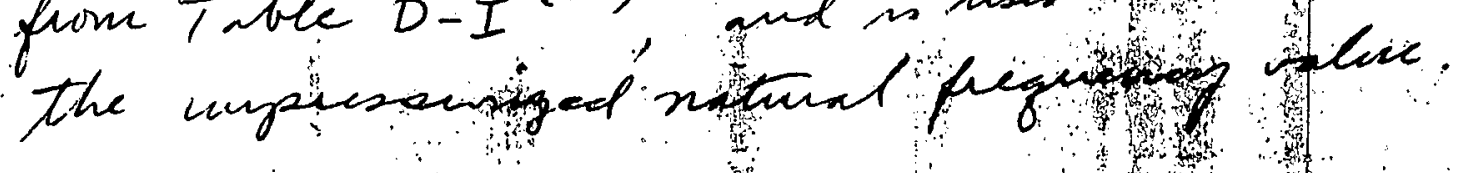




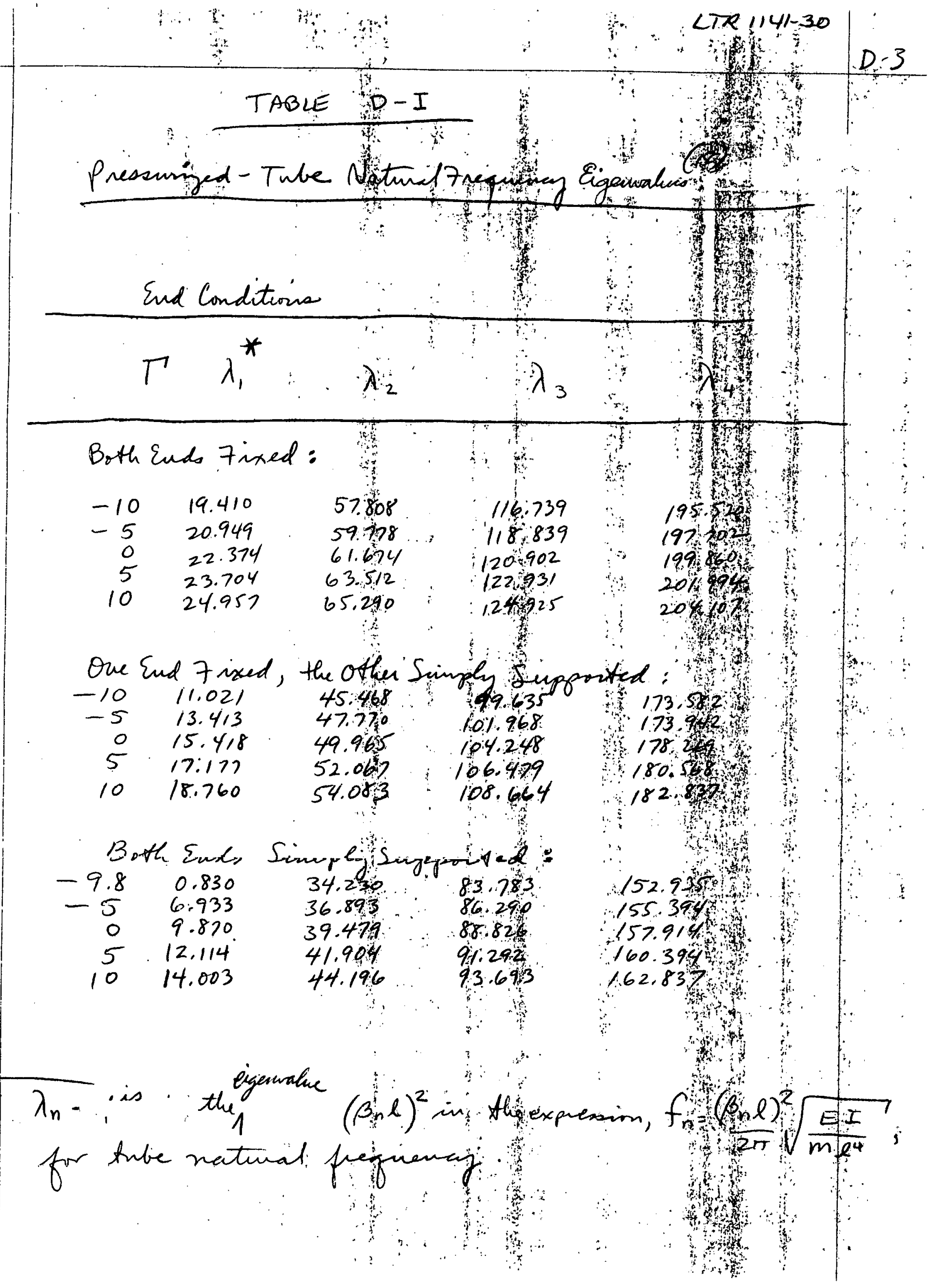




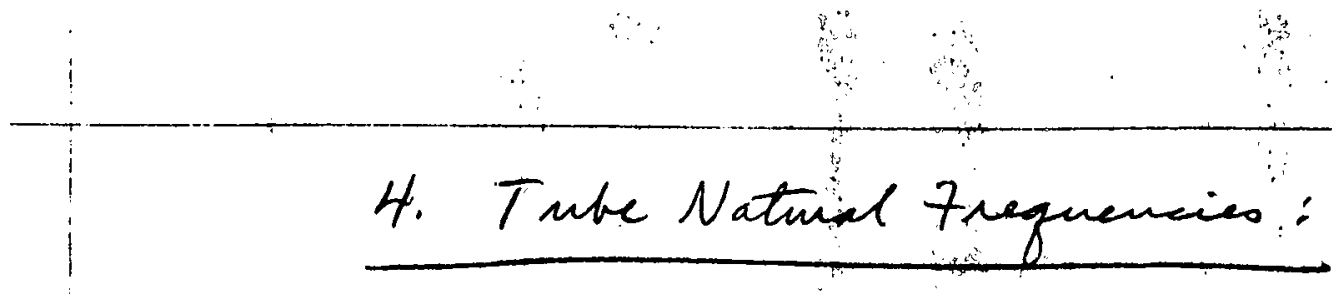

$D-4$

He resulting tube span natural freginencis are calculated from the expression.

$$
f_{n}^{\prime}=\frac{\lambda_{n}}{\left(\beta_{n} l\right)^{2}} f_{n} \text {, }
$$

where $f_{n}=$ unpresseninged tubespaninatongl frequency of mode $n$;

$\lambda_{n}=$ eigenvalue from Tate D II,

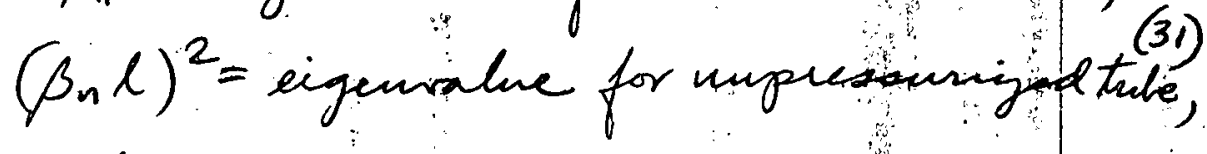

and $f_{n}^{\prime}=$ natural frequency of presented tube for: mode $n$.

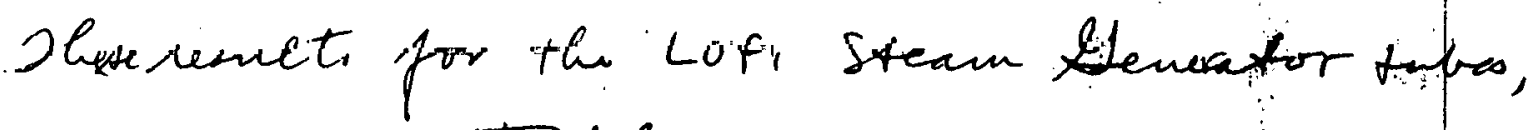
are given in Table D -II. 


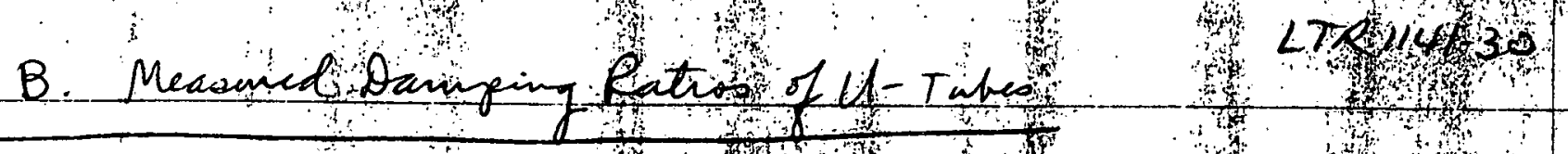

D)

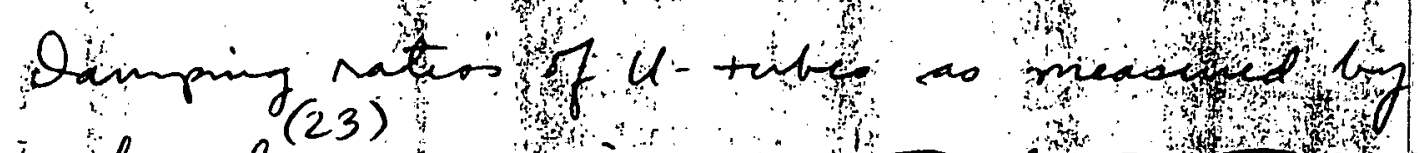
Halle it al., are given in Table D IIT these ratios were measured

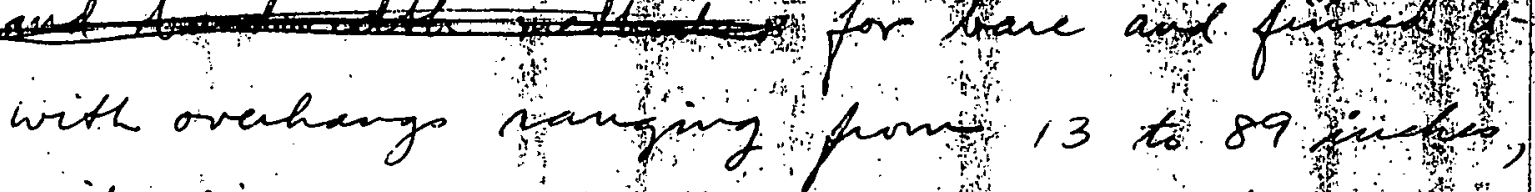
vilisiting in ais. The minimum measured clanging Nevis

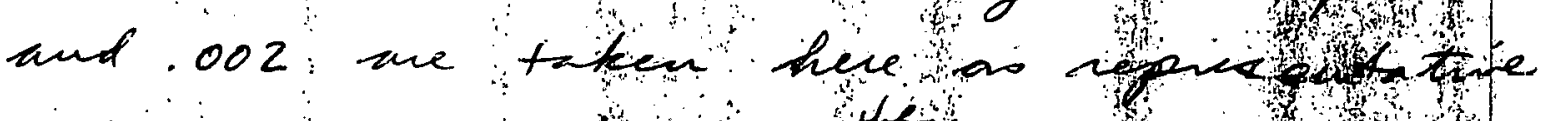

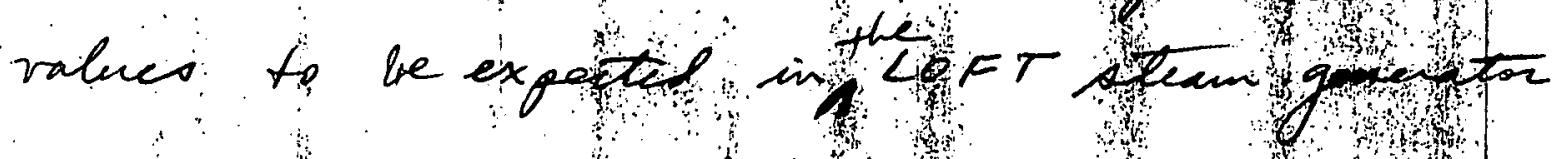




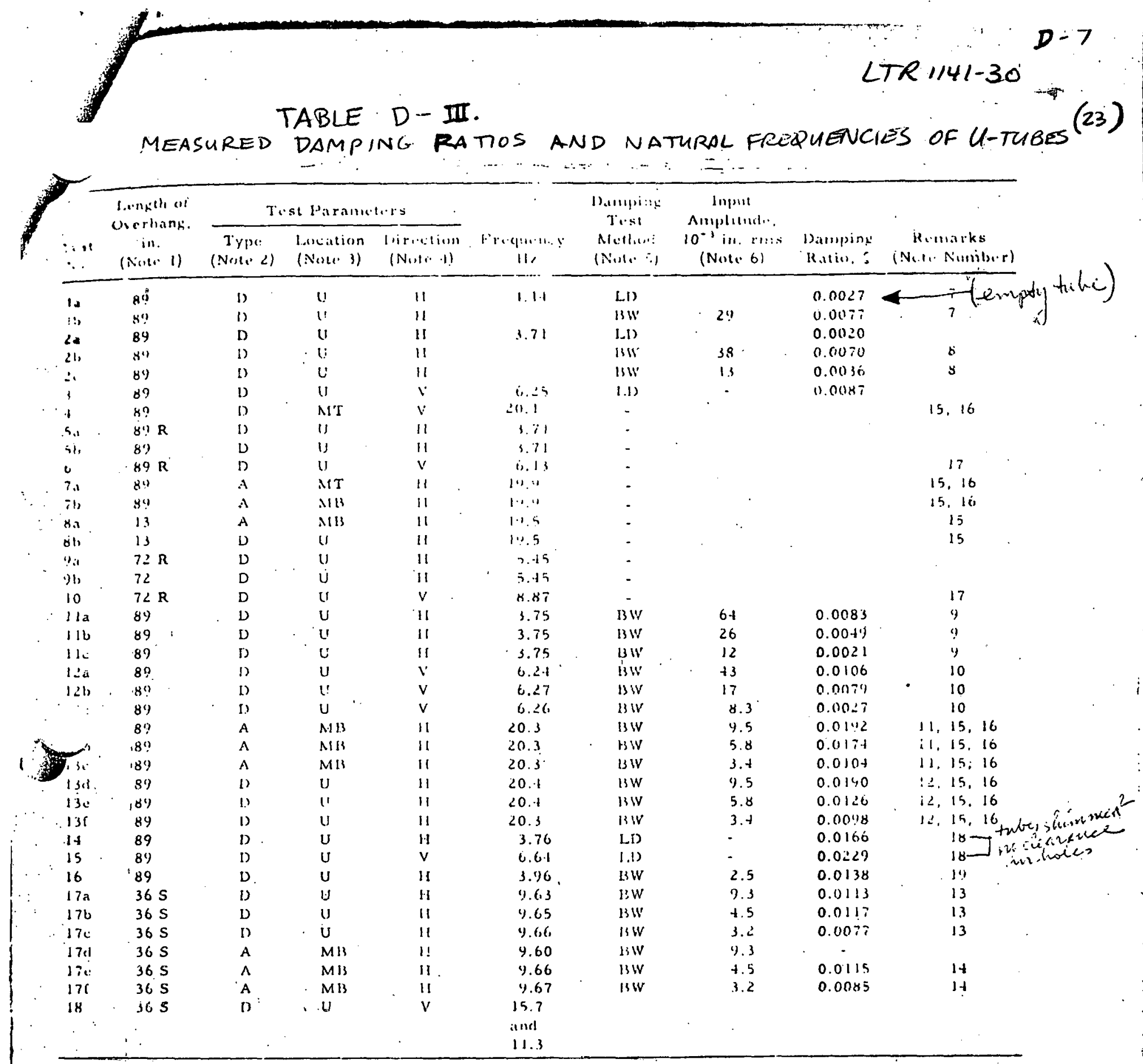

\section{Explanation of Notes:}

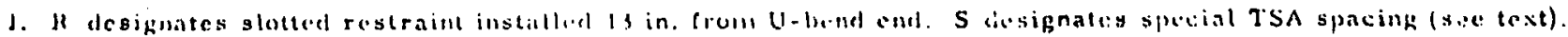

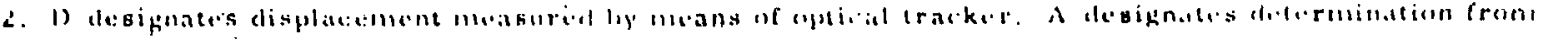
accelermoler signals.

3. Refers 10 Jocation of measurement. II designates the U-bend end. MI and Mll designate the midspan location between the second and thirel 'TSA's, on the top and bothom tubes, respectively

4. V (vertical) and If (Itorizontal) correspond, respestively, to vibratory motion in and out of the plane wi the U-bend.

5. LD degignates the Ing-decrement and isw the bandwidth mothed of damping determination.

6. Average inpet amplitude applied by vibration exciter in licicizontal direction at fube conds opposite to thi: $1 /$ - bend. Finipty tube (no wate: fill). i.1.

Siven sets of damping deterninations performed at two ur thece difierent levels of input excitaticin.

The 20-1lz excititich corresponds th the first-mode deformation of the 83-in. spans which vibrated simuttancously in buth the horizontal and vertical direction. The horiontial amplitules were ubserved to be

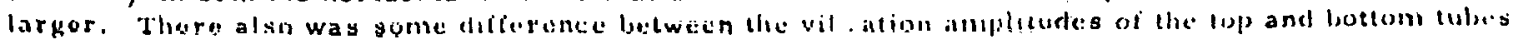

16. On the 89-in. overhanging $U$-bend, the 20-1/z excitation : sulted in a decond-modr-type horizontsl deiormialion, characterized by a nocle aluont $30 \mathrm{in.}$ from the $U-\mathrm{h}$. 1 ind.

17. Test not repeated without slotled restraint because viluritung tubes sllil not toich.

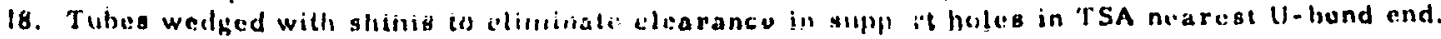

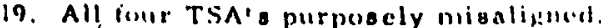




\section{APPENDIX E}

Physical Properties and Geometric Details 


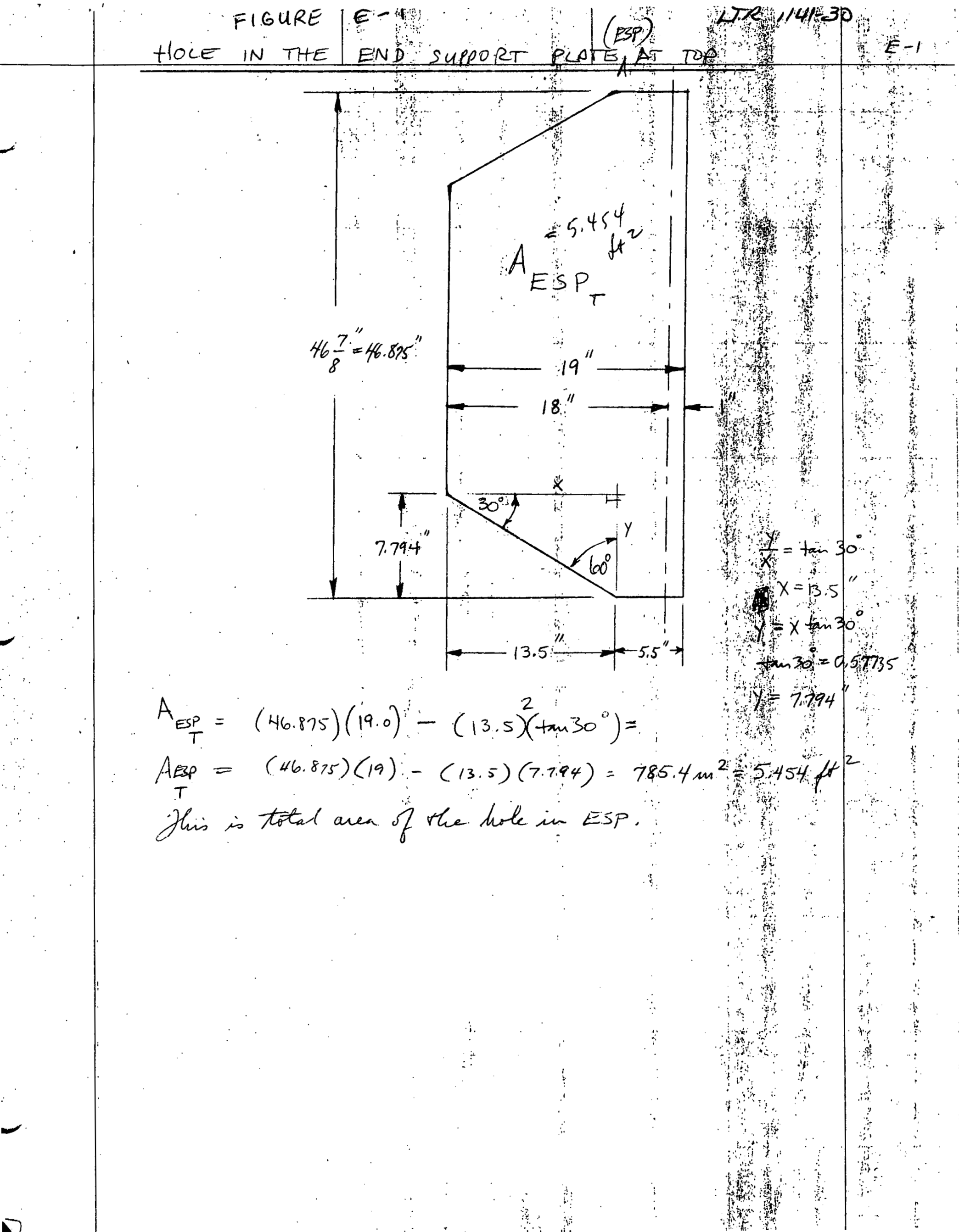


FIGURE E-2

ER

TUBE SPACING GEOMETRY

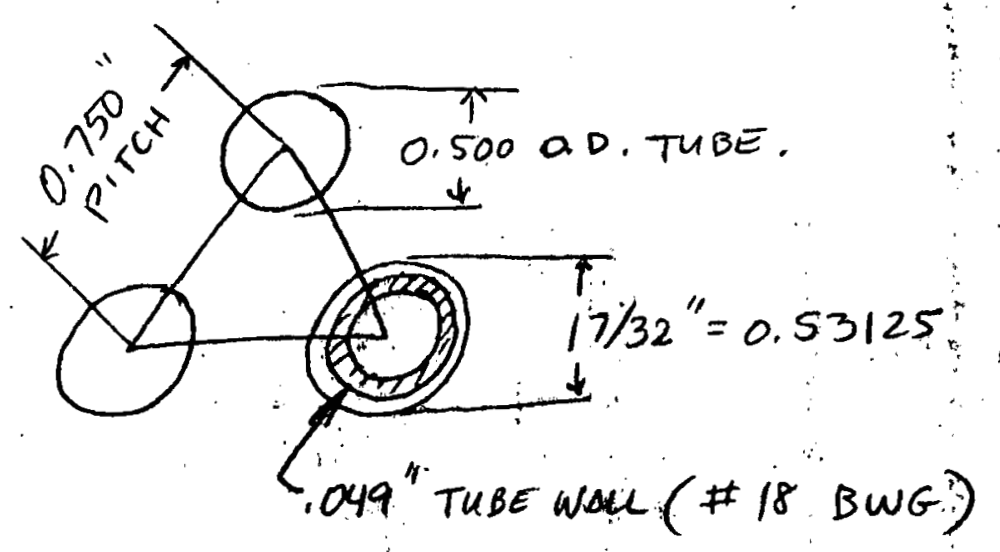

EQUIlATERAL TRIANGLE SPACING 


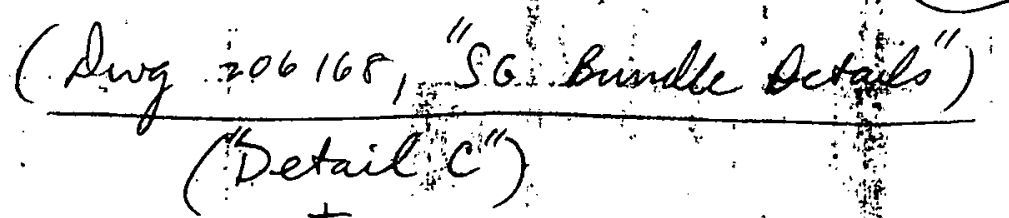
("planvieur pjumlle".)

\begin{tabular}{|c|c|}
\hline $\begin{array}{l}\text { SUPPORT } \\
\text { PLATE }\end{array}$ & $\begin{array}{l}\text { No. of } \\
3 / 16 \text { " Holes }\end{array}$ \\
\hline ESP $-8-9$ & 4308 \\
\hline$S_{P}-8-1$ & 3556 \\
\hline$s p-(8-2)$ & 3556 \\
\hline
\end{tabular}

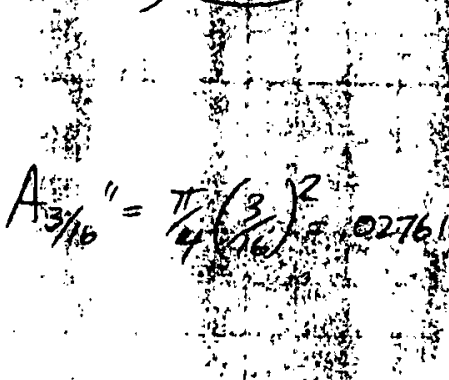
$y^{2}$ 


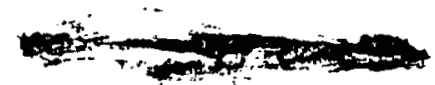

TABle E-I

CHARACTERISTICS OF TUBING

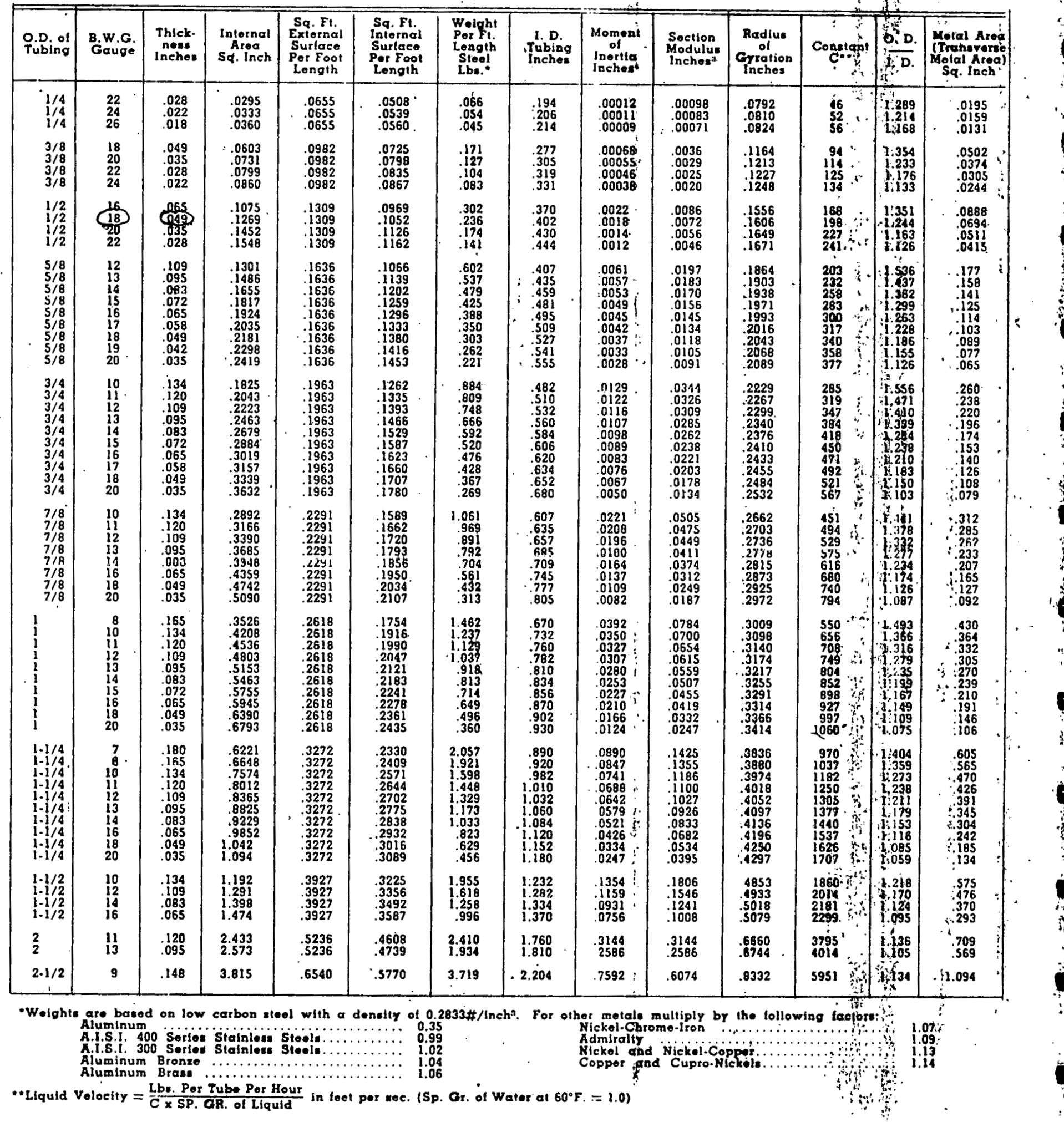




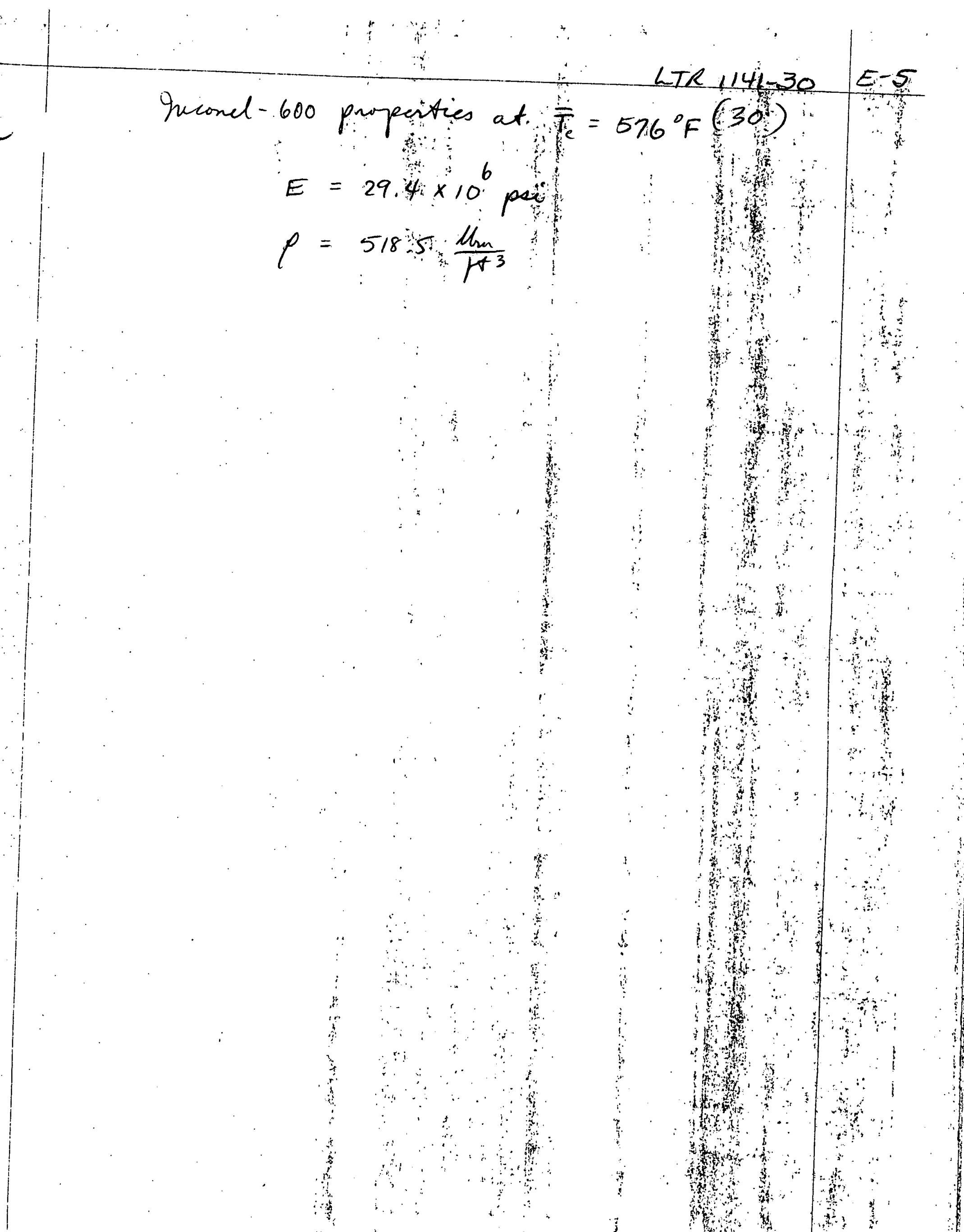


APPENDIX F

U-Tube Bend Region 


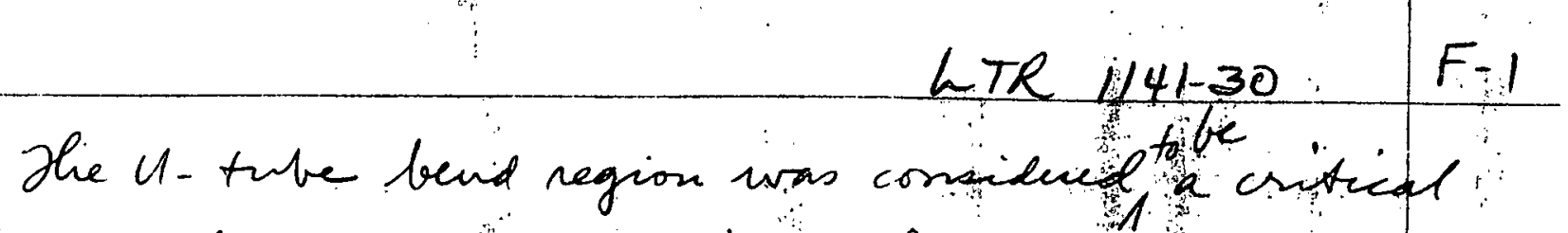
location for flow-infuced vitiation; diet fo its combinations of maximum flow velocities. tong unsugrosted spans of tubing, and thischered shape of the tubes, which decreases ty e otto plane national frequencies.

the bend region therefore turgid in notice detail, using a SAP IV computer nigel for the protaral response of two selected U-tube perdido:

(a) the maximin - diameter $\left(49,5^{\prime \prime}\right)$ be ur at the outer edge of the binder and

(b) the maximum - diameter (36") which had access to the hole win the sud support plate (ire. total tube length combined with thick gap flow velocity ):

The flow velocities past the 4 tr tends used for these models, were calivisoffd by

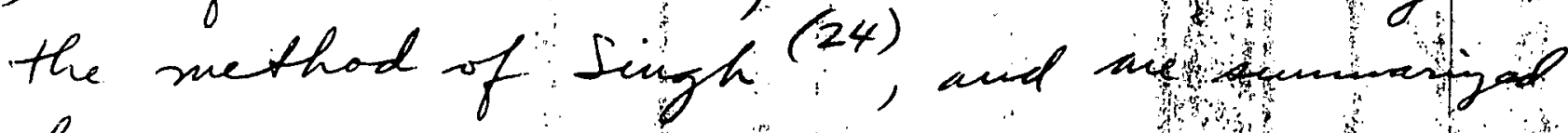
here. 


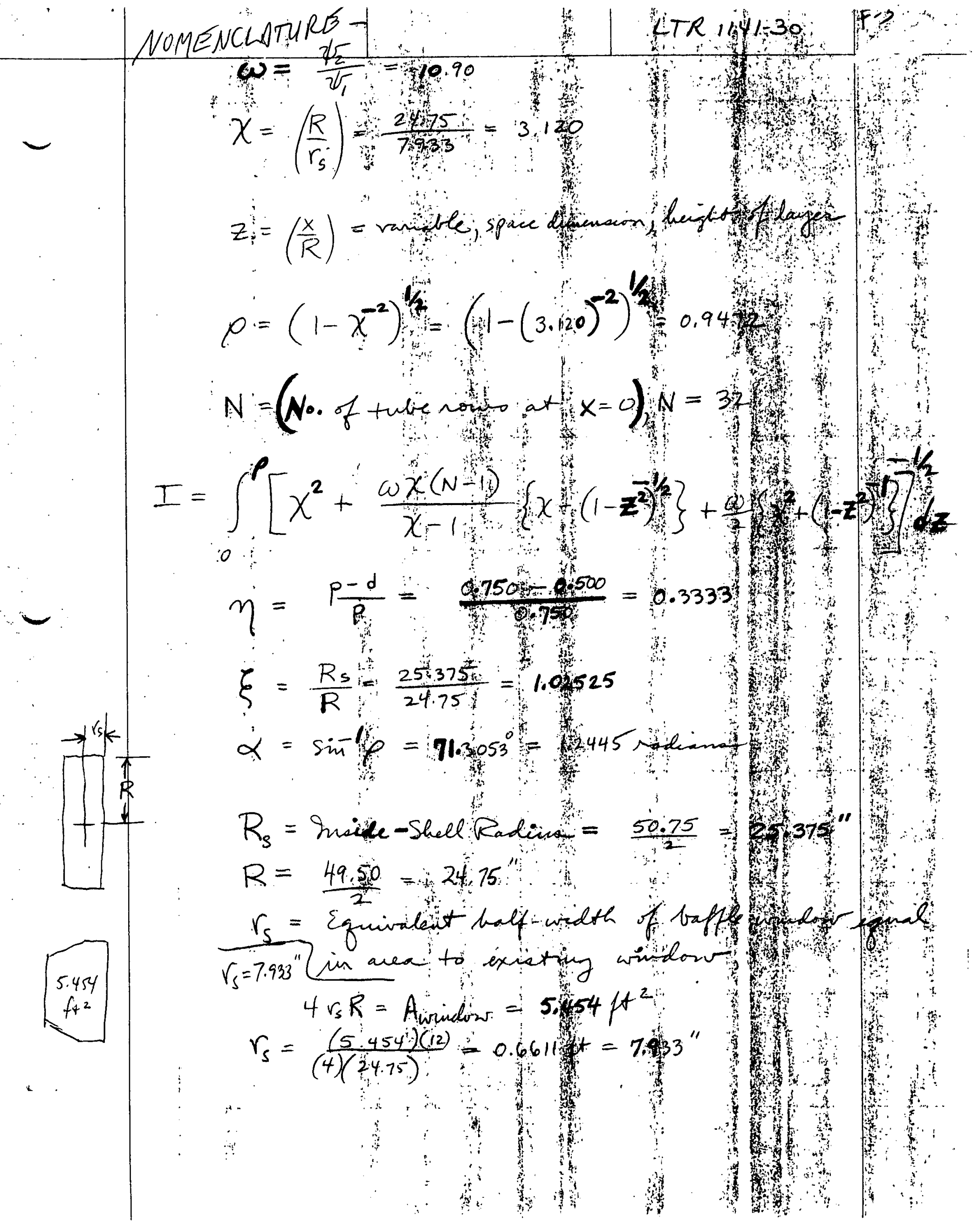




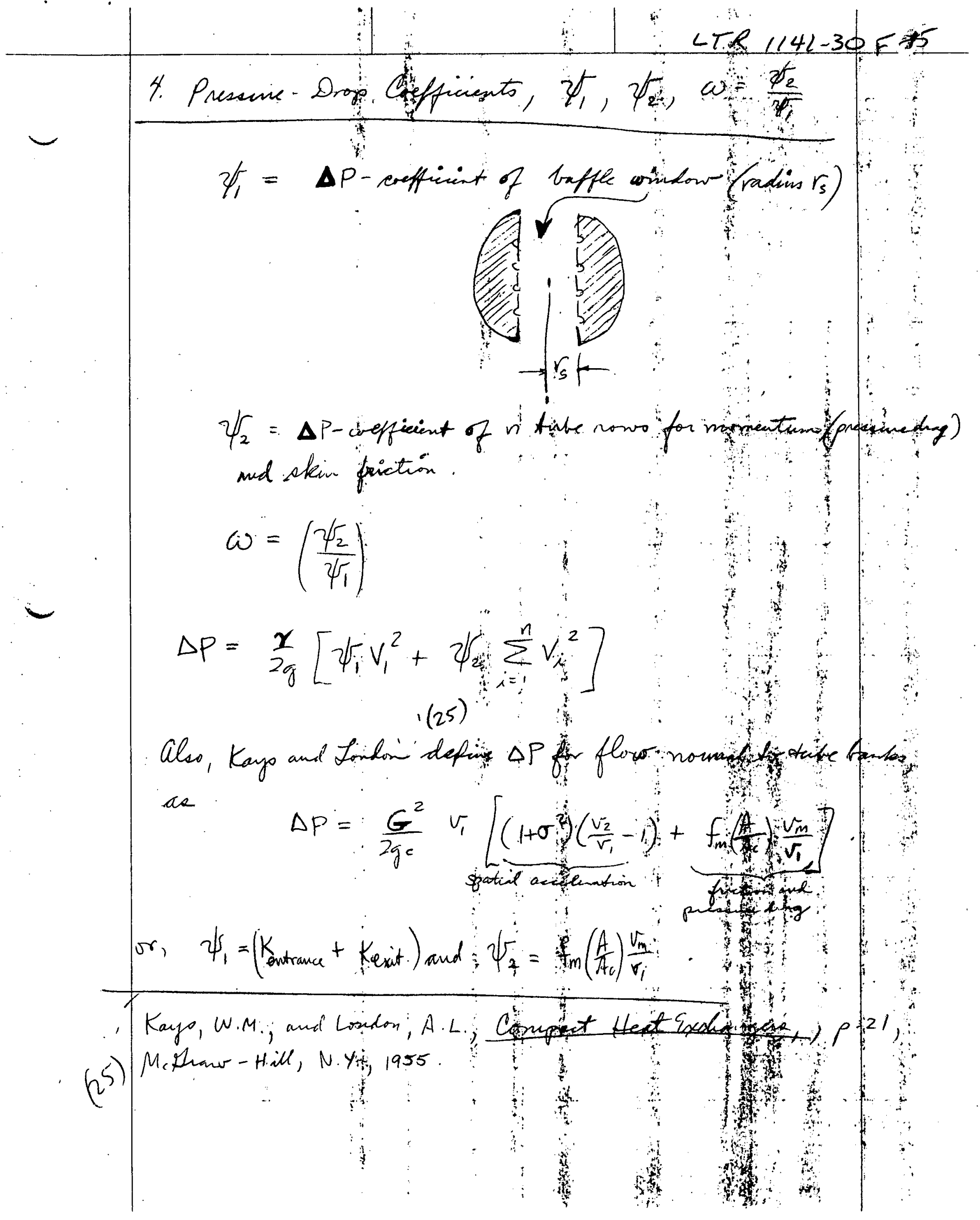




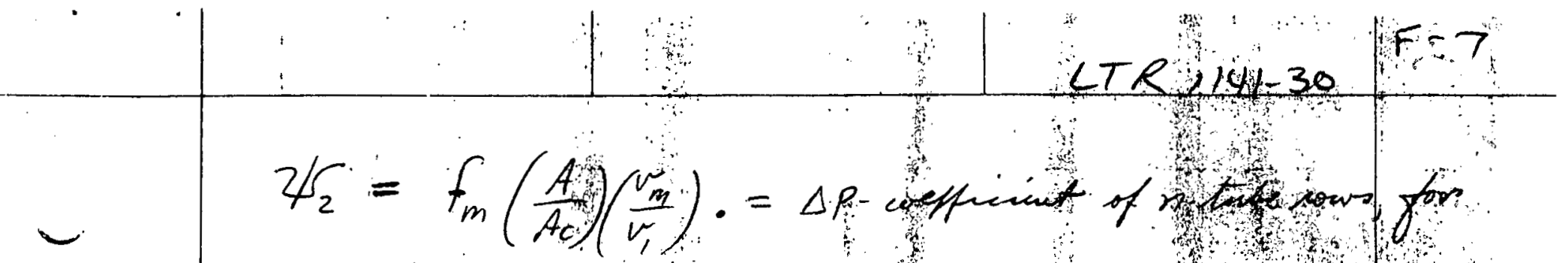

$$
\begin{aligned}
& \text { skin friction and prenangt drag. } \\
& 7 \text { egenilatain } \\
& \text { For an triangenter } \\
& .06<f_{m}<.08
\end{aligned}
$$

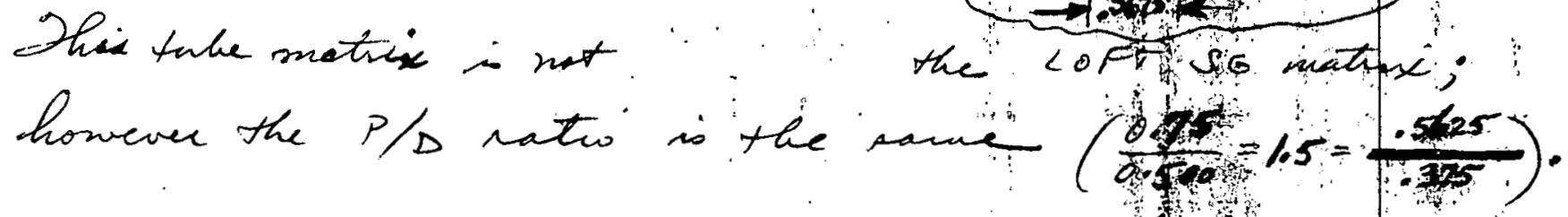

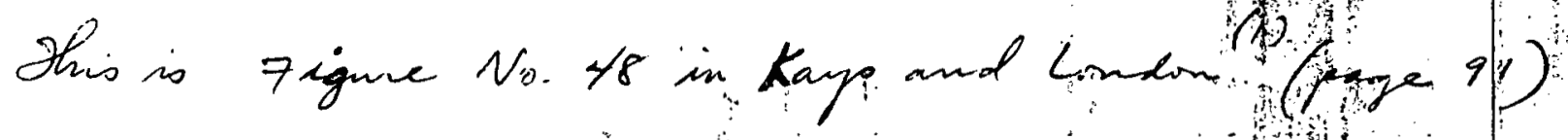

$$
\begin{aligned}
& \left.\sigma=\frac{A_{c}}{A_{f r}}=0.366\right\} f \quad \ldots \\
& \psi_{2}=f_{m}\left(\frac{A}{A_{c}}\right)\left(\frac{v_{m}}{v_{j}}\right) \\
& A=\text { ht. transfer area }: \quad \forall=\text { total free scheme } \\
& A_{c}=\text { minimum free flow area. } \\
& A_{f r}=\text { prontel area } \\
& \left(\frac{A}{A_{c}}\right)=\frac{\left(\frac{A}{\sigma}\right)}{\left(\frac{A_{c}}{A_{f r}}\right)} *\left(\frac{\forall}{A_{f r}}\right)=\left(\frac{\alpha}{\sigma}\right)\left(\frac{\forall}{A_{f r}}\right) \\
& \forall=\forall=\text { hemiaghere volume - take white }=\forall h \text { tiutes } \\
& \forall h=1 / 2\left[4 / 3 \pi \cdot R^{3}\right]=1 / 2\left[(4 / 3 \pi)(24 \cdot 75)^{3}\right]=18 \cdot 3 \cdot 3 t^{3}
\end{aligned}
$$

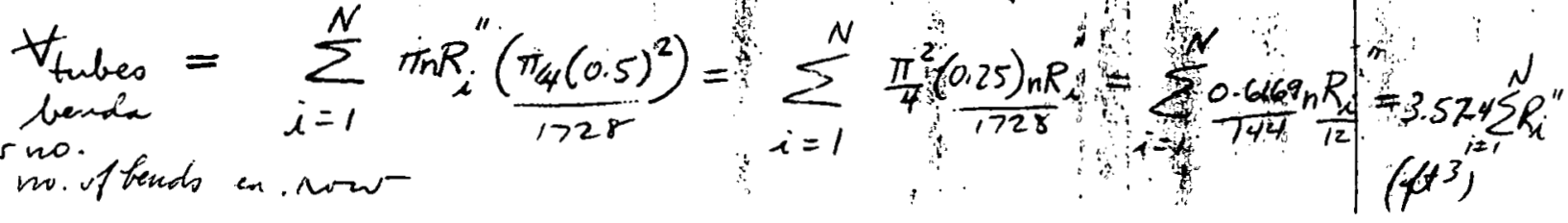




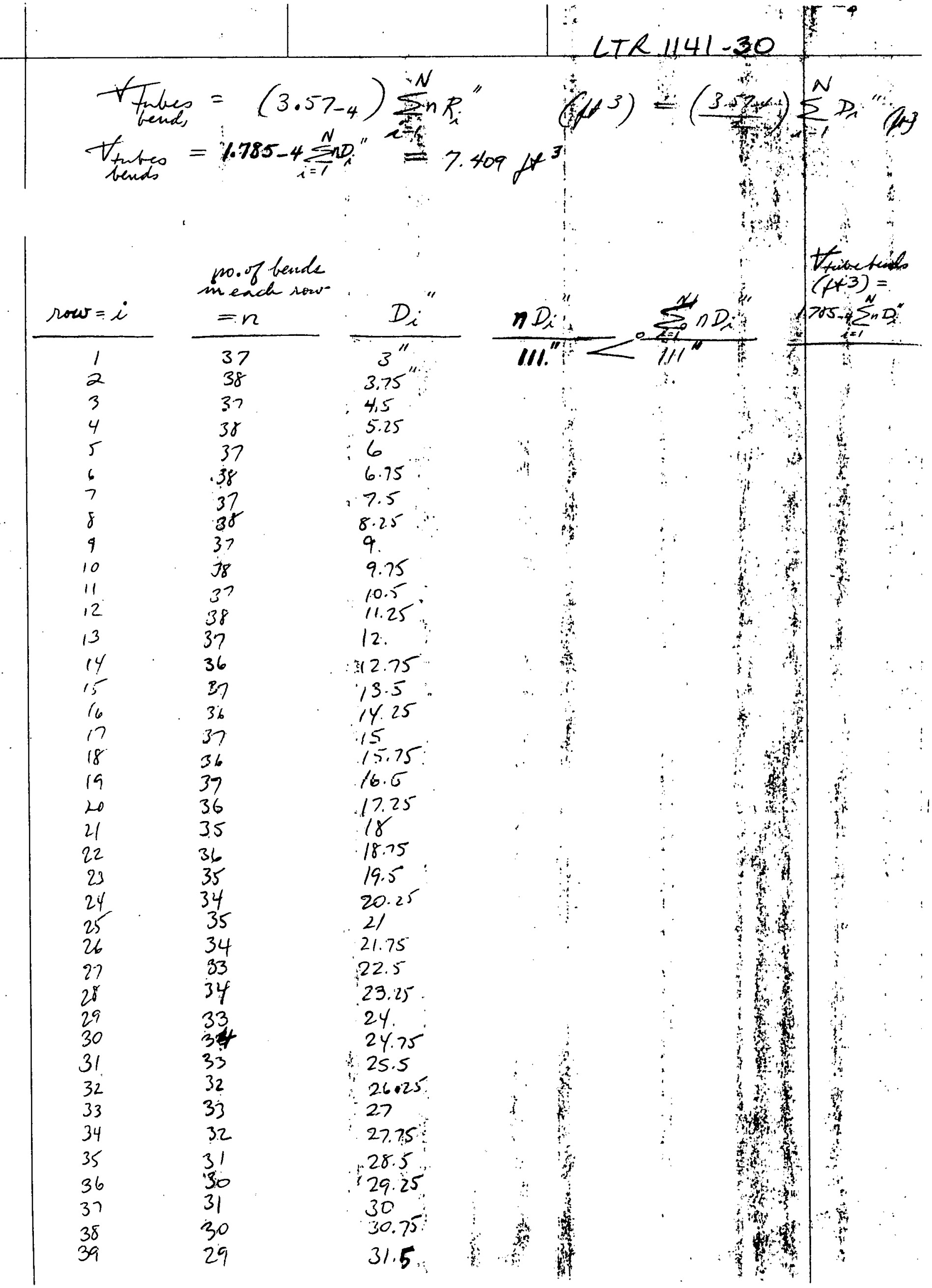





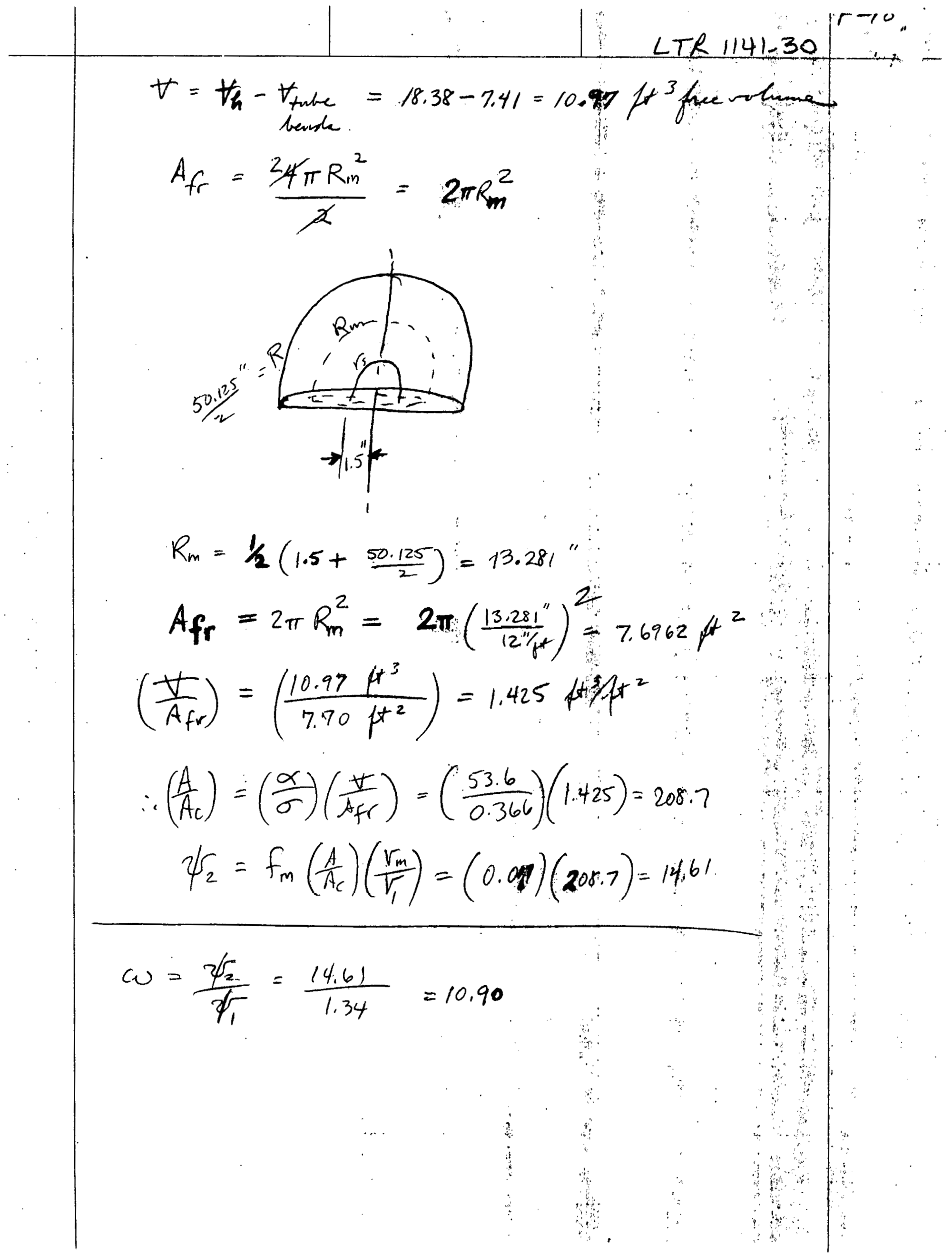




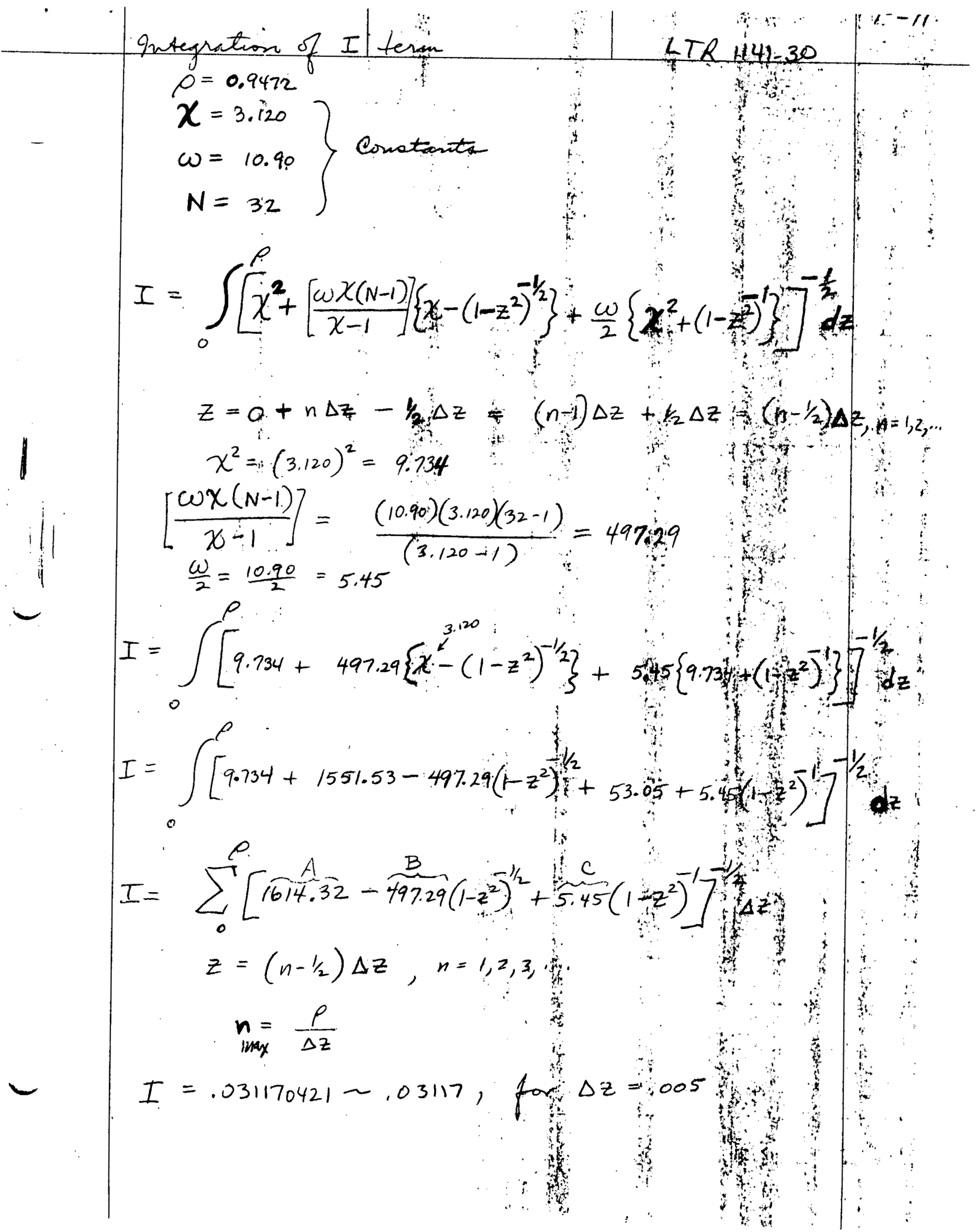





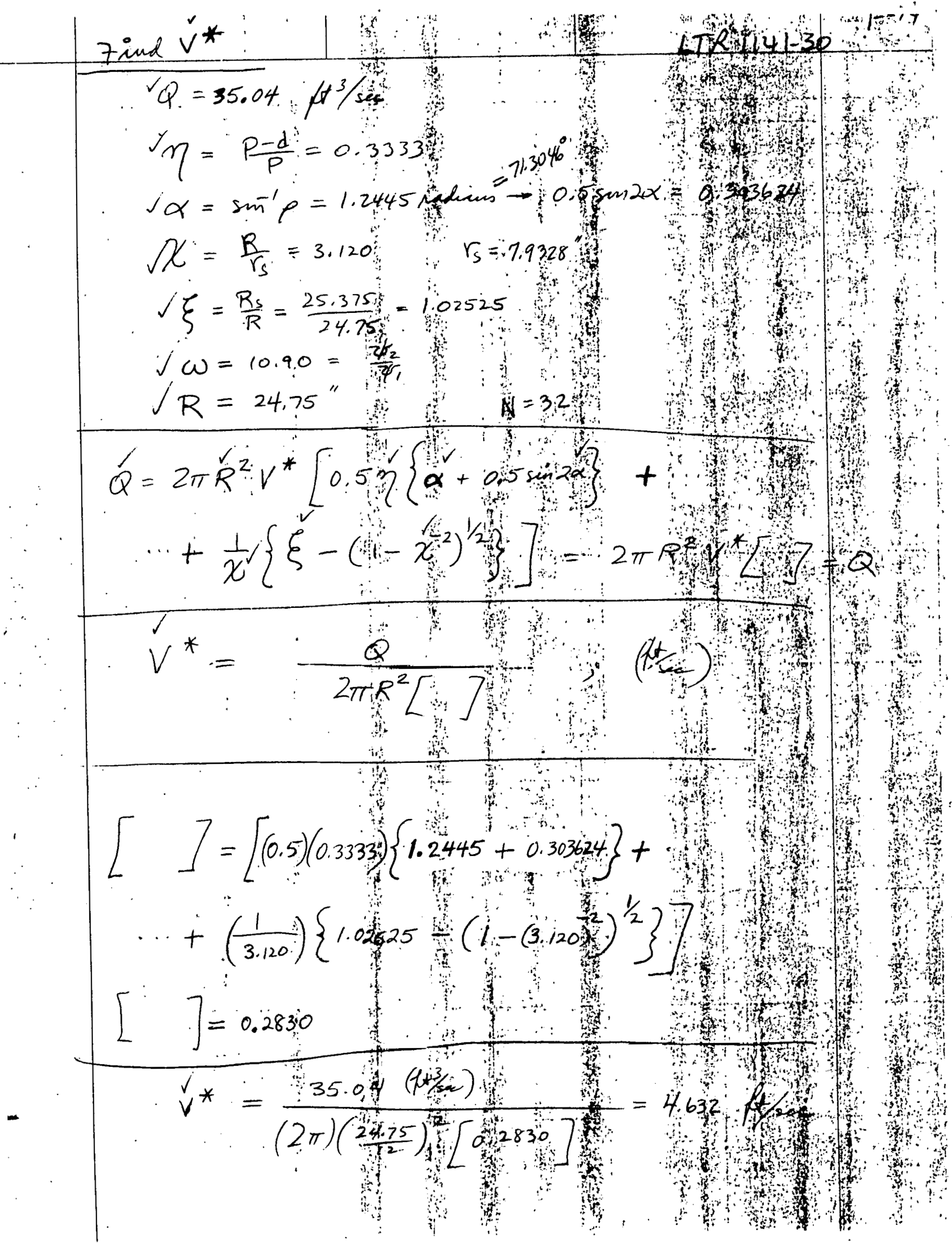




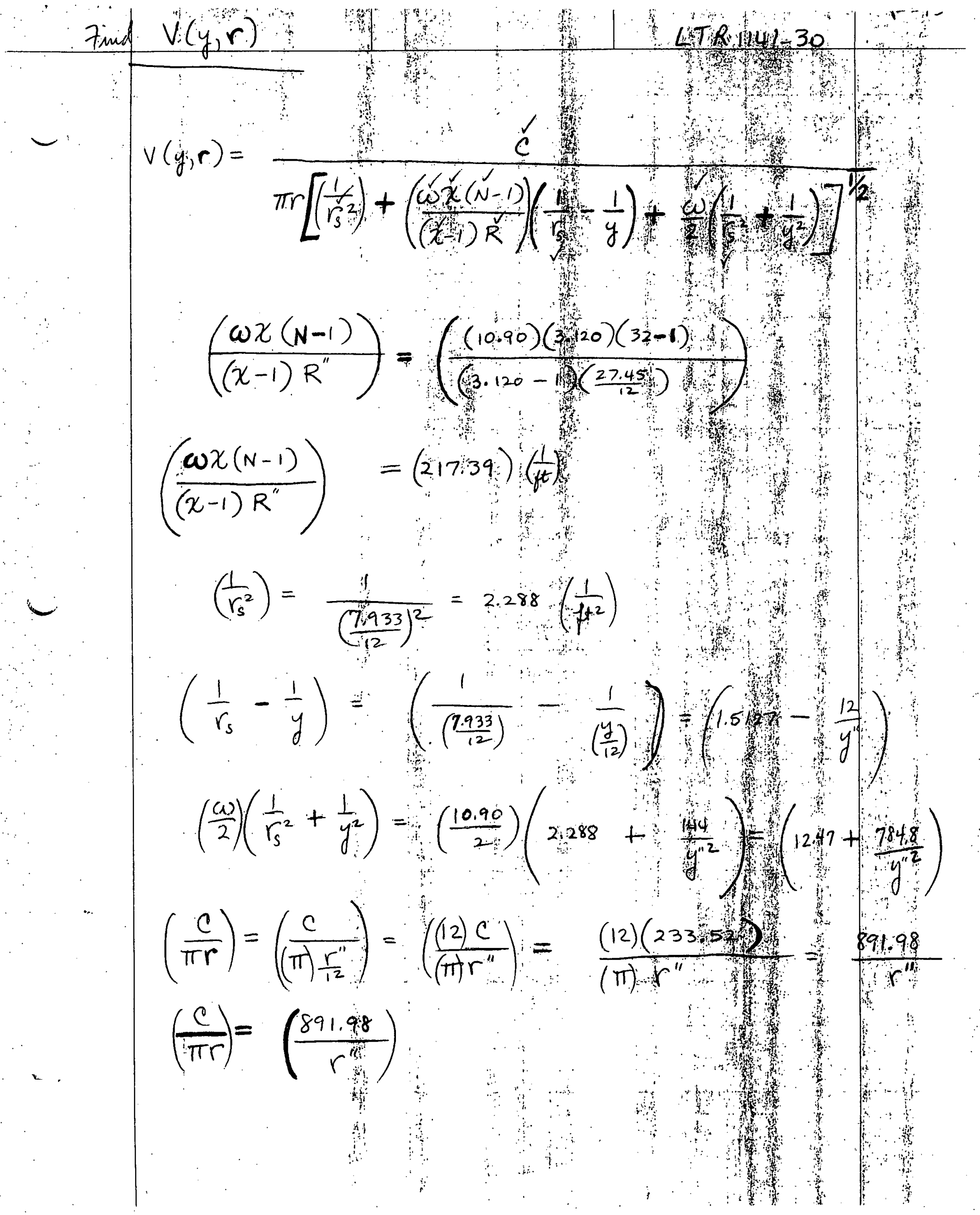


APPENDIX G

SAP-IV Models for Vibration Response of. U-Tubes in the Bend Region of the LOFT Steam Generator 


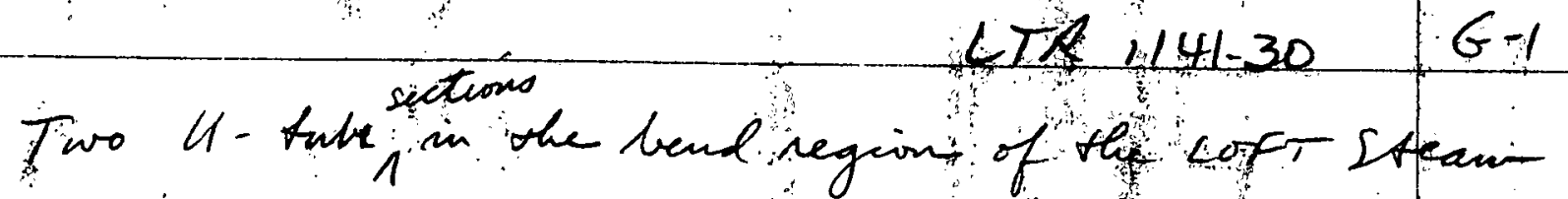
Senecator were selected for modeling in ola $5 A P$ - IV shustiuat malyois program. These two Hodeflo were structural cases 17 and 18, representing the 49.5pecinch

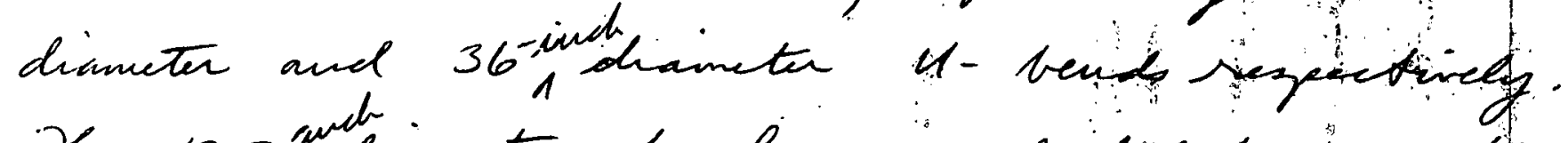

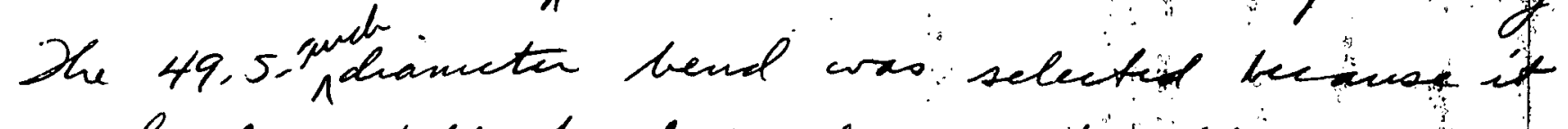
is the largest $U$-bend in the tube bindle, and the 36-inch bend was the lay est 4 -lend witch had access to the bole in the Ind soppartiplat, thereby maximizing the tube unsupported length e and combining that with ais higher student velocity than that seen by the 495 - inning bevel.

It is passible that come other bend region could have a more critical coubrituting of low national frequency and high imposed fonts force, but these two cases on consifued likely worst cases. The forcing ficinency is these to their second -mode natural frequencesply whereas a

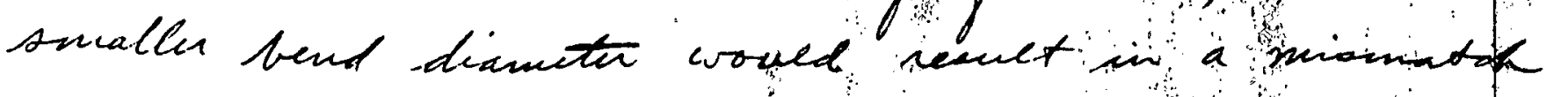
of forcing frequency and natural Aputay 


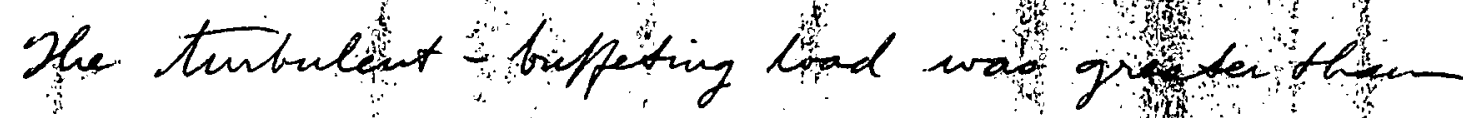

- the ron Kerman vortex load, the the tube natural frequency was apromintelis close a match to the turfinlence frejuction? to the vortex frequency; therefore the turbulent buffeting forcing function wo toed (Xe) also was the case for Case 18.$)$

The damping ratio was taken as thrace 002 , 1. le the minimum value measincle by t hack at al (23)

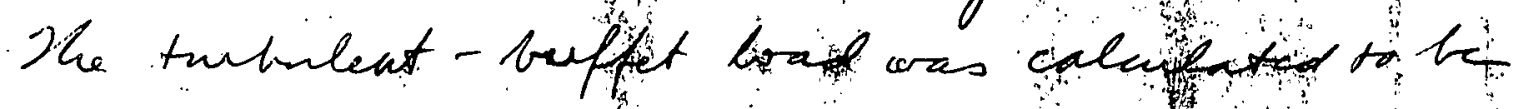

$$
\begin{aligned}
& w=C_{D} q_{t} \frac{S}{l}=C_{D} q_{t} \frac{l d}{l}=C_{D} g_{t} d \\
& d=0.5^{\prime \prime} \\
& q_{t}=0.25 q=\frac{0.25 v^{2}}{2 g v}=\frac{0.25\left(.5033^{2}(4.632)^{2}\right.}{(288)(32174)(.1915)} \\
& q_{t}=.0007648, \mathrm{pos} \\
& w=(1.2)(.0007648)(0.5)=.000458 \mathrm{~d} / \mathrm{fm} / \mathrm{min} .
\end{aligned}
$$

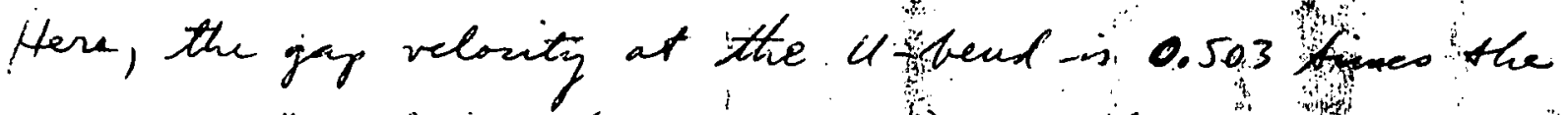

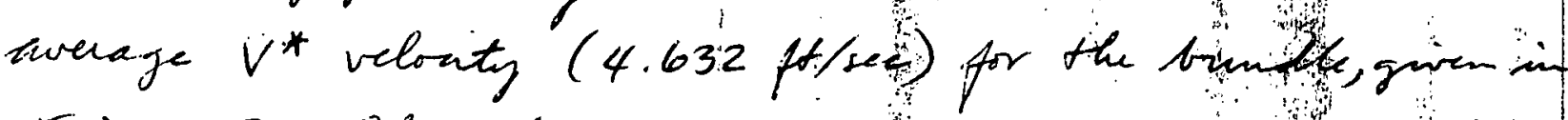
Figure 3. The a outhit specific volume, $0.1915 \mathrm{H}^{3} /$ than; is ned for in $=18 \mathrm{~s} \mathrm{Mm} / \mathrm{sec}$, which gives high tet degnandic veloitity head). 


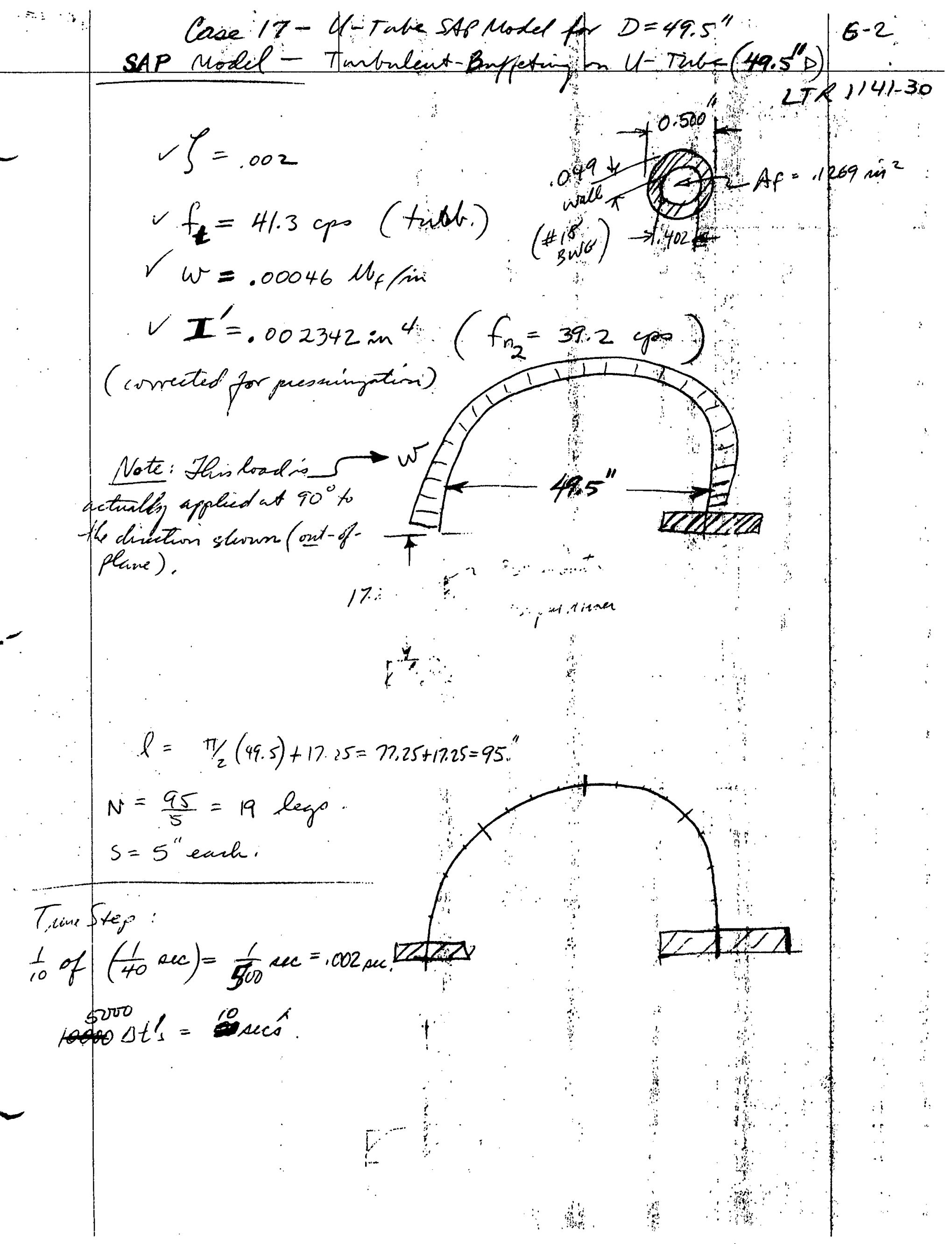




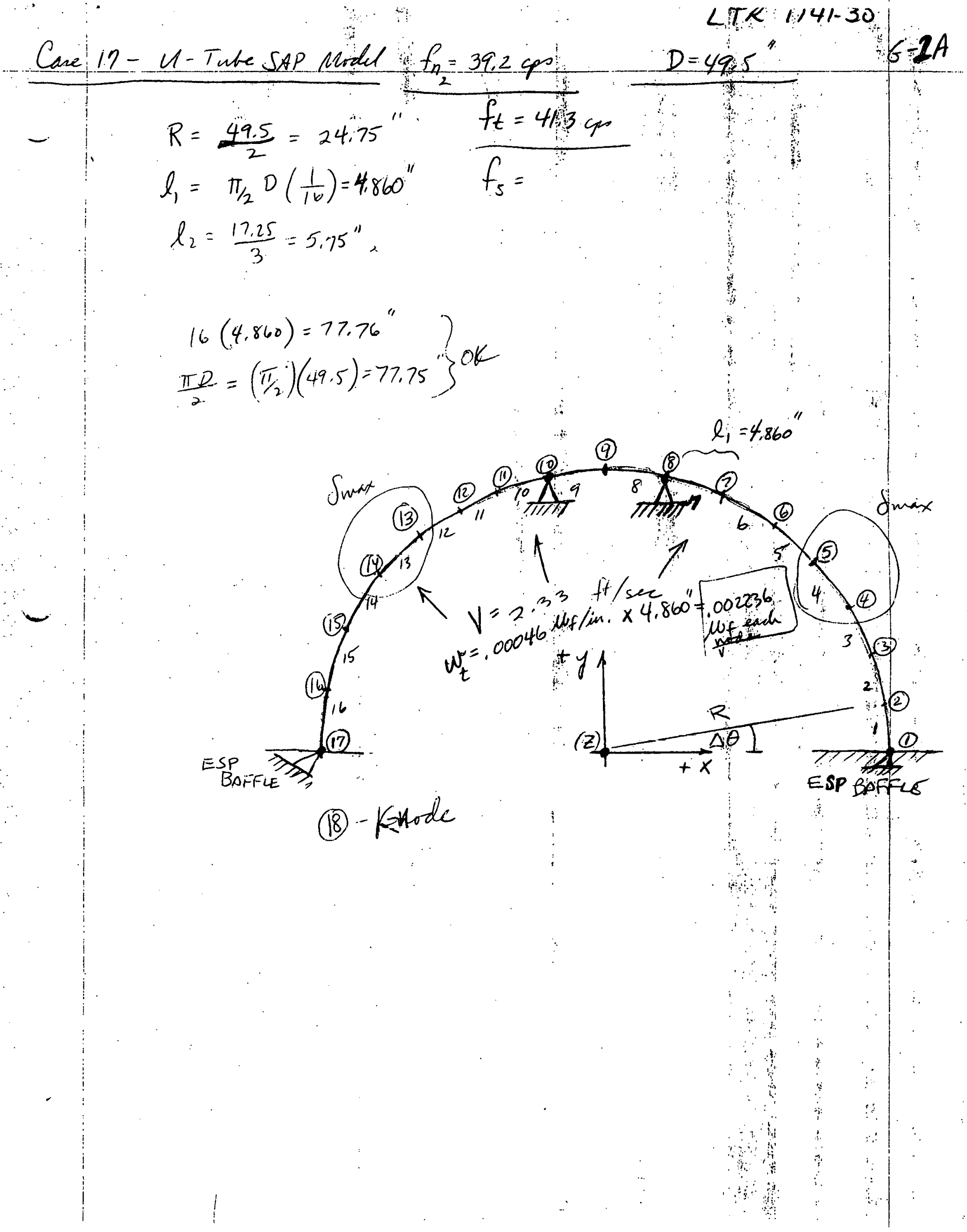




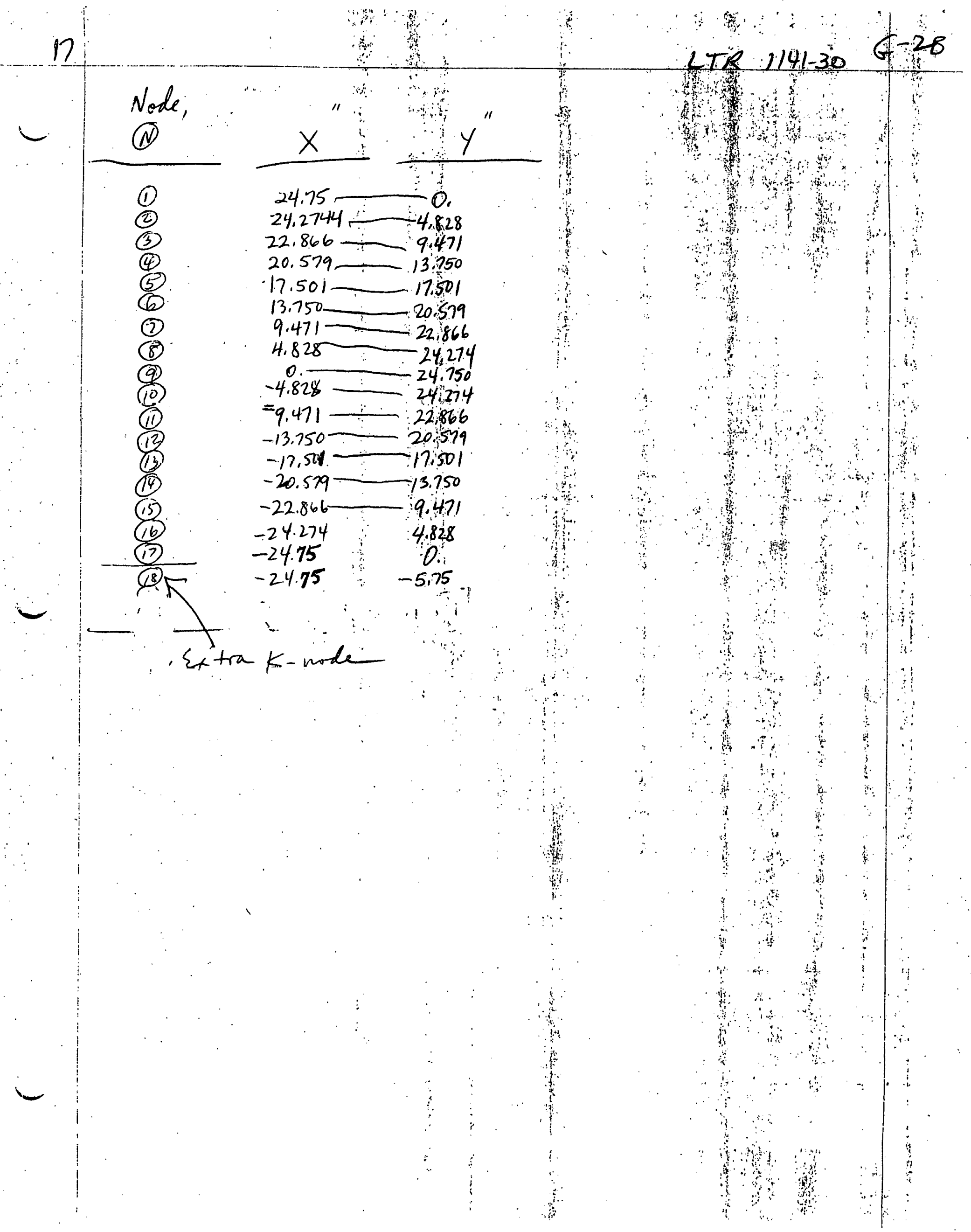


17 Loads on Tube

$$
\text { LTR } 1141.30 \text { G } 2 C
$$

$$
\begin{aligned}
& y^{*}=\left(\frac{y}{R}\right)=1.0 \\
& r^{*}=\left(\frac{r}{R}\right)=1.0 \\
& \left(\frac{V}{V^{*}}\right)=0.5028 \\
& v^{*}=4.632 \text { fos } \\
& V=2.329 \text { fro } \\
& \quad q=\frac{\rho V^{2}}{2 g c}=\frac{v^{2}}{2 g_{c} v}=\frac{(2.329)^{2}}{(288)(32.174)(.1915)}=.00306 \mathrm{psi} \\
& q_{t} \cong 0.25 g=.000764 \text { pai }
\end{aligned}
$$

a) Karman:

$$
\begin{aligned}
&\left(\frac{L}{l}\right)_{k}=\frac{c_{L} q S}{l}=\frac{c_{l} q l d}{l}=c_{l q d}=(0.28)(100306)(15) \\
& w_{k}=\left(\frac{L}{l}\right)_{k}=.000428 \mu_{f}
\end{aligned}
$$

b) Tubbulent-Buffet:

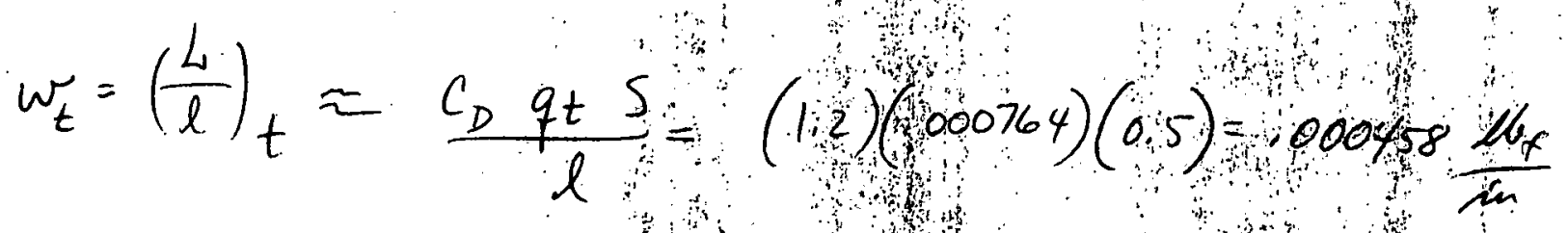

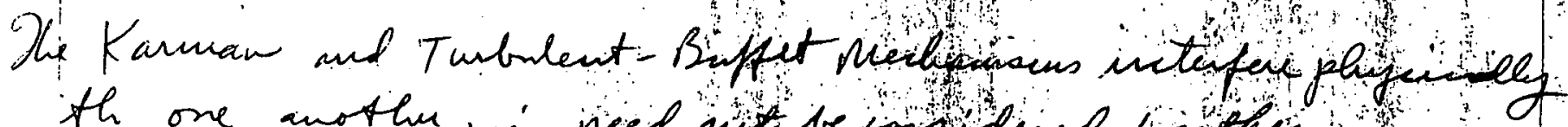

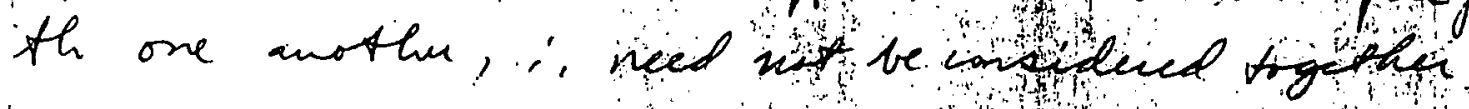

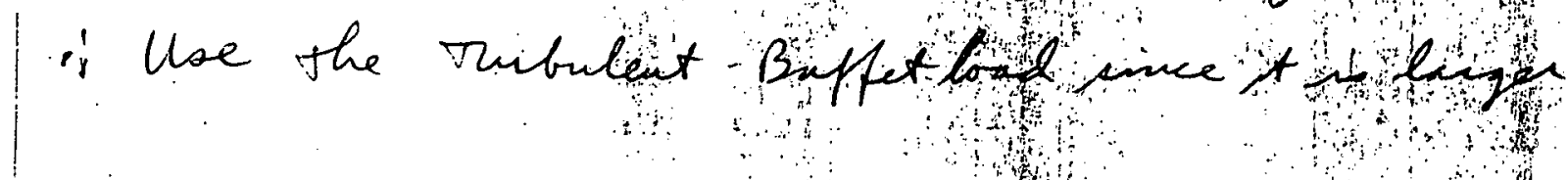




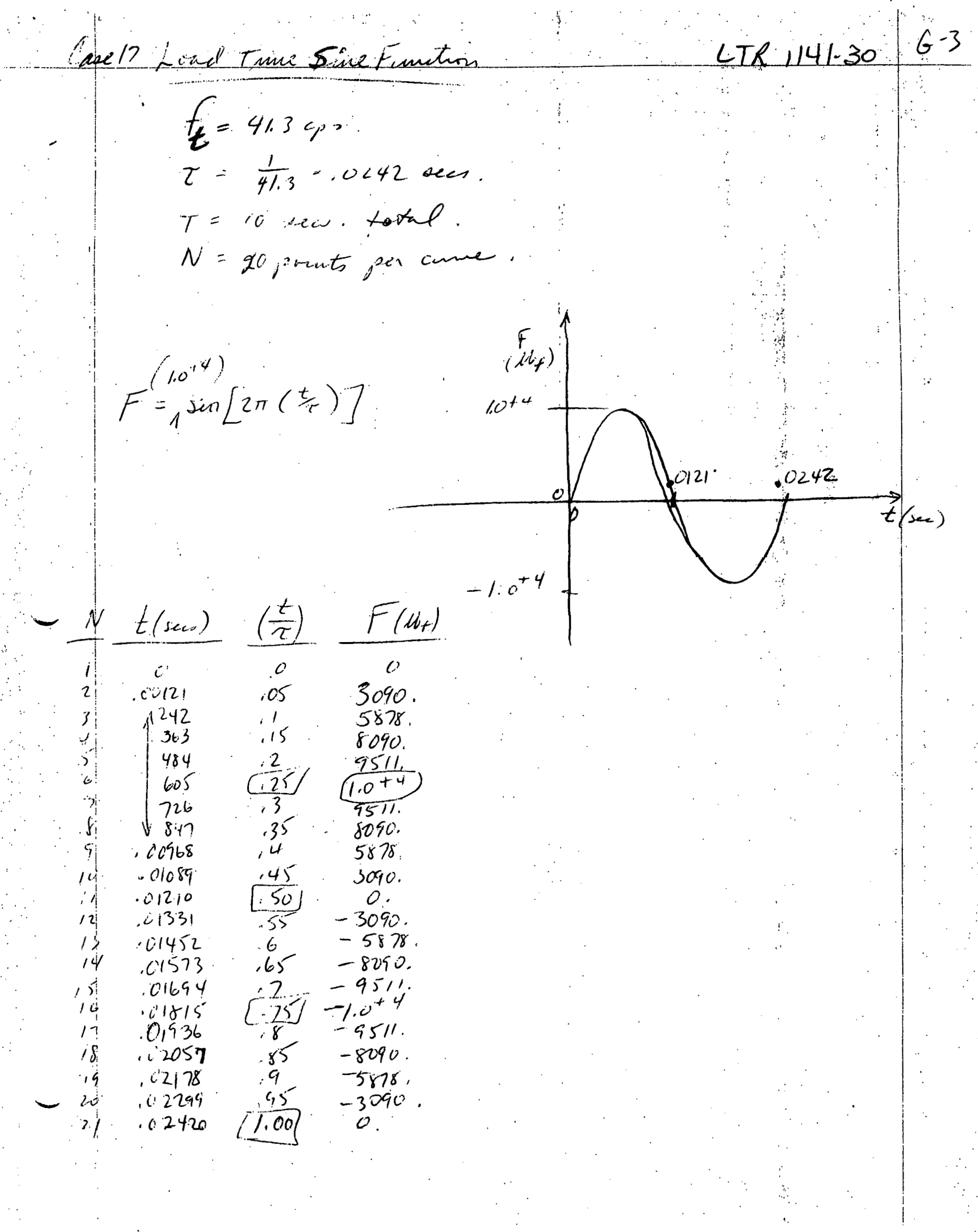


Case 17

Mass Density $\left(\rho=\frac{U_{s} \sec ^{2}}{\text { in }^{4}}\right)$

$$
\begin{aligned}
& F=m a \\
& F=\rho g_{c}=w \\
& \rho=\frac{w}{g_{c}}=\frac{\mu_{f} \sec ^{2}}{\operatorname{in}^{4}}=\left(\frac{l_{f}}{m^{3}}\right)\left(\sec ^{2}\right) \\
& w=\frac{0337}{A \omega} \frac{\mu_{f}}{m}\left(\frac{1}{1.0694 \mathrm{~m}^{2}}\right)=0.4856 \frac{\mu_{f}}{\mu^{3}}
\end{aligned}
$$

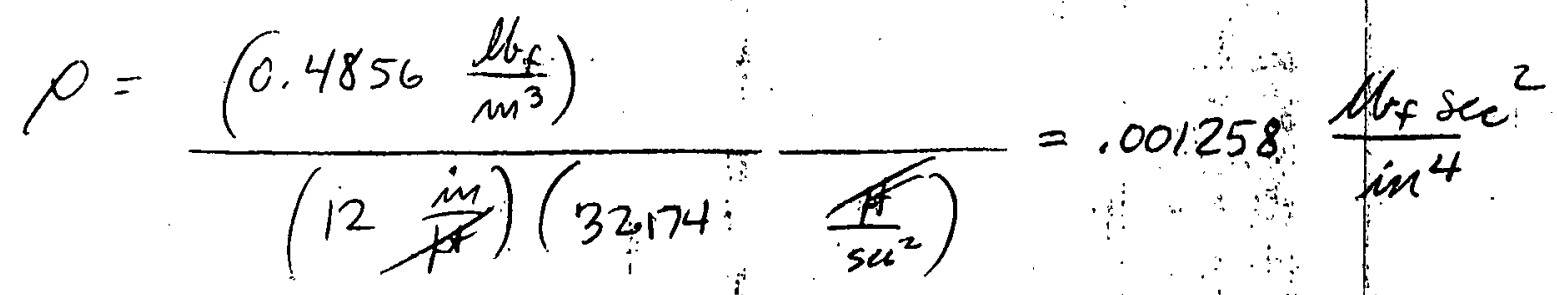




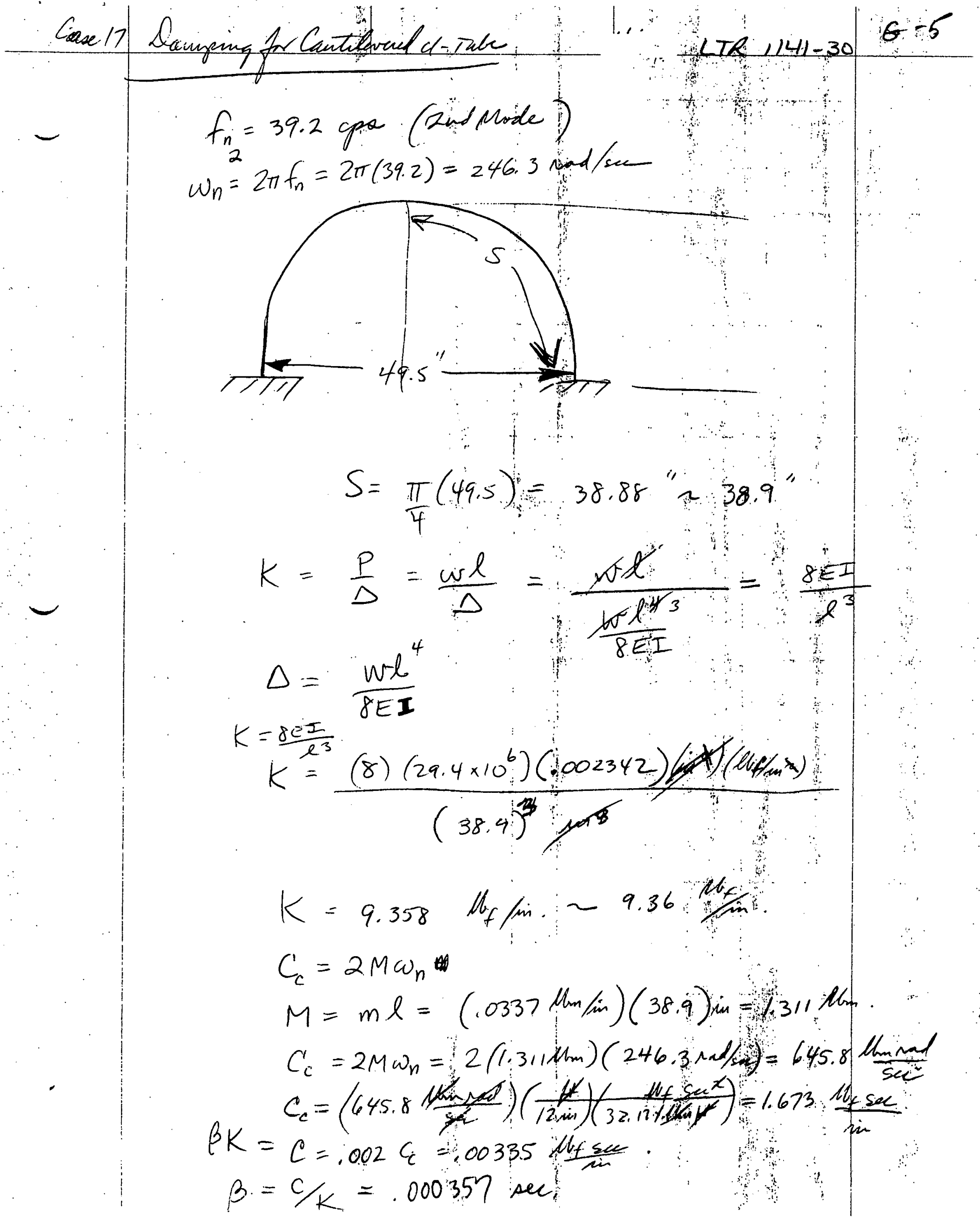


LIR $1141-30 \quad G-6$

Following is the SAP -II unguent for Cased to (the 36-inch 4 -bend, including a 17,375-inchistraight ley to the buffer below the End support plat). she gap velocity in the 11 -bend region is increased to 3.49 feet per second because of the small at bent diameter, He load on the straight section it. neglected even though the radial velocity it the centerline, mostly because the tube is far removed from the curterlinc and sea more (parallel) leakage flow than wiofaflow. 


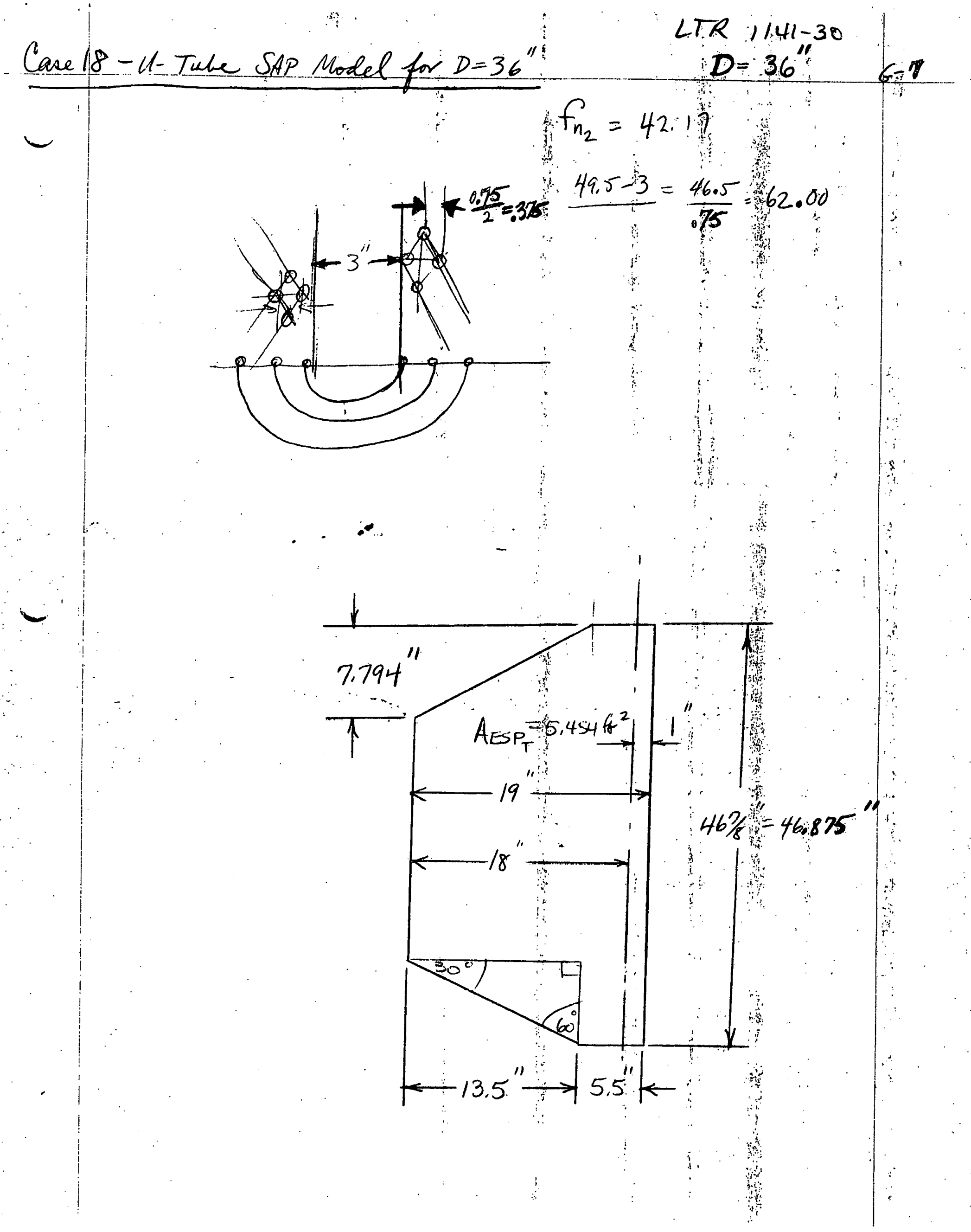




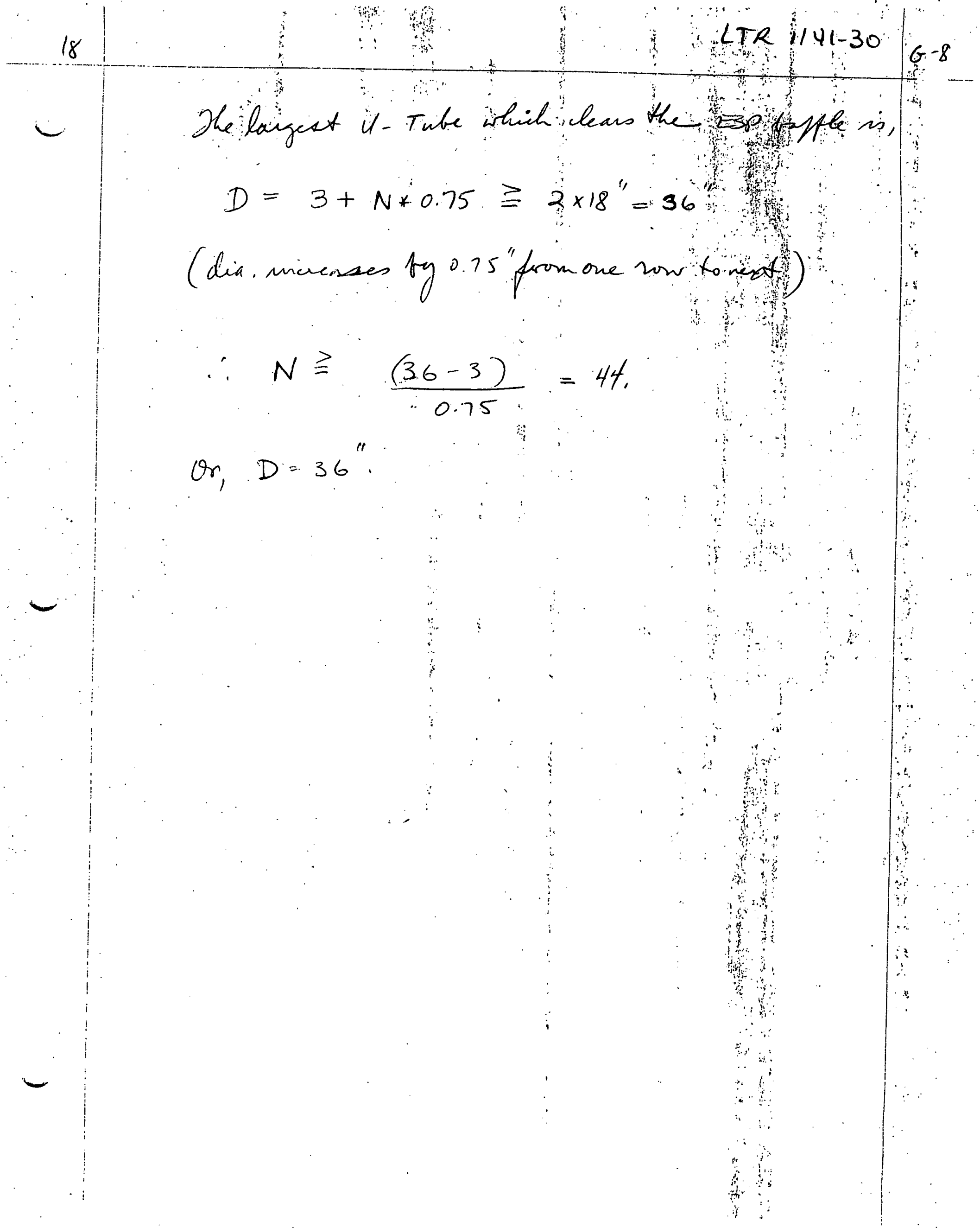




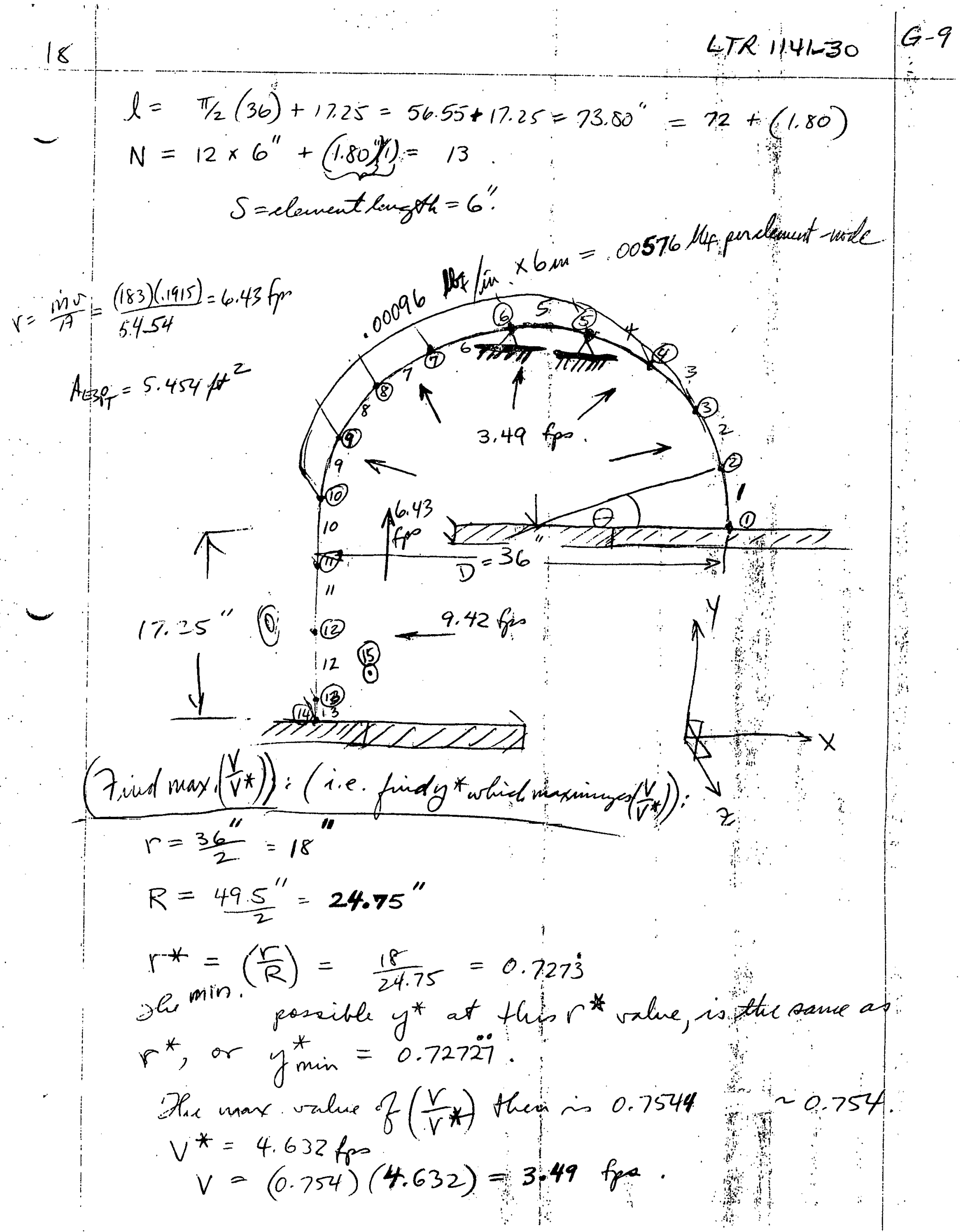




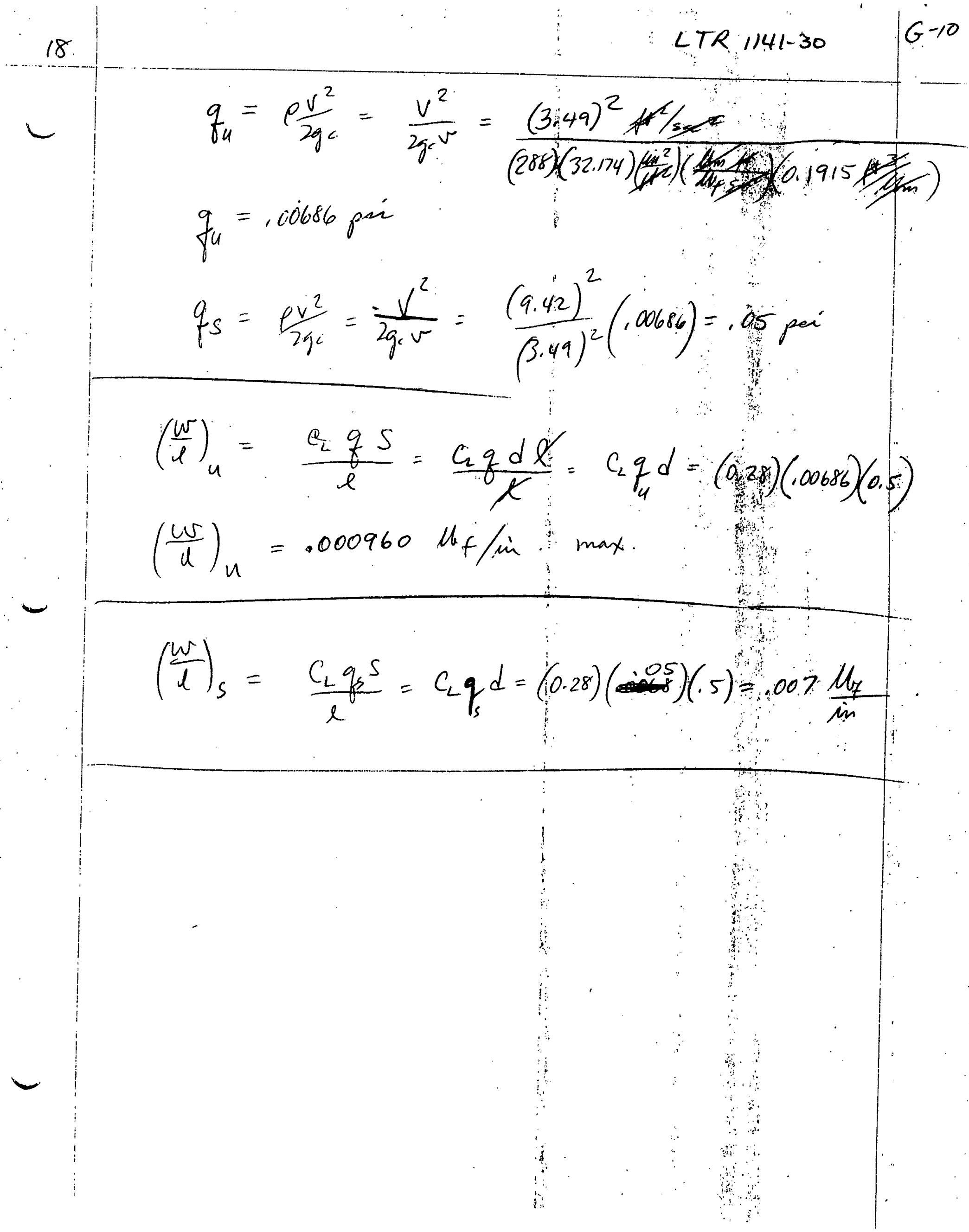




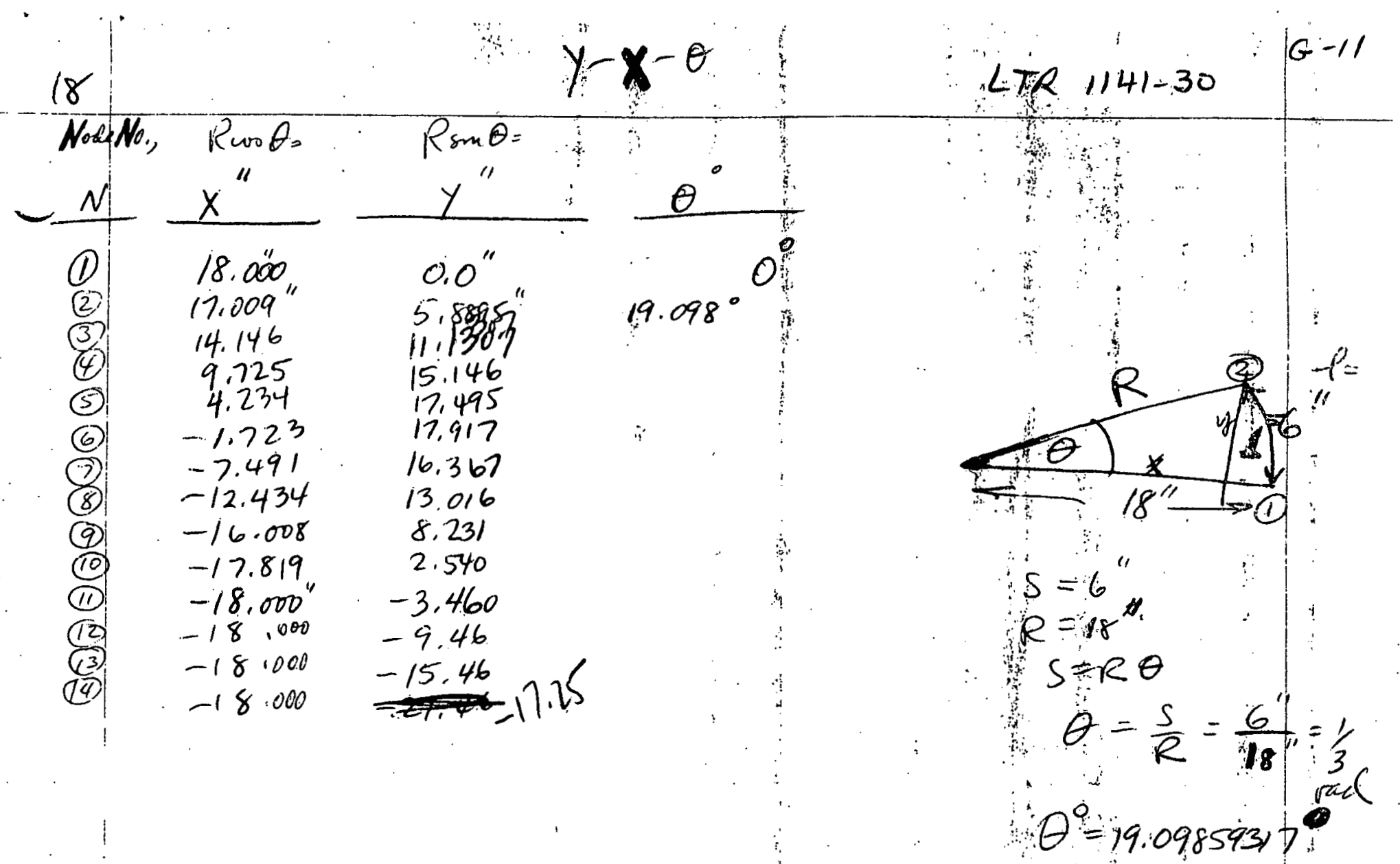


18

Natural Frequencies$$
\begin{array}{r}
f_{n}=\frac{\lambda_{n}}{2 \pi}\left(\frac{1}{R \theta}\right)^{2}\left(\frac{E I}{m}\right) \\
l=\frac{2 \pi R}{2}+77.25=73.8^{\prime \prime}
\end{array}
$$$$
E=29.4 \times 10^{6} \mathrm{psi}
$$$$
I=.001786 \mathrm{in}^{4}
$$

$y=$

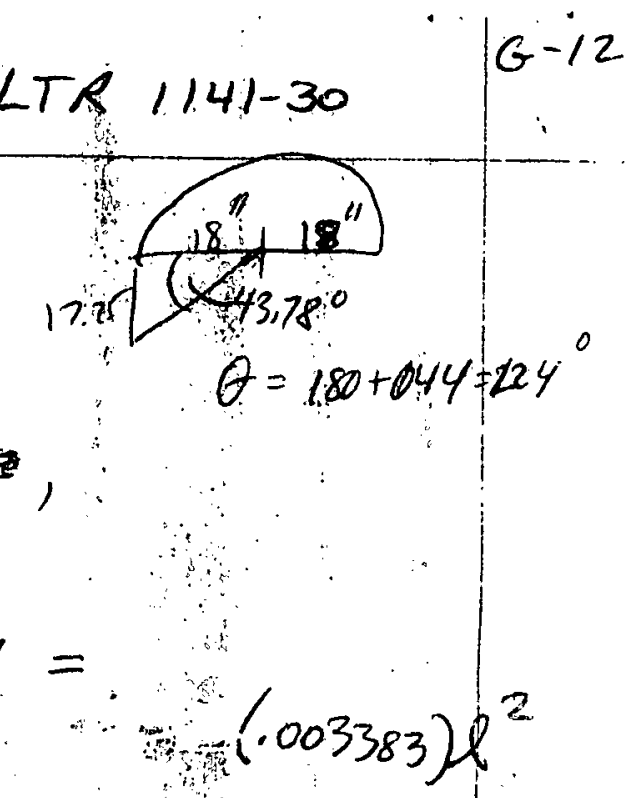

$$
\pi=0(.003383) e^{2}
$$

$m=.0337 \mathrm{~lm} / \mathrm{in} \quad f_{n}=$

$$
\begin{aligned}
& R=18^{\prime \prime} \quad R \theta=(18)(3.91)=73.8^{\prime \prime} \\
& \theta=180^{\circ}+44^{\circ} .
\end{aligned}
$$

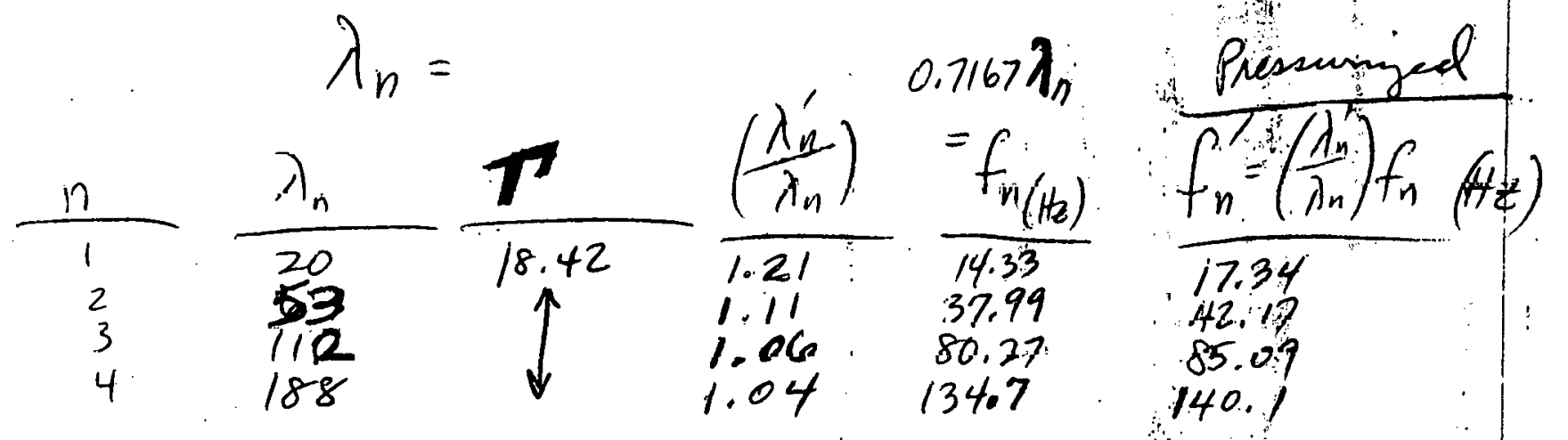

(Hz)

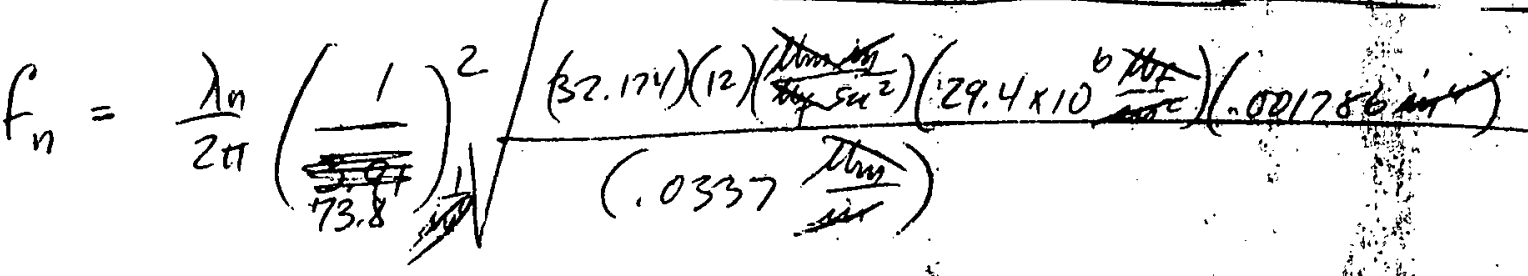

$$
\begin{aligned}
& f_{n}=0.7167 \lambda_{n} \quad(\mathrm{~Hz})
\end{aligned}
$$




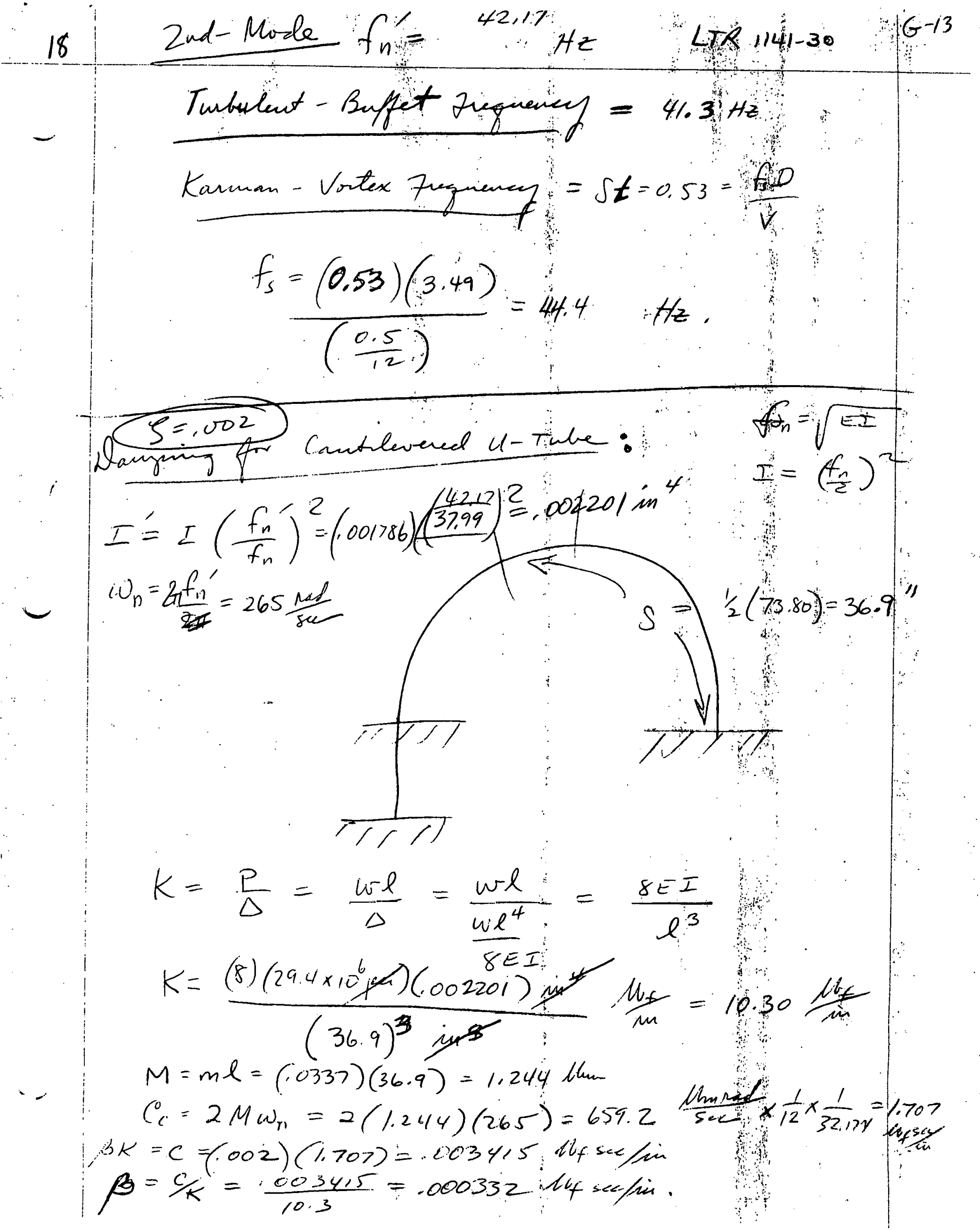


Scalar Mulfighei (SF)

LTR $1141-30 \mid G-14$

$$
\begin{aligned}
& S F=\frac{F(t)}{f(t)} f_{n}^{\prime} \text {. } \\
& F(t)=\delta F * f(t) \\
& l=\text { element leugoth }=6 " \text { ". } \\
& \left(l_{f}\right) \\
& f(t)=1000 . \quad \text { (max) } \\
& F(t)=.00096 \text { lnf fim (max). } * 6 \text { in }=.00576 \text { lm. } \\
& \text { per elenint. } \\
& \text { (rode) }
\end{aligned}
$$$$
.00576=S F * 1000 \text {. }
$$$$
S F=\frac{.00576}{1000}=5.76-6
$$$$
\underset{\text { inax. }}{F(t)=(5.76-6)(1000)=576-3=.00576 \mu_{f}}
$$

imax. 


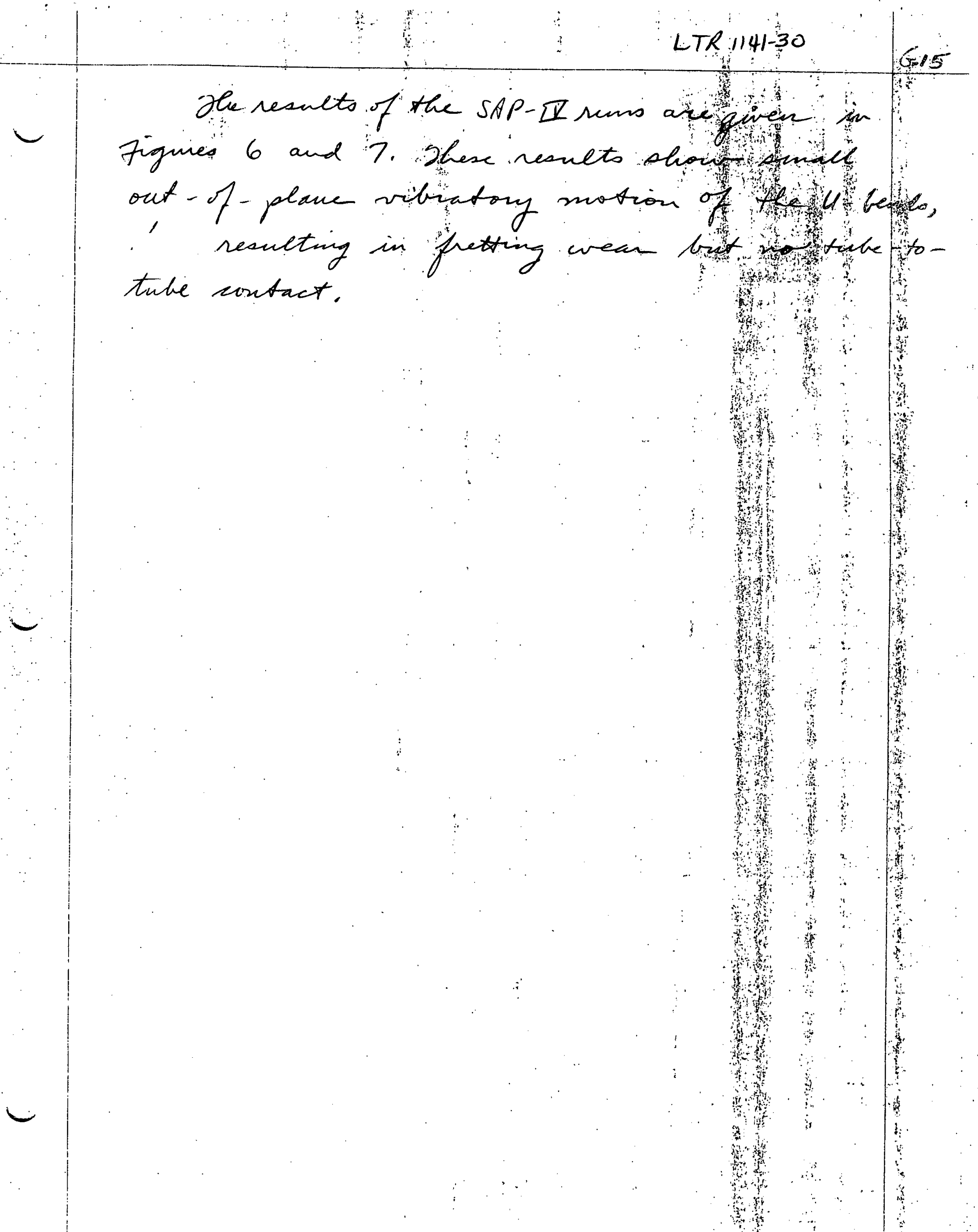


CONTROL INFOR IA TION
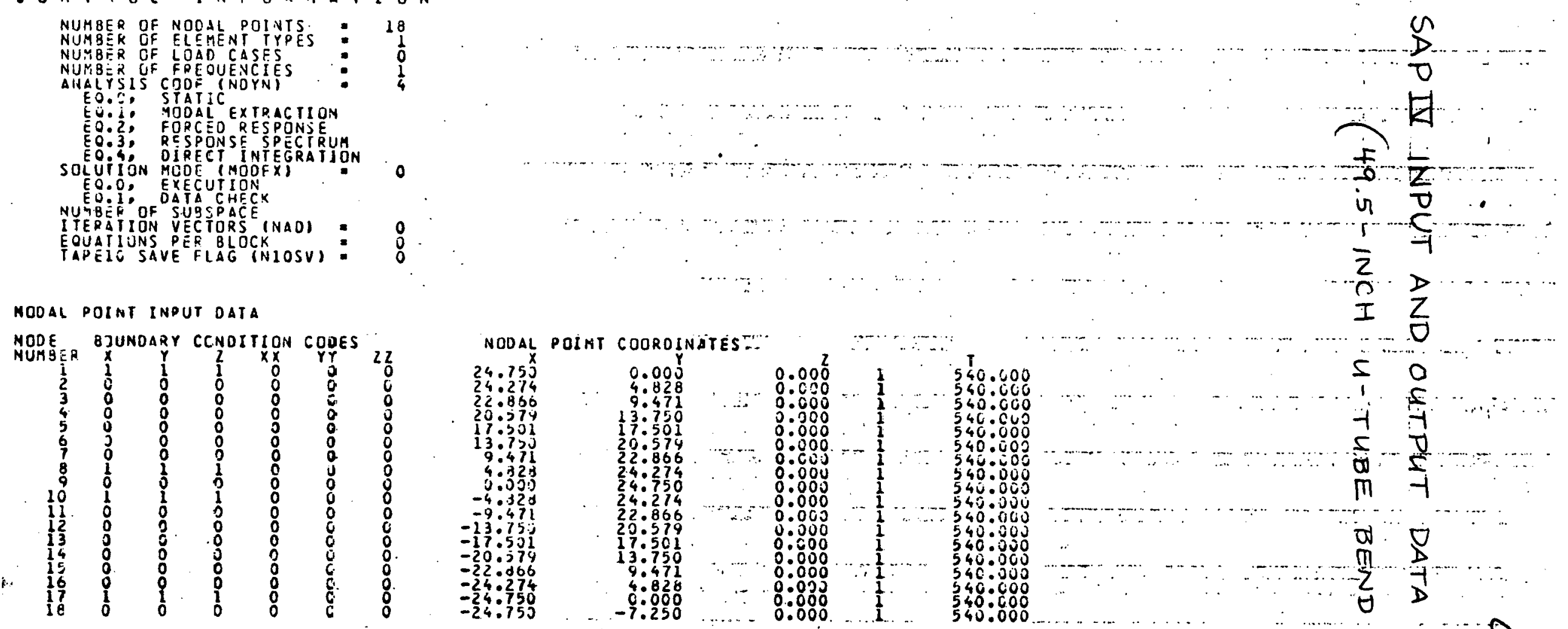

GENERATED NOOAL DATA
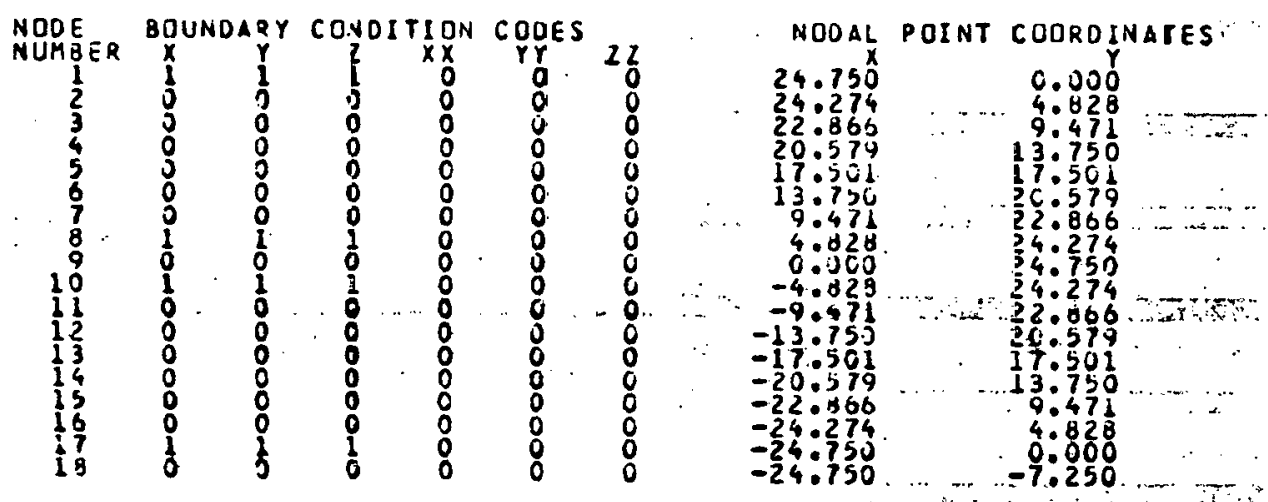

EOUATION NUHBERS
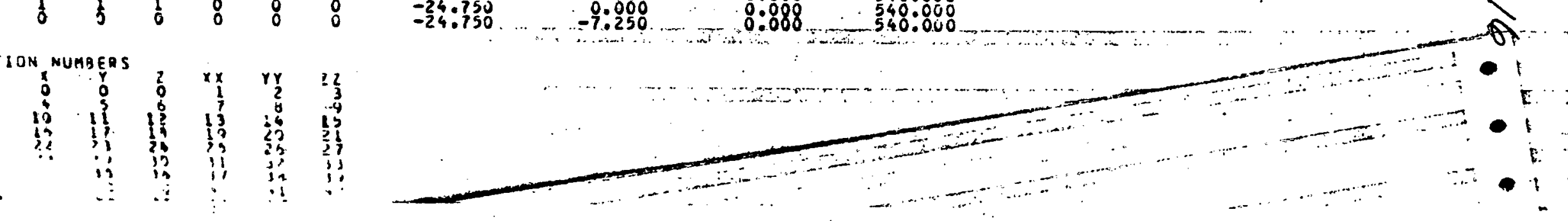

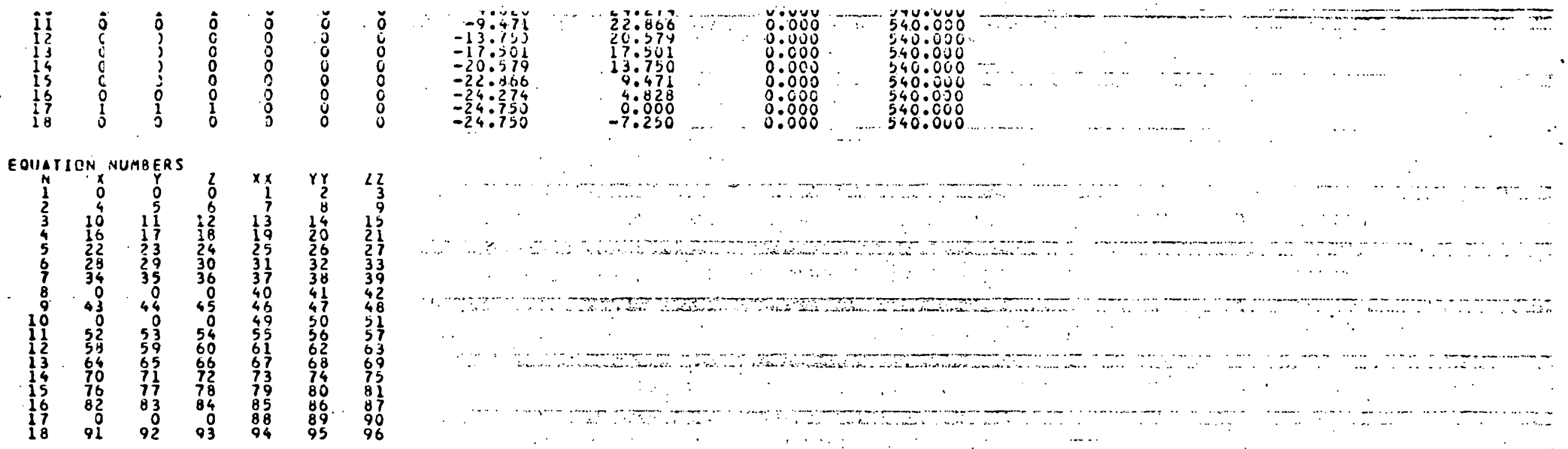

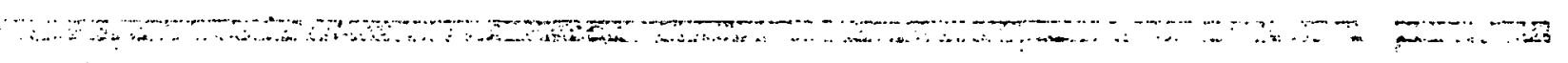

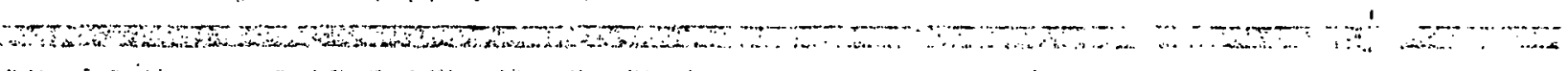
. i.

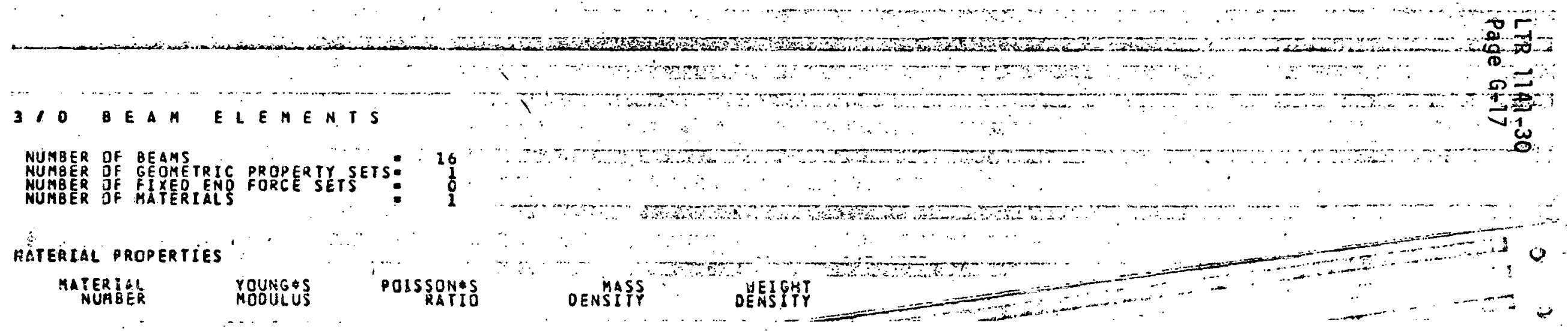


31 D BEA M ELEMENTS

NUMGER OF BEAMS
NUMBER DF GEOMETRIC PROPERTYSETS: 16
NUMBER JF FIXEDEND FORCE SETS
NUMBER OF MATERIALS

MATERIAL PROPERTIES

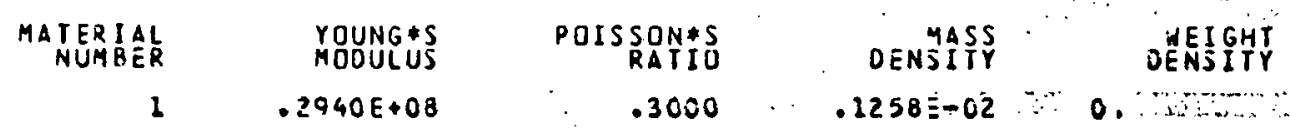

(n)

BEAH GEOMETRIC PROPERTIES

SECTION AXIAL AREA

SECTION

IXIAL AREA

SHEAR ARE

1

$.6943 E-01$

$.6743 E-01$

SHEAR AREA A TORSION

$1000 E+02$

INERT I 1 A

INERTIA

ELEMENT LDAD MULTIPLIERS

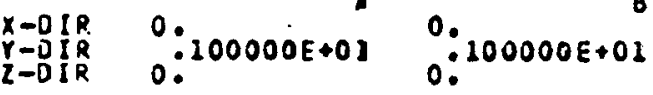

0.

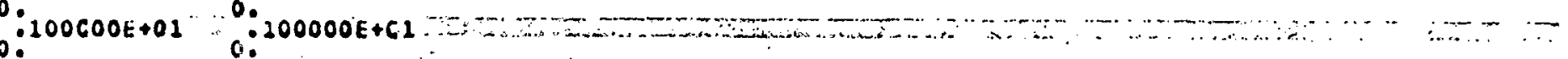
……

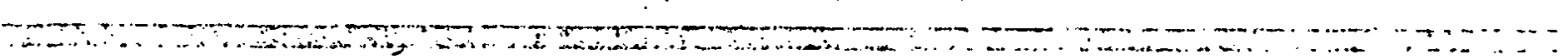
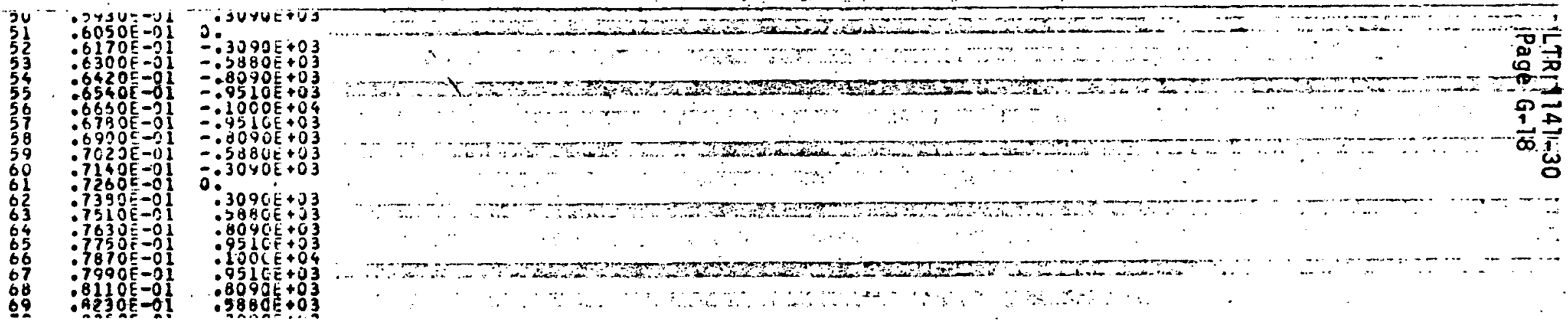

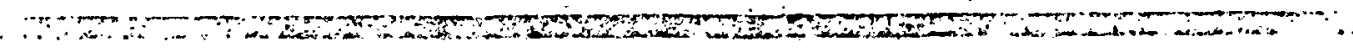


- 3/0 bEAT ELEYENT DA:A

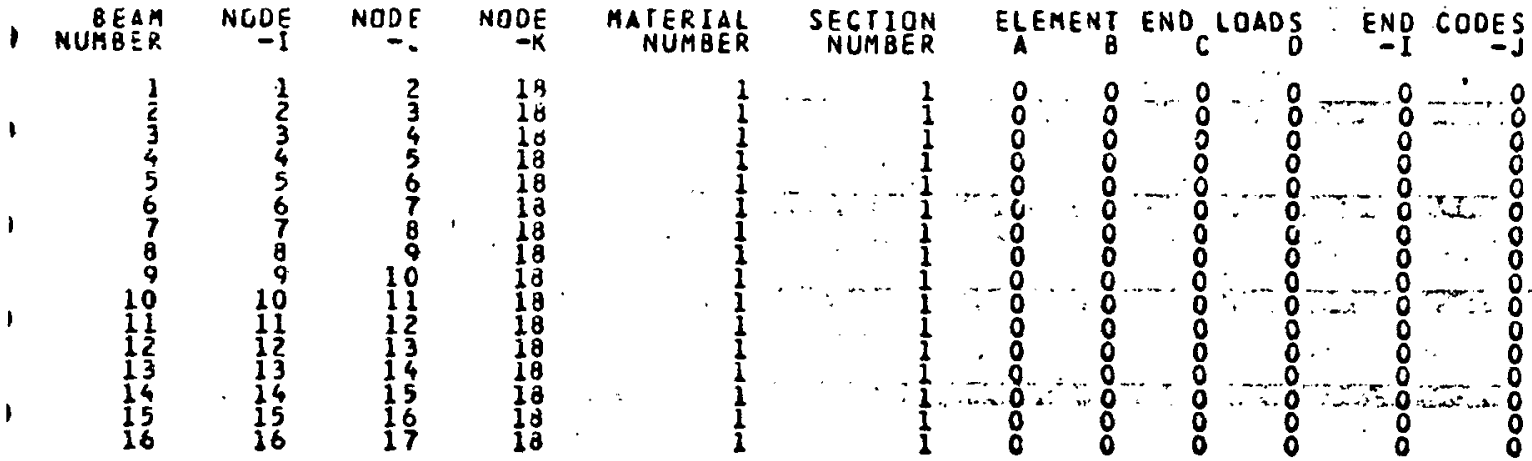

IEOUATI ON PARADETERS

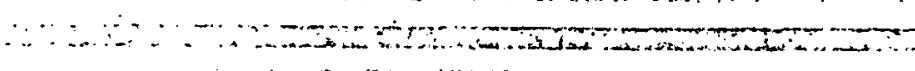

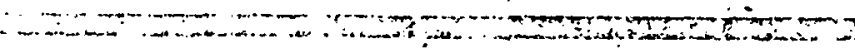

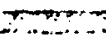

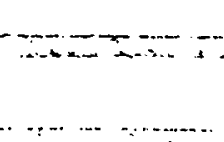
. 
- e a uat l o n PARAMETERS $\because$ TOTAL NIMMBER OF EOUATIONS
BANOWIOHH
NUMBER JF EOUATIONS IN A BLOCK: 90
NUMBER OF BLOCKS - 96
-

$\div$

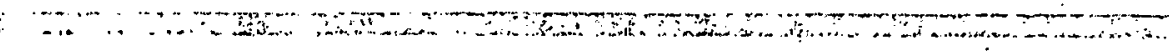

a. - -

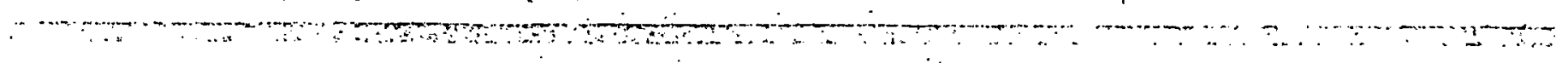

osuYuetus

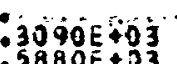

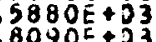


- nodal loads

(S TATIC)

DR MASSES IDYNAMIC!

- numajer case

X-AXIS
FORIE
YEAXIS

Z $-A X I S S$
FORCE

X-AXIS
MOMENT

$Y$ YXIS
MOMENT

ZOAXIS

- strugture

\begin{tabular}{ccccc}
\multicolumn{1}{c}{$\begin{array}{c}\text { ELEMENT } \\
0.000\end{array}$} & 0.000 & 0.020 & 0.000
\end{tabular}

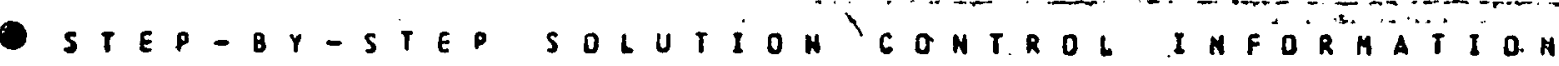

NUABER OF TIME VARYing FUNCTIONS

GROUND MOTION INOTCATOR

ET:O: REAO aCCELERATION INPUT NUHBER OF ARRIVAL TIHES

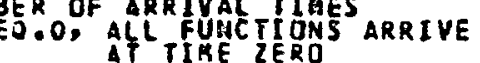

HUiBER OF SOLUTIOS. TIHE STEPS

-1
-1
0


- STEP-BY-STED SOLUTION GONTROL INF ORRAATION

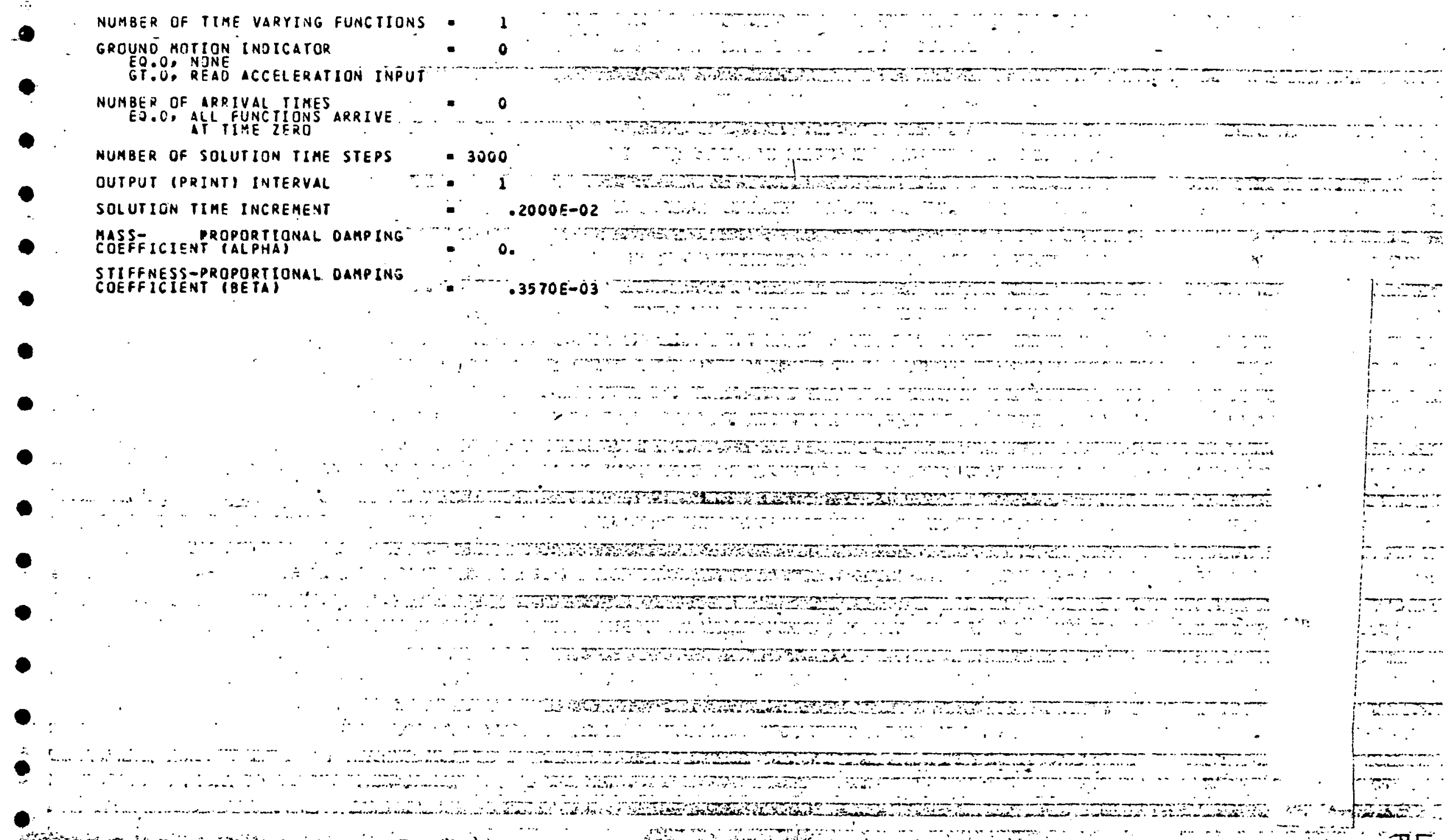

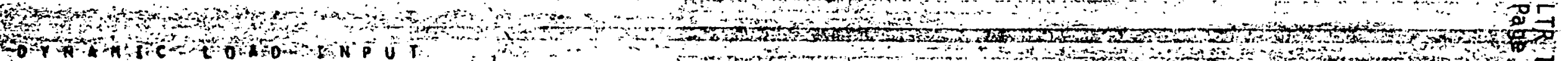

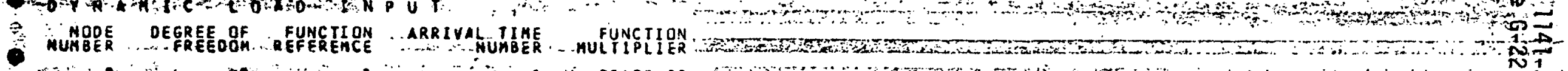

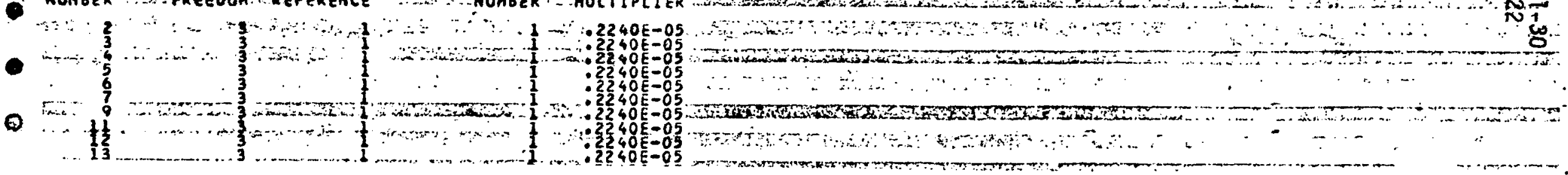


D. $Y N \& M+C$ \& OAD I N P U T

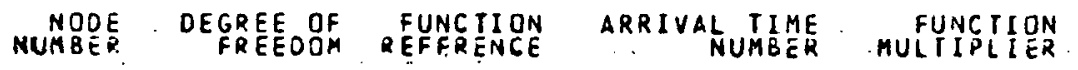

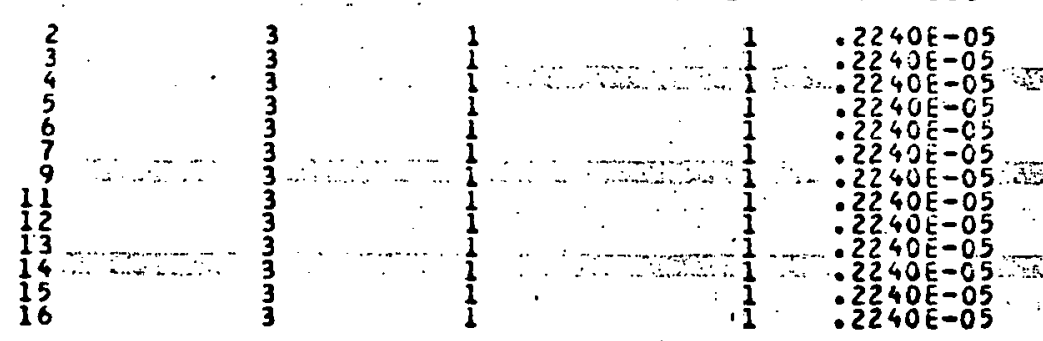

STH

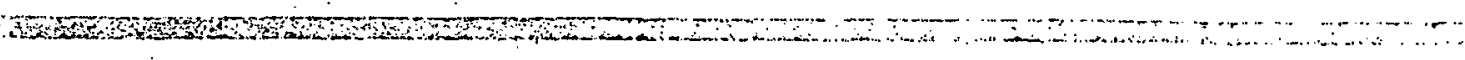

D.

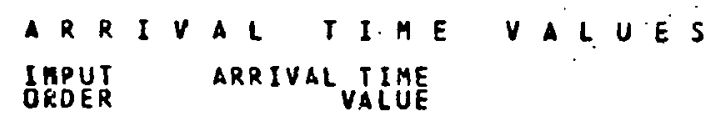

10.

a a a r a . 
- it i f function data

1 TIME FUNCIION NUMBER $=111$

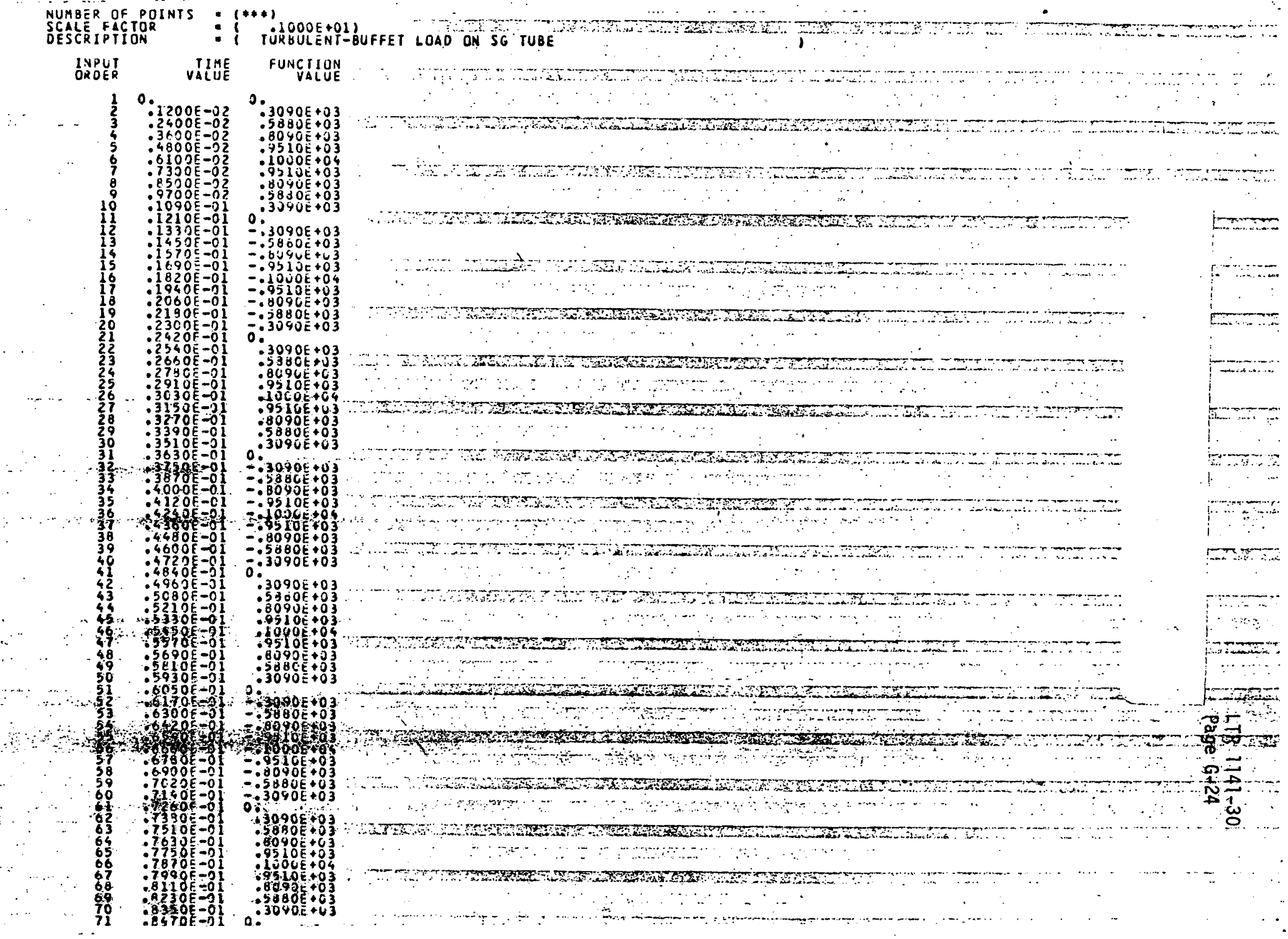




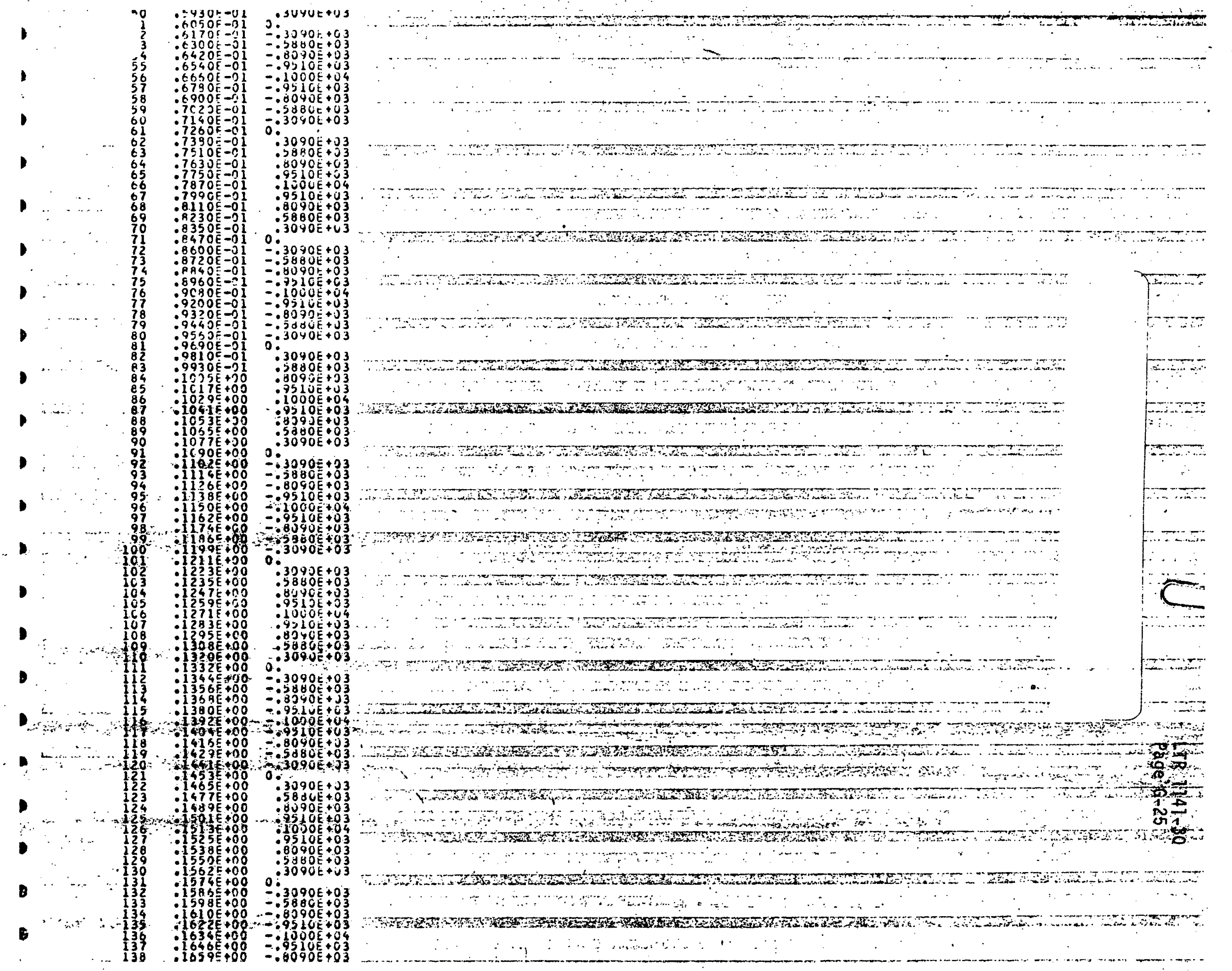




\section{CODE FOR OUTPUT TYPE
EO. T, AISIDRY TARLE
EO.2, PRINTER PLOT}

PRINIER PLOT SPACING - O NUMOER OISPLACERENT COMPJNENT

$\begin{array}{rllllll}4 & 3 & 0 & 0 & 0 & 0 & 0 \\ 3 & 3 & 0 & 0 & 0 & 0 & 0 \\ 13 & 3 & 0 & 0 & 0 & 0 & 0 \\ 14 & 3 & 0 & 0 & 0 & 0 & 0 \\ 0 & 0 & 0 & 0 & 0 & 0 & 0\end{array}$
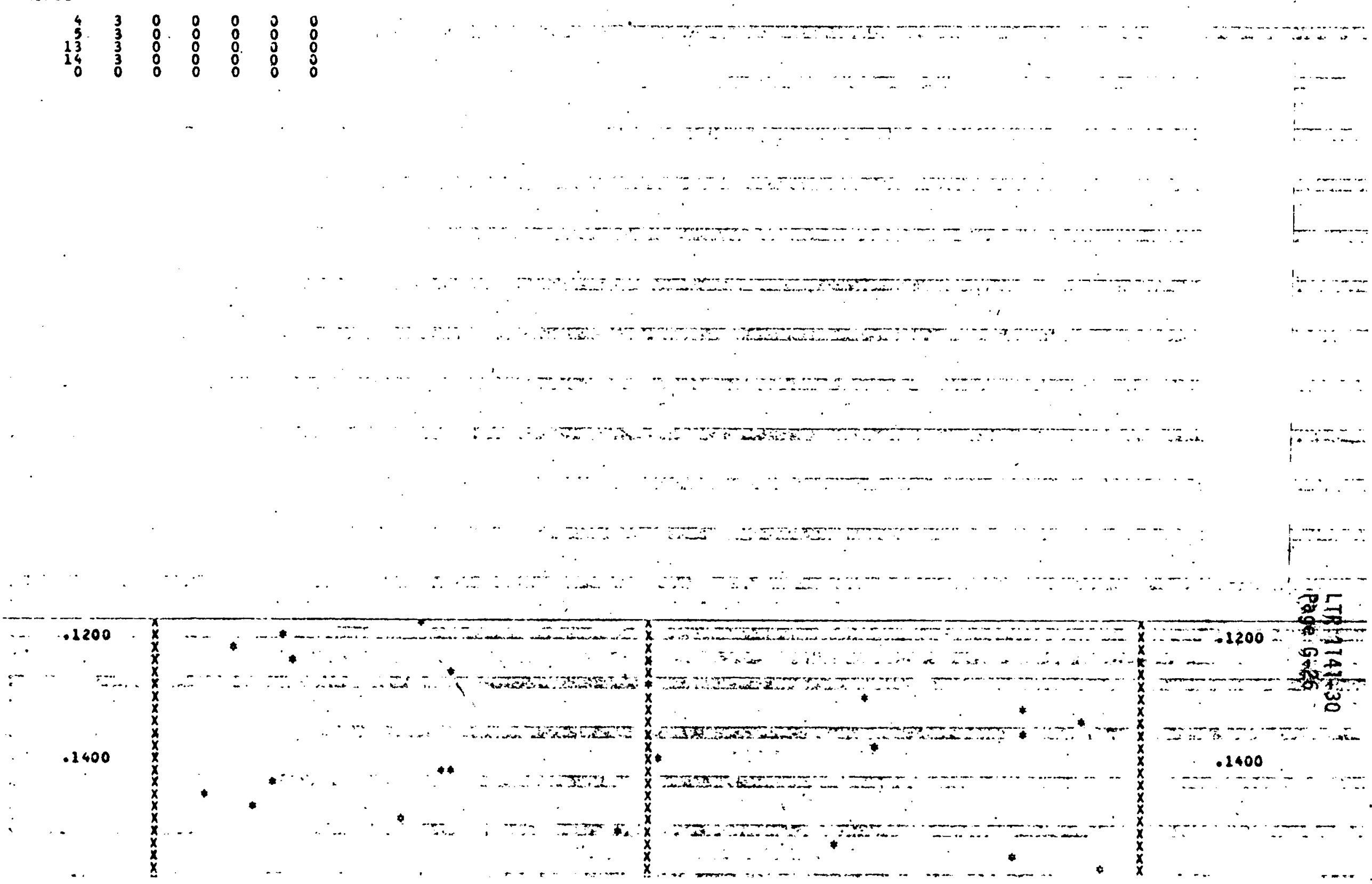


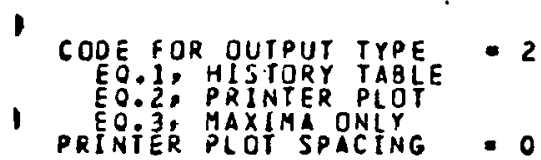

ELEHENT TYPE (2)

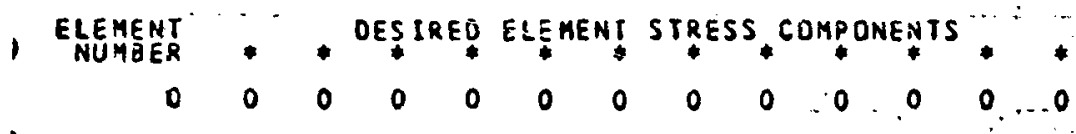

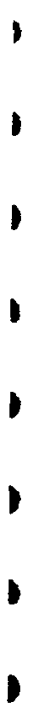

- E O U A t I n Parameters

- TOTAK NUMBER OF EOUATIONS TOTAL NUHBER OF EOUATION BLOCKS:
NUMBER OF COUPLING BLOCKS

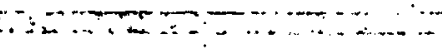

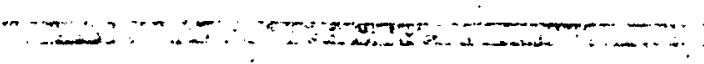

1

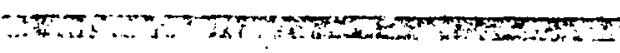

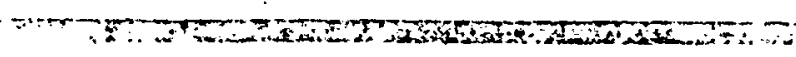

and

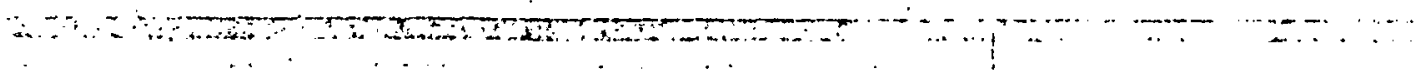


- eouation paraiteters

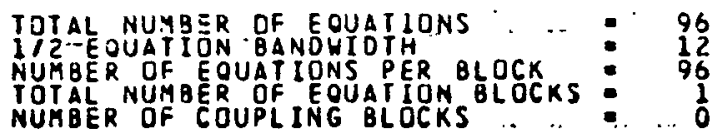
TOTAL NUMBER OF EQUATION

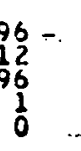

.
$\vdots$
$\therefore$
$\therefore$
$\therefore$
$\therefore$
$\therefore$
$\therefore$

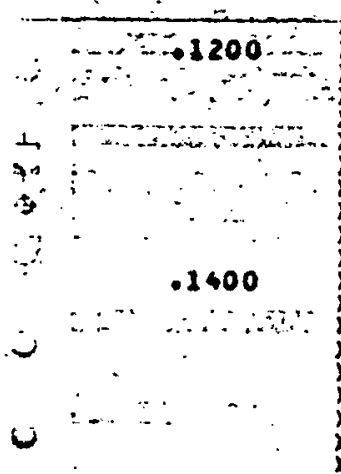
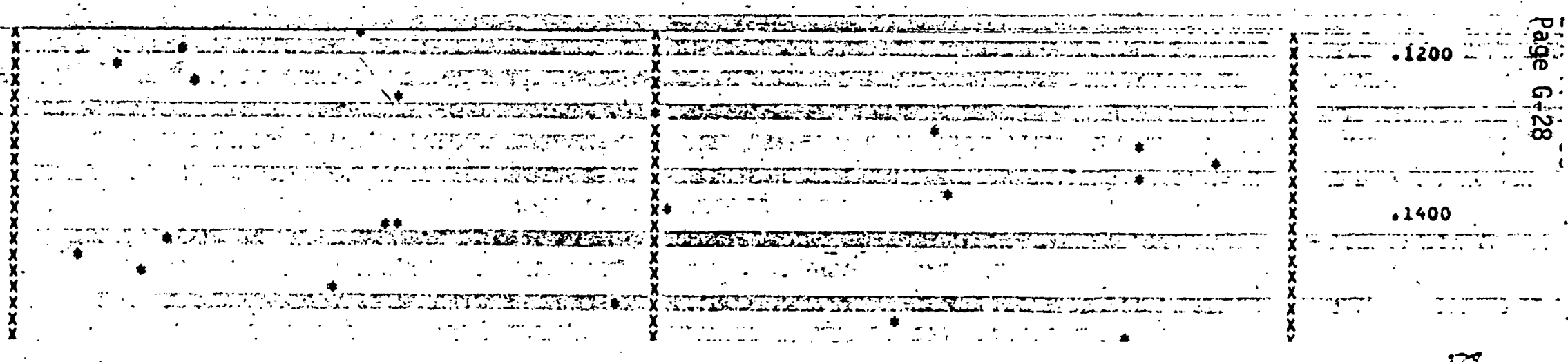


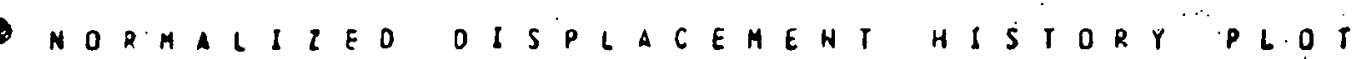
DUTPUT SET NUMGER = 1

D

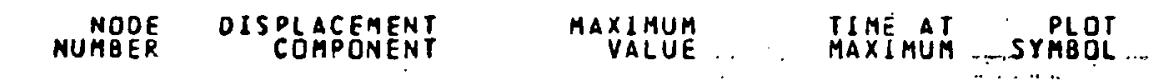

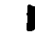

$\begin{array}{r}4 \\ 5 \\ 13 \\ \quad .14 \\ \hline\end{array}$

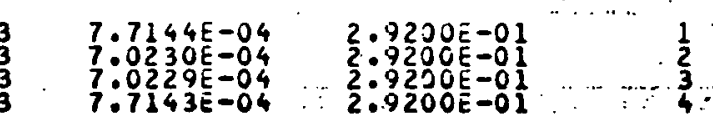

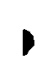

1

.

O R D I NAT E

$\therefore$ \%

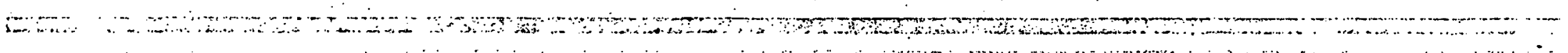

1.

To.050

-
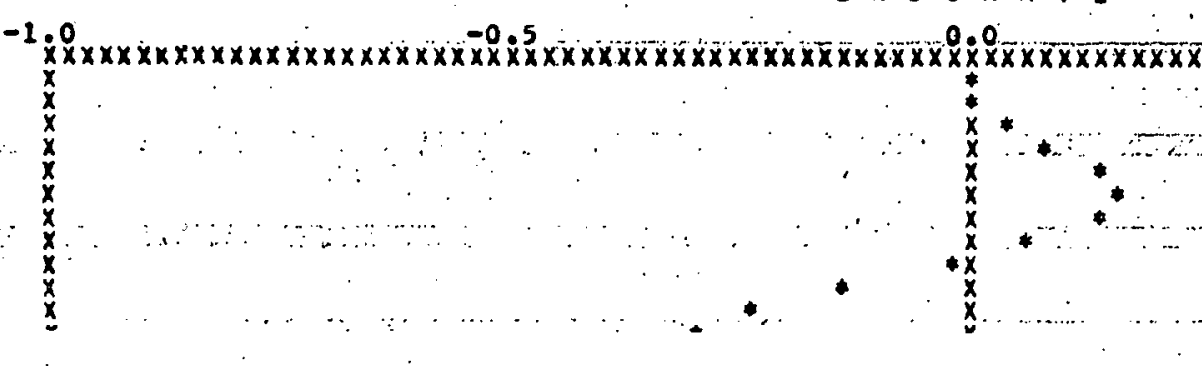

to. 0.0005 
OR O I NATE

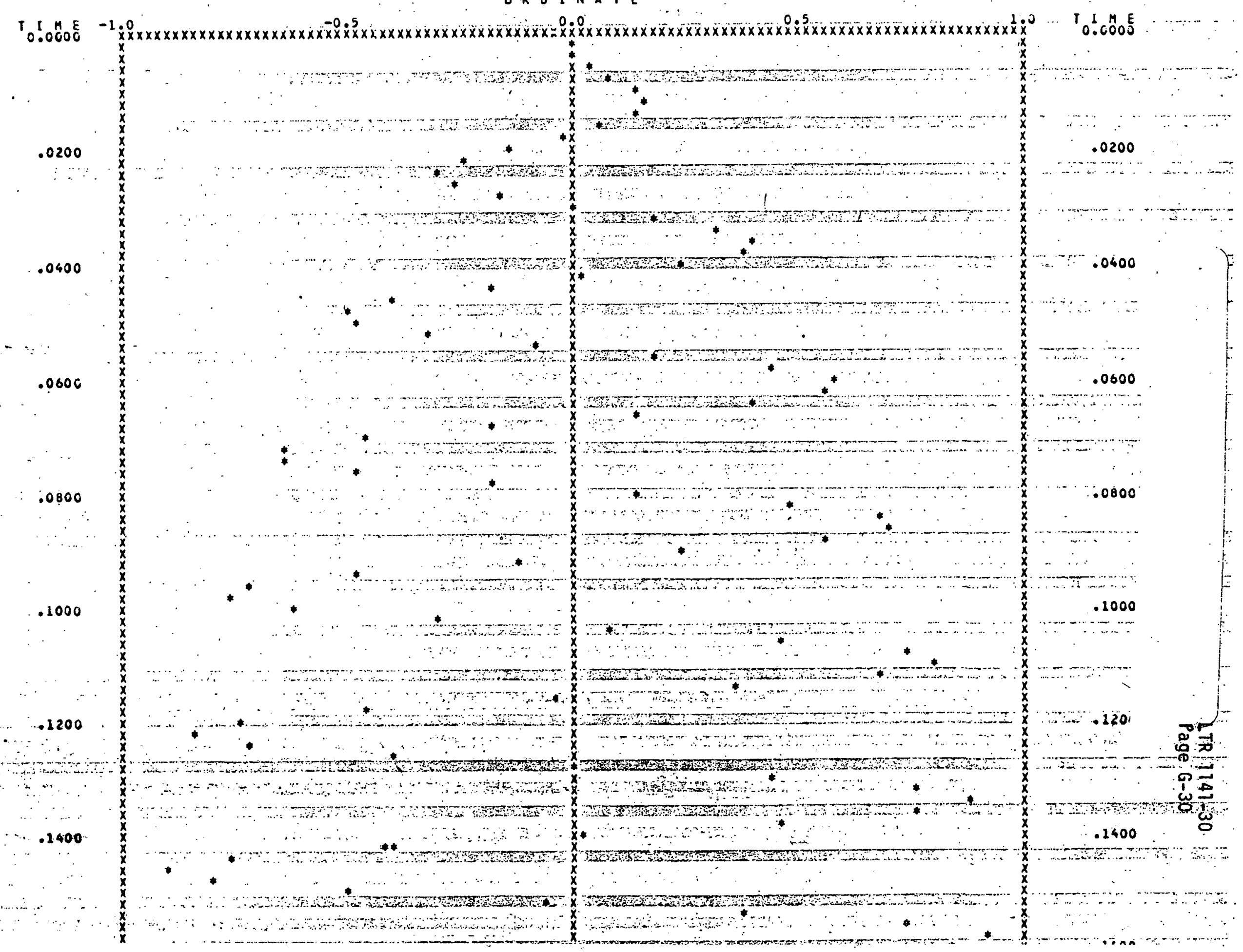




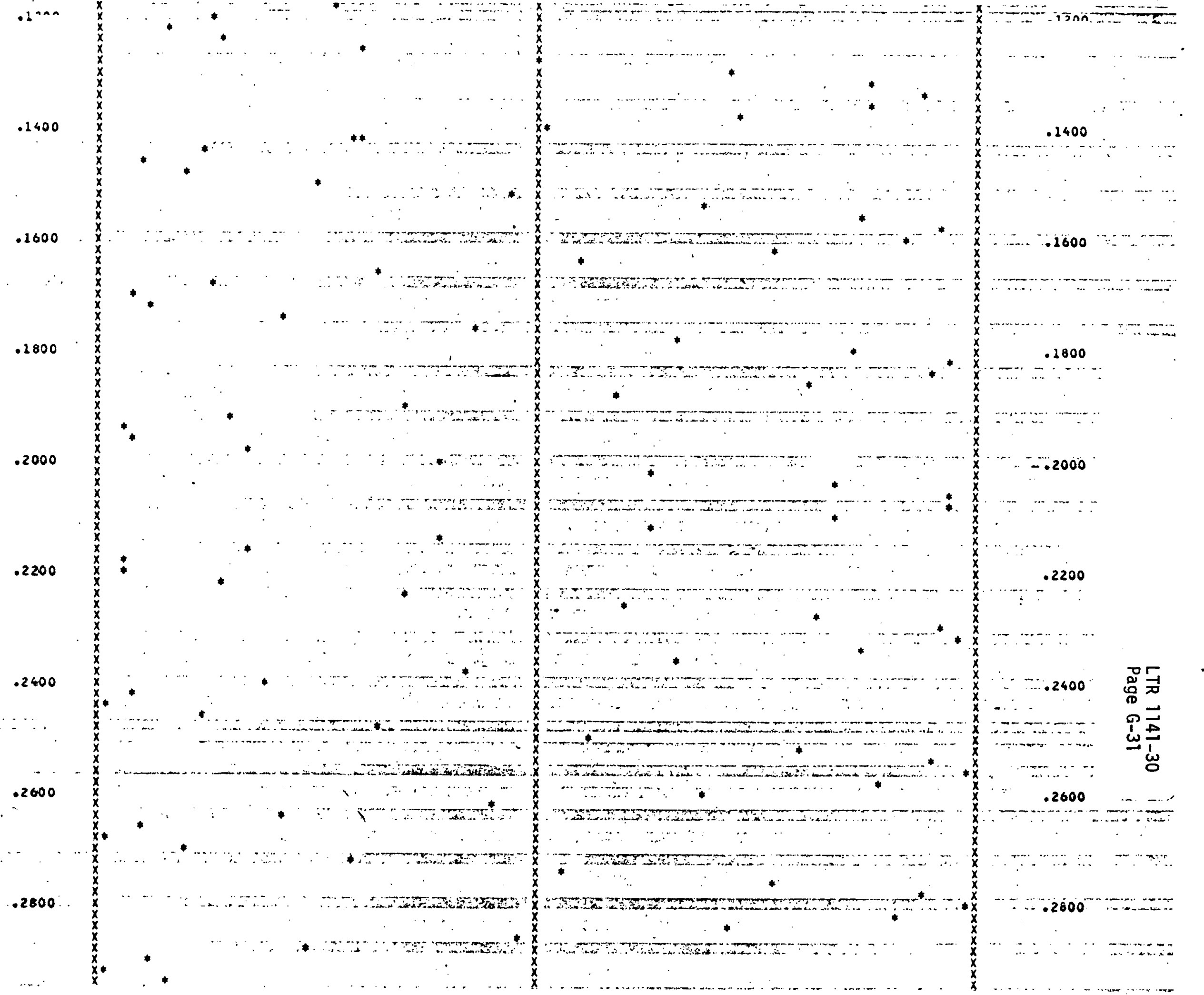




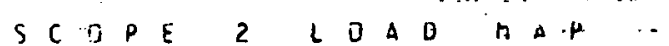

OVERLAY (zi, ()

LI]AD AI 1,310251

PROGRAM WILL BF ENTEPEO AT SBSSÜL

$(32034)$

SCM LENGTH

41622

LCM LENGTH

10
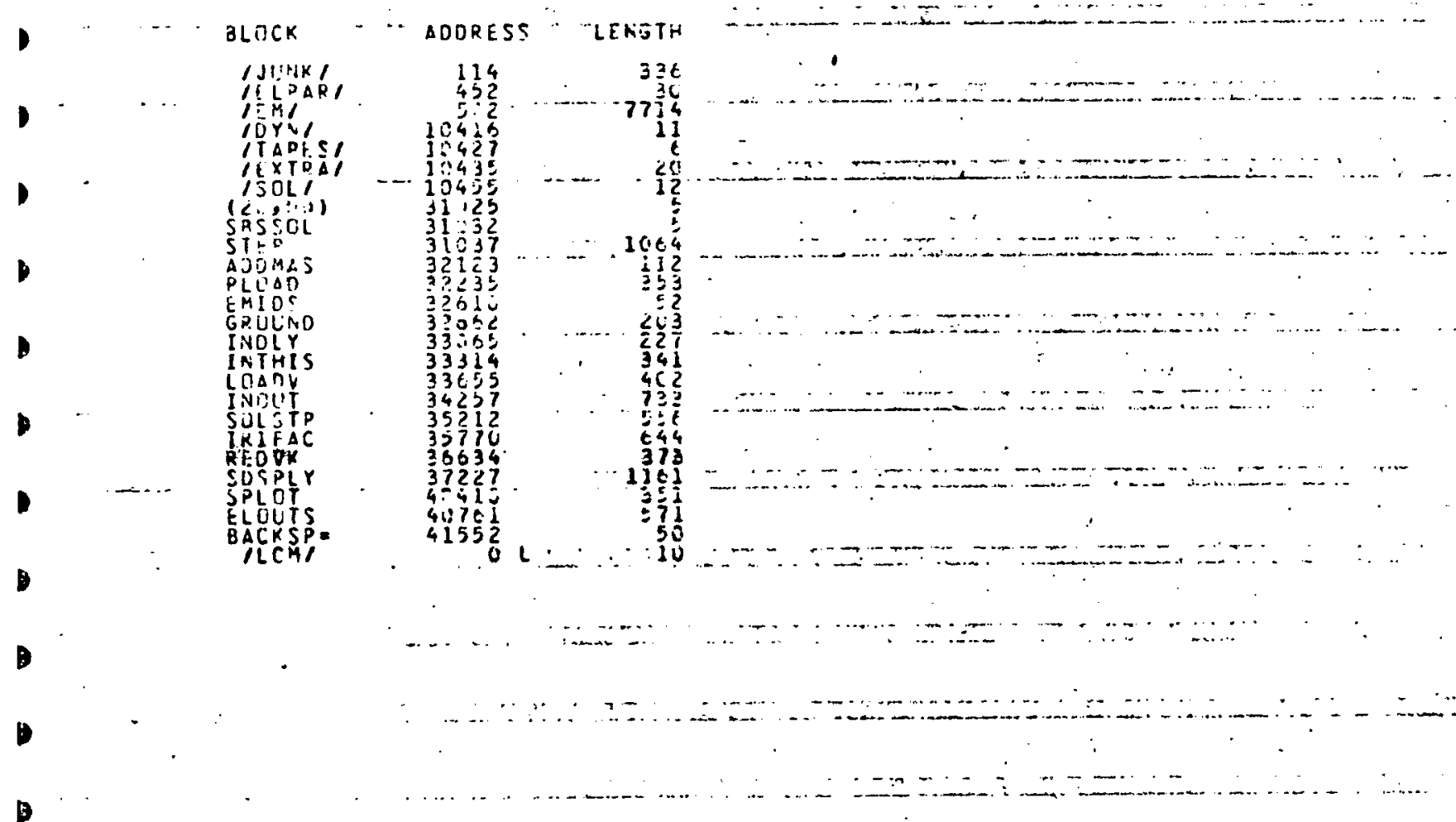

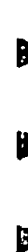
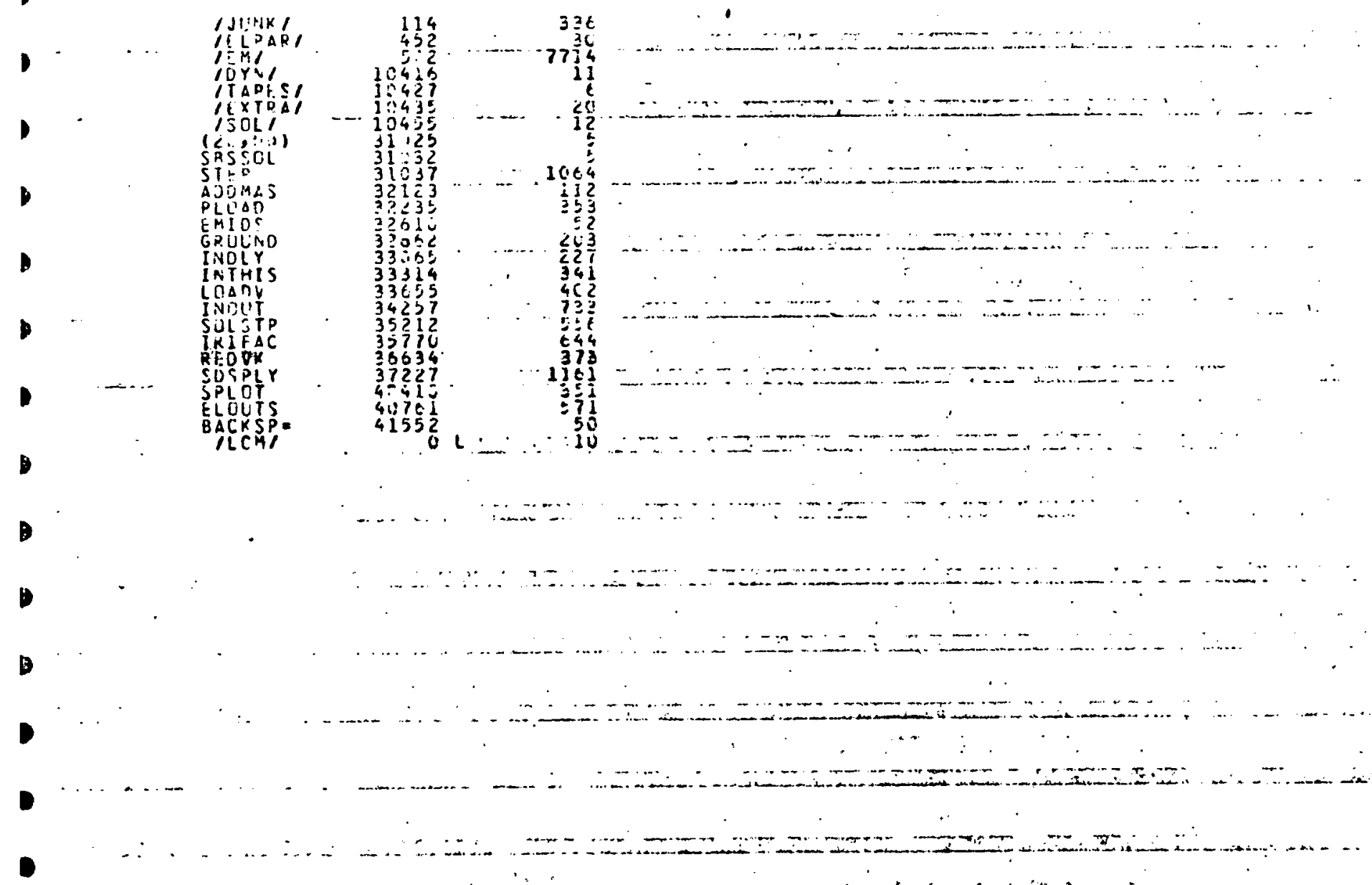

( ...............

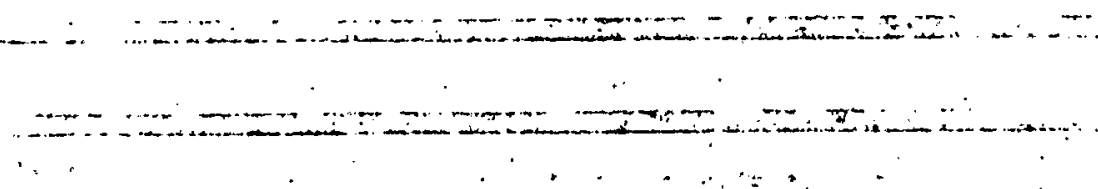

$-3$

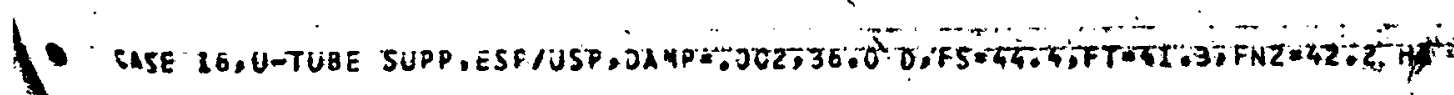

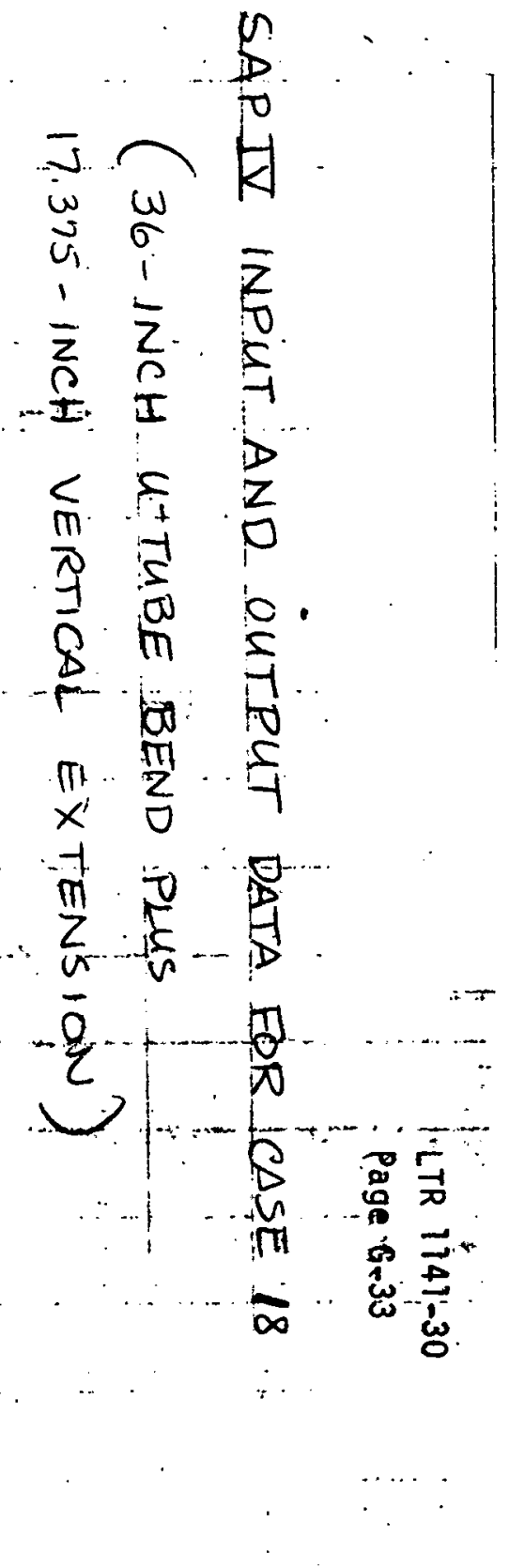

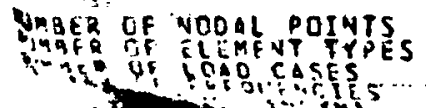

OS LEAD CASESES
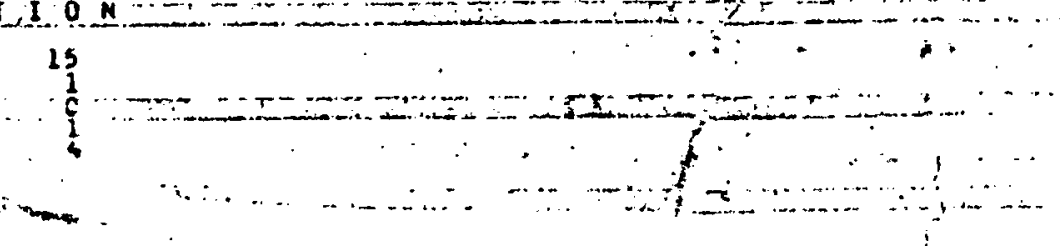


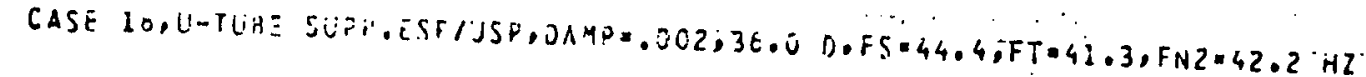

C. ONIREL INFURMAIION

NUMBLR LF MCOAL POIYTS

NUMBCR OF LCAD CASES

ANALYSIS S.JCE TNCTNS

EO: STATIC

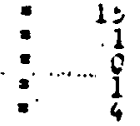

acosigan

SOLCTIUN DIRECT INTEGRATION

Eu. OD, IY CUTIOK

NUTAER'D OATA CHEC

DOERAICN VECTCPS (NAO)

TAPEIOSAVEFLAG (NLOSV):

NODAL POLNT INPLT DATA

- numeer agunoary conditign codes

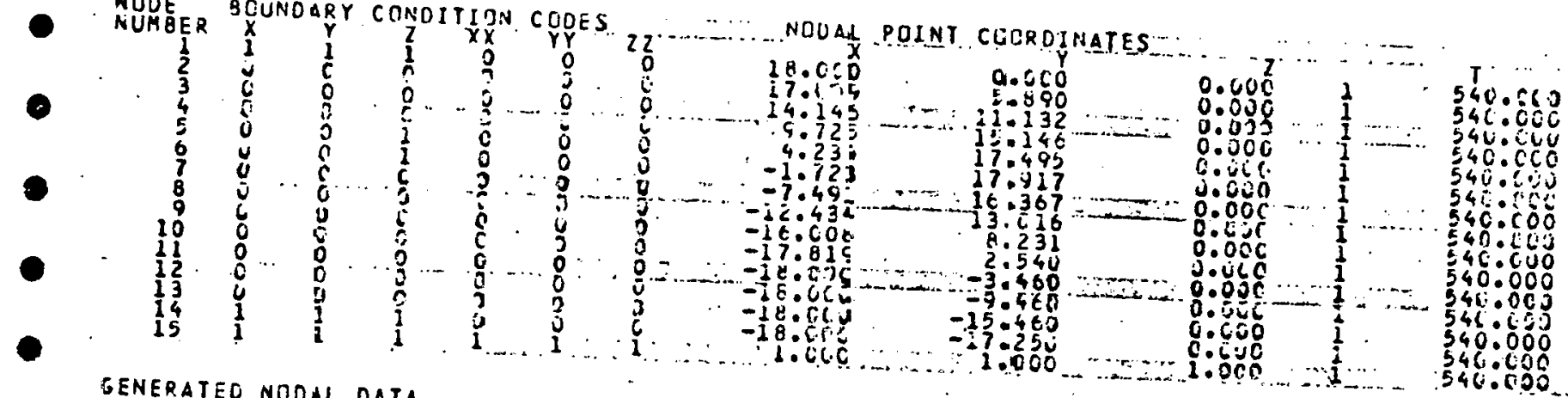

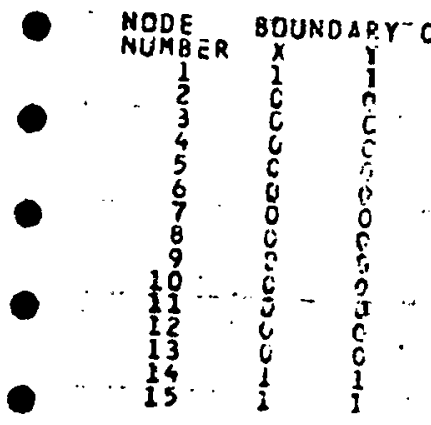
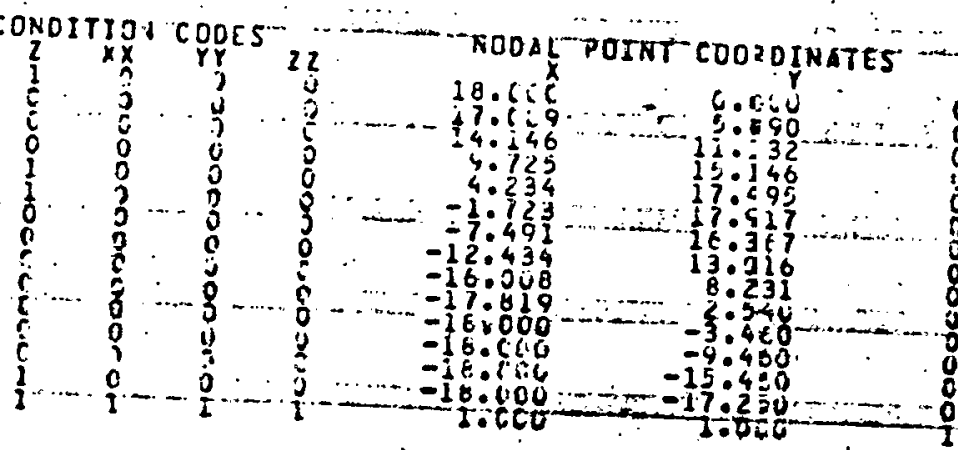

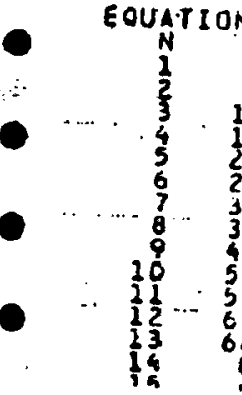
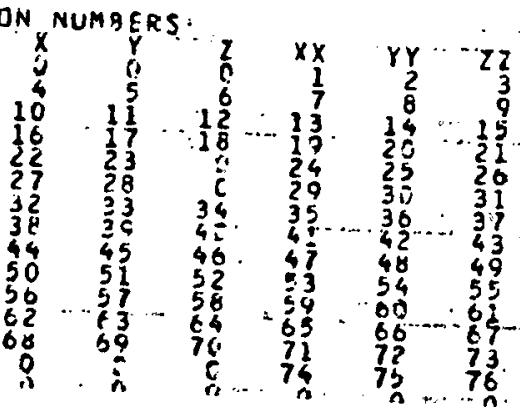

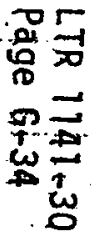




\begin{abstract}
1310 B E A Y E LEMENTS......
\end{abstract}
- NUMgER UF geAMS

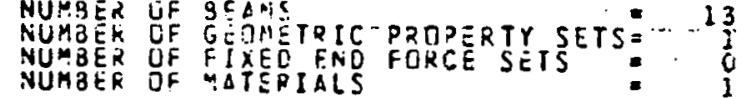

,

MATERIAL PROPERTIES

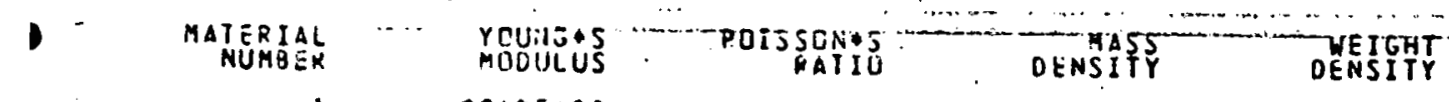

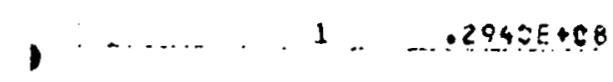

BEAK GEOMETRIC PRDPERTIES

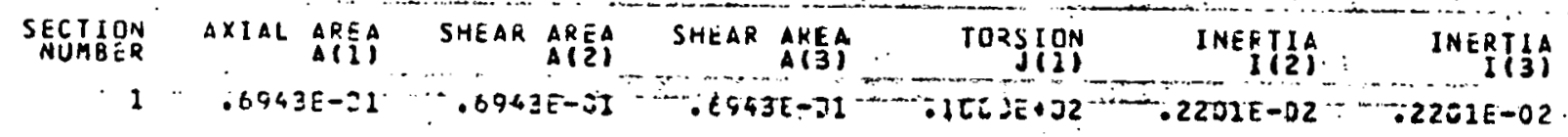

ELERENT LOAO MULTIPLIERS

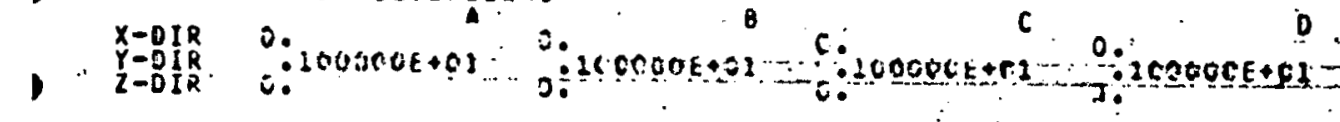

:

- 3/0 Beam elenent data

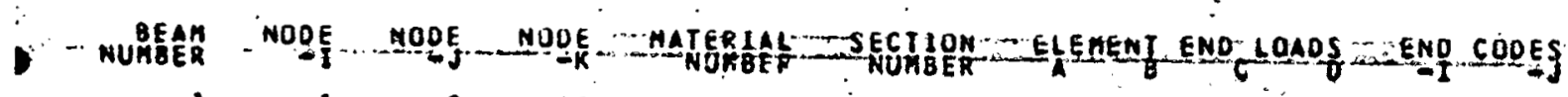

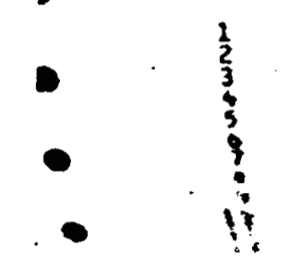

$\begin{array}{ccc}1 & 2 & 45 \\ 2 & 3 & 15 \\ 3 & 4 & 15 \\ 4 & 5 & 13 \\ 3 & 2 & 13 \\ 3 & 4 & 13 \\ 3 & 15 & 13\end{array}$

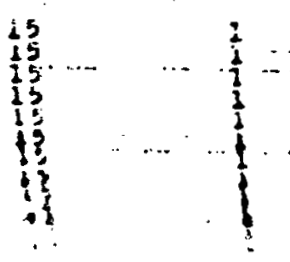

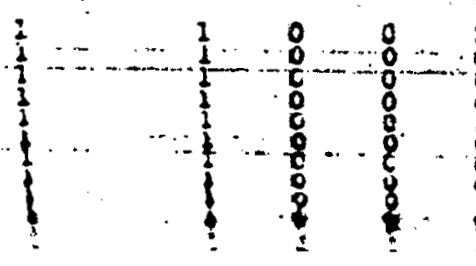

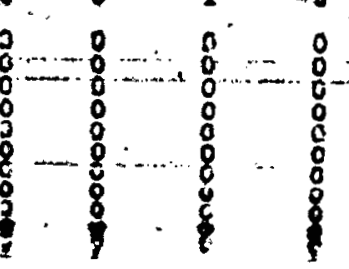




\section{$3 / 0$ BEAM ELFMENT DATA}

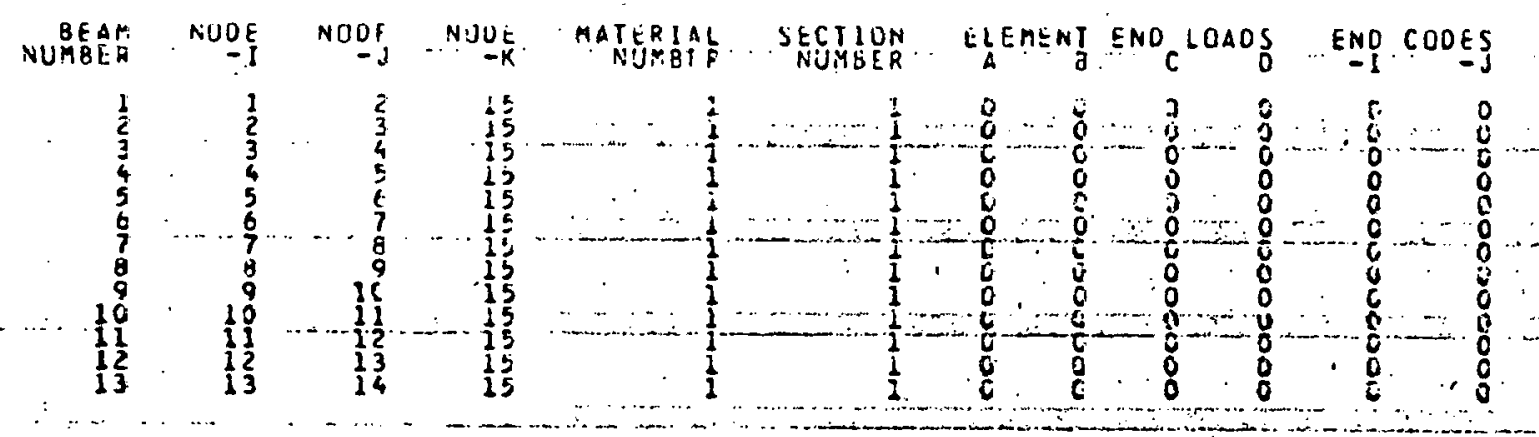


E OUATION PARAMETERS

TOTAL VUMGiR OF EOUATIONS

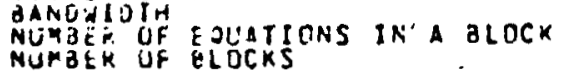

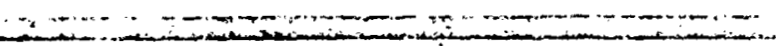

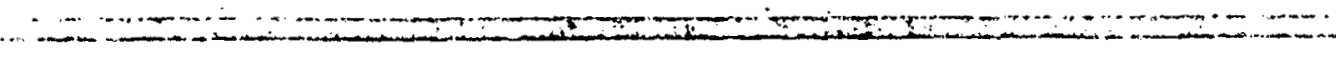

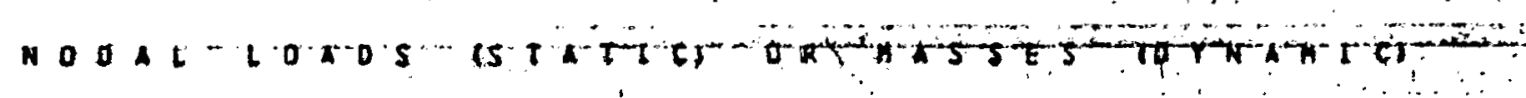

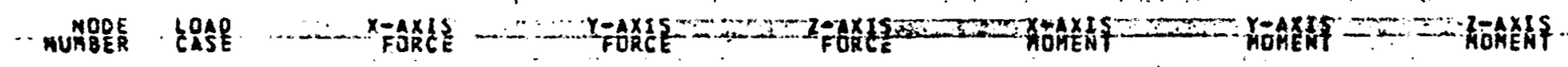

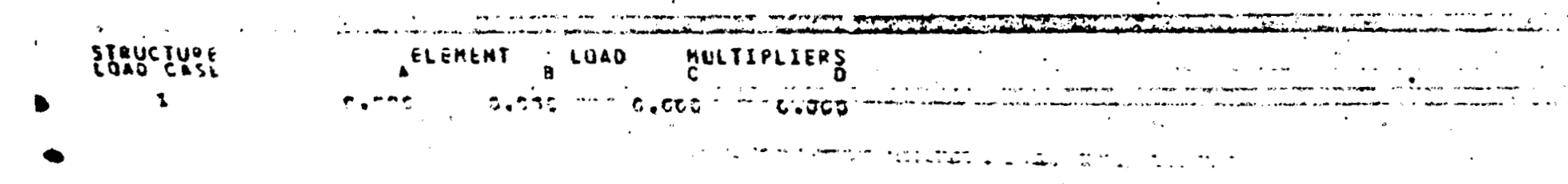




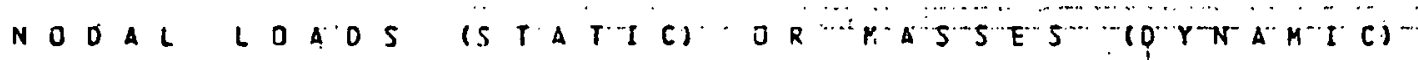

NUMOER LOAD

\section{STRUCTURE
LOADCASE \\ 1}

$$
\text { COLEMENT \& LOAO MULTIPLIERS }
$$

…. $\ldots \ldots, \ldots \ldots$ 
- STEP-B t

NUMBER DF TIME VAPYING FUNCTIONS.

GROUND MOTION INOICATUR

GI:S: NGAE ACEELERAIION IVPUT:

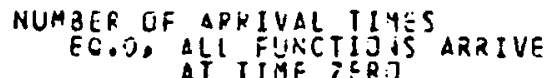

NUYBER OF SCLUTION TIME STEPS

DUTPUI (PRINT) INIERVAL

SOLUTION TIME INCAEMENT

MASS- POEFICIENT (ALPHA) DAL DAMPING

STIFFNESS-PPOPOPTIDNAL OAMPING
COEFFICIENT GEETAI

\section{- 5000}

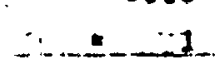

$\therefore=-\cdots 1$

. 2LOUE-02

$+\cdots \cdots$

- $\quad 3320 t-c 3$

,

-

.

1.

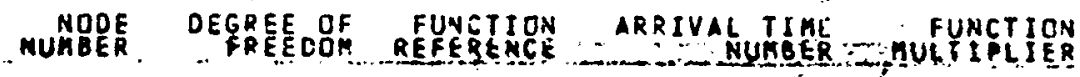
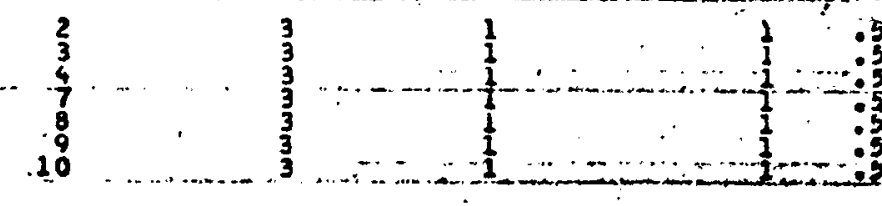


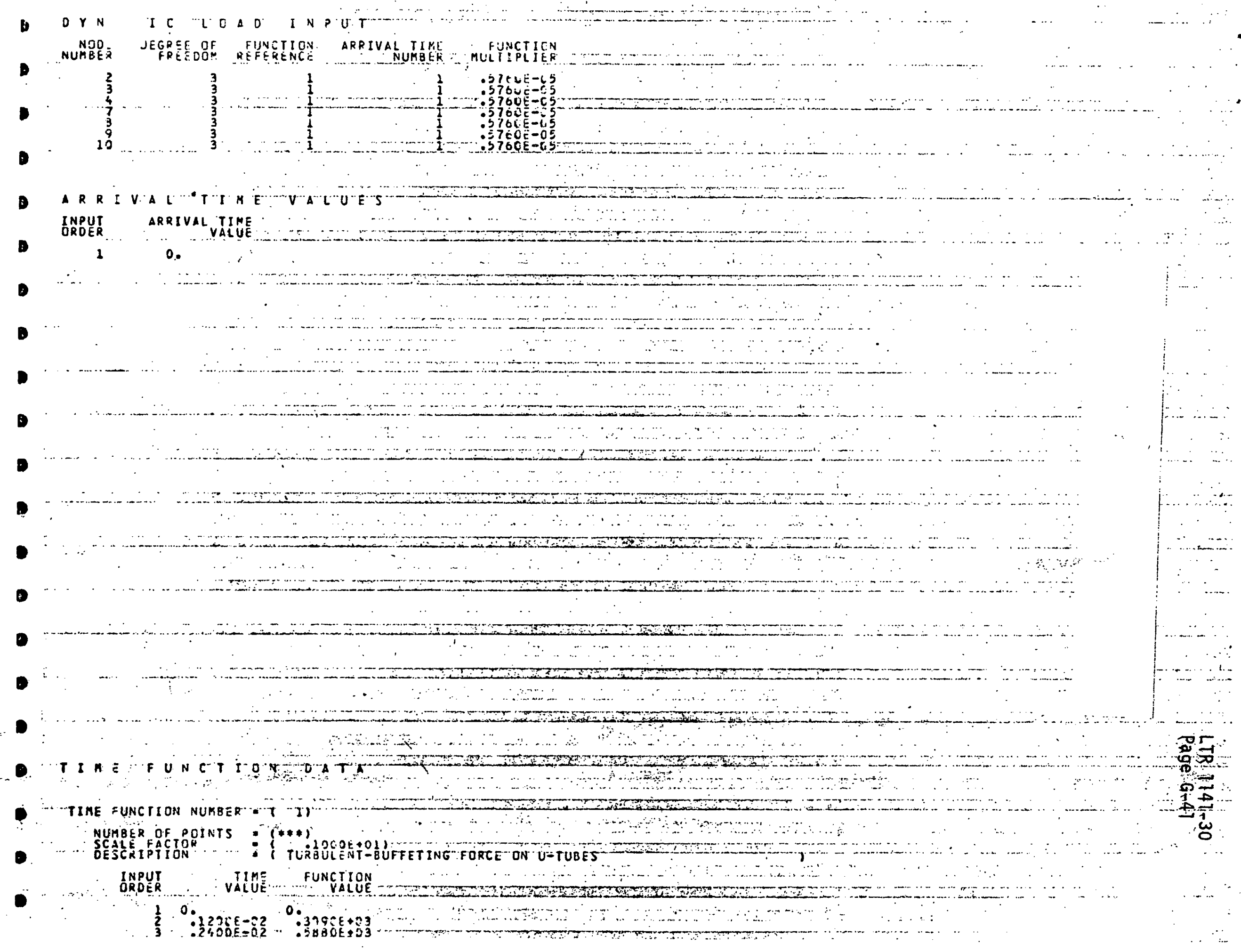




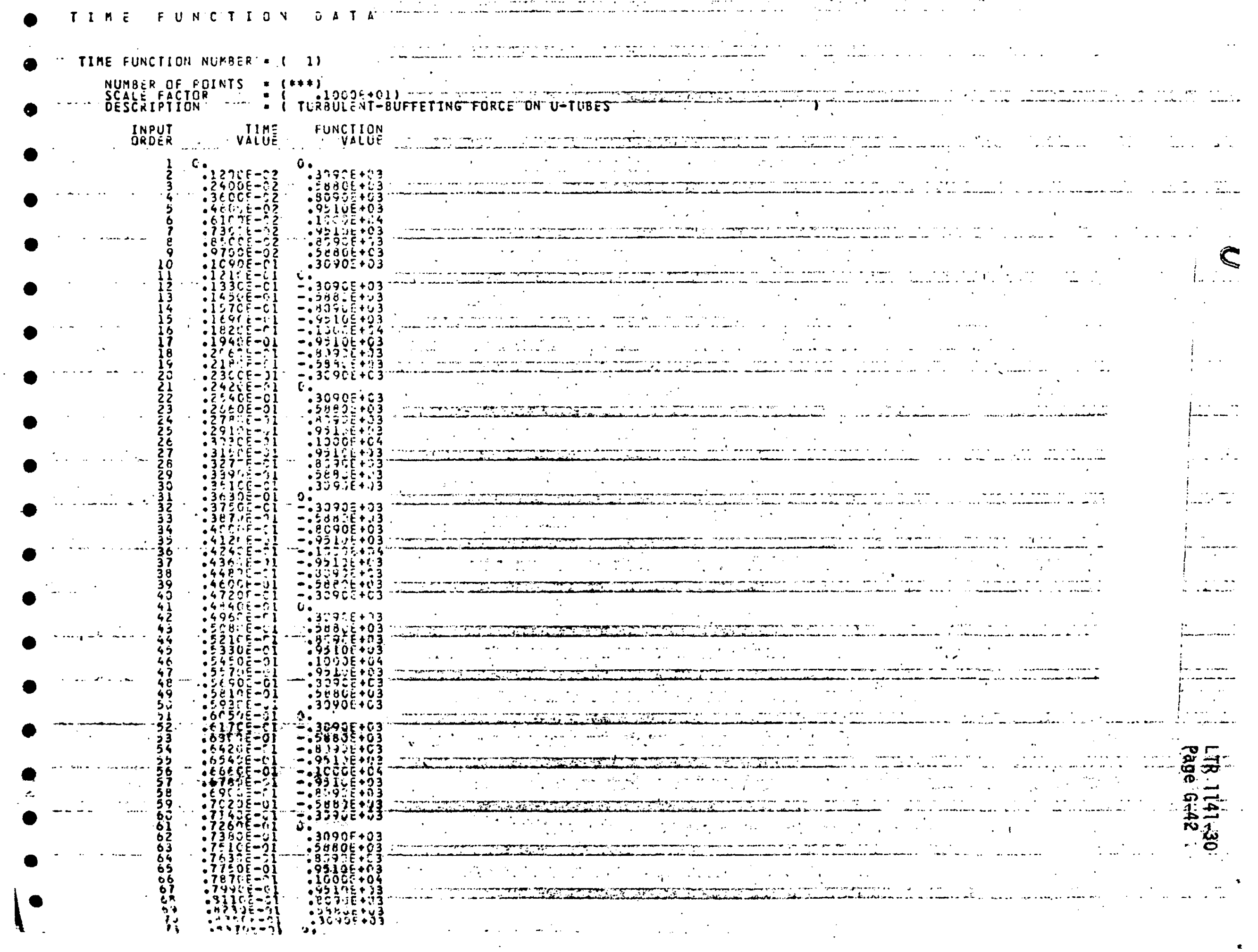




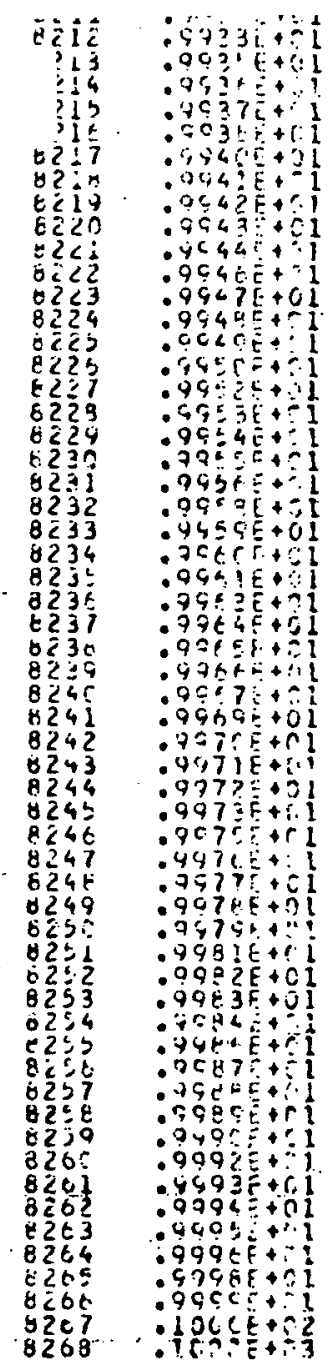

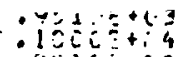

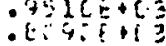
:3jocitio $0 . \operatorname{arghet}$ $=00$ ant: $=0+1$ $-9210+03$ :atitity $02: 9: 2 x+0$ sombitio ap $.9530+03$

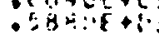
$\because 3: i ;=\ldots+3$ $-: 3 \mathrm{UPCE}+\mathrm{CB}$ $=0$ $=351$ iet $\because a y^{2}$ :asile $-03 \div \div \div+13$ $33925+6$ (5.6. $.9510=03$ 3510 tog

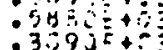
$=: 3096+y^{3}$ $=: 9519+2$

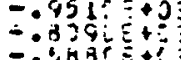
$=: 309: 4: \frac{3}{3}$ 3576et:3

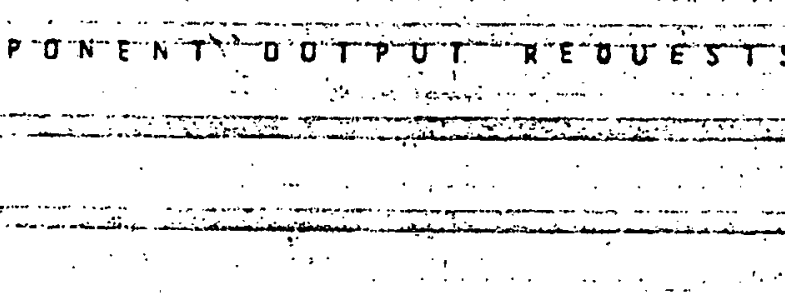




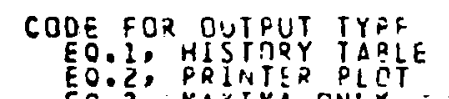 \\ EOD, PRINIER PLCT}

- NUMOER OISPLACEMENT COMPONENT:

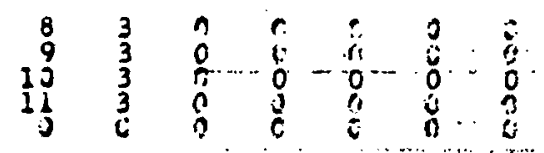

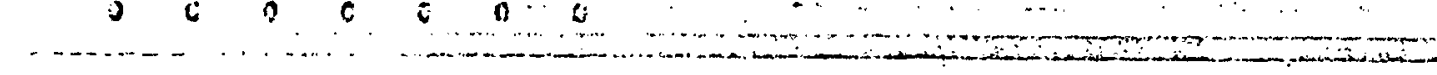

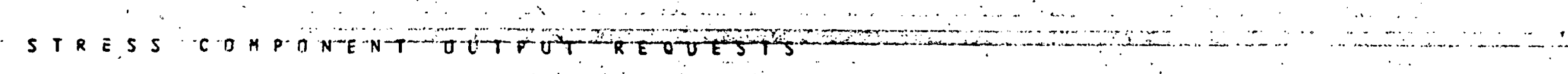

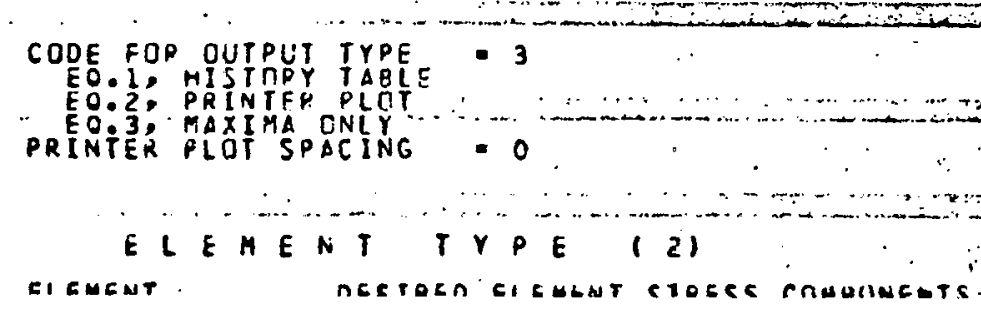

ELEMENT TVPE 1 (2) 


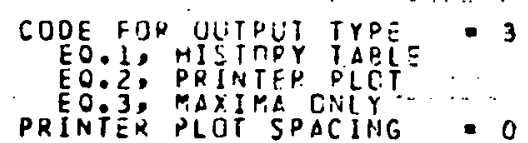

ELEMENT T TPE $(2)$

ELEMENT . * DESIREO ELEMENT STRESS COMPUNENTS O

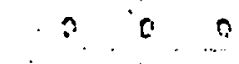

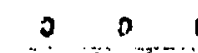

c $?$

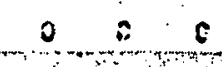


E OUATION P A R.A IS E T E R S .

TOTAL NIIMBER ORF JUATIONS

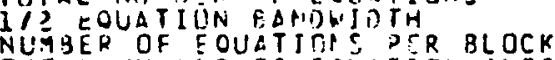

NUTAL NUMBER OF EDUATION BLCCKS
NUMBER OF CCUPLIMG BLOCKS

$$
\begin{array}{r}
76 \\
=-76 \\
S=\quad 1 \\
=\quad 0
\end{array}
$$

- a..

$A-2=0$

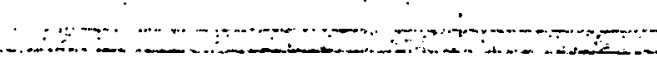

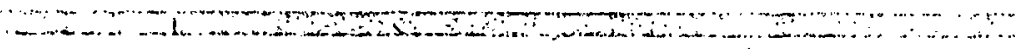

$\therefore$.

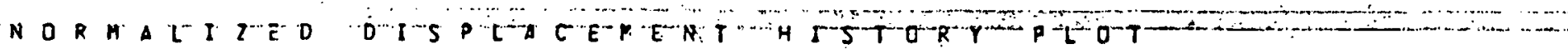
OUtPUt SET NUMger - 1

\begin{tabular}{|c|c|c|c|c|}
\hline $\begin{array}{l}\text { NODE } \\
\text { NUMBER }\end{array}$ & $\begin{array}{l}\text { DISPLACEMENT } \\
\text { COMFONENT }\end{array}$ & $\begin{array}{l}\text { MAXINUM } \\
\text { VALLIIE }\end{array}$ & MIME AT & SYPLOT \\
\hline $\begin{array}{r}B \\
23 \\
12 \\
12\end{array}$ & {$\left[\begin{array}{r}3 \\
3 \\
3 \\
3 \\
3\end{array}\right.$} & $E-E-4$ & 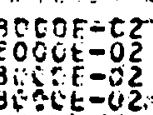 & 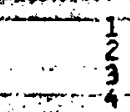 \\
\hline
\end{tabular}


No R M L

E D D L S L L U C E E H OUTPUT SET

NUABDE OISPLACEMENT

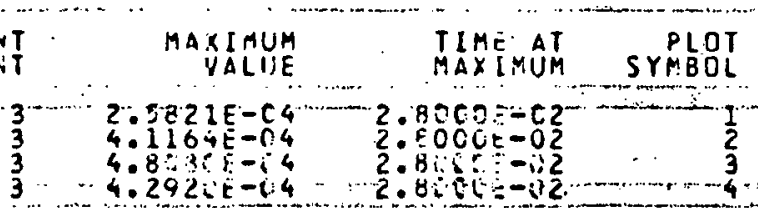


$O R$ O I NAIE

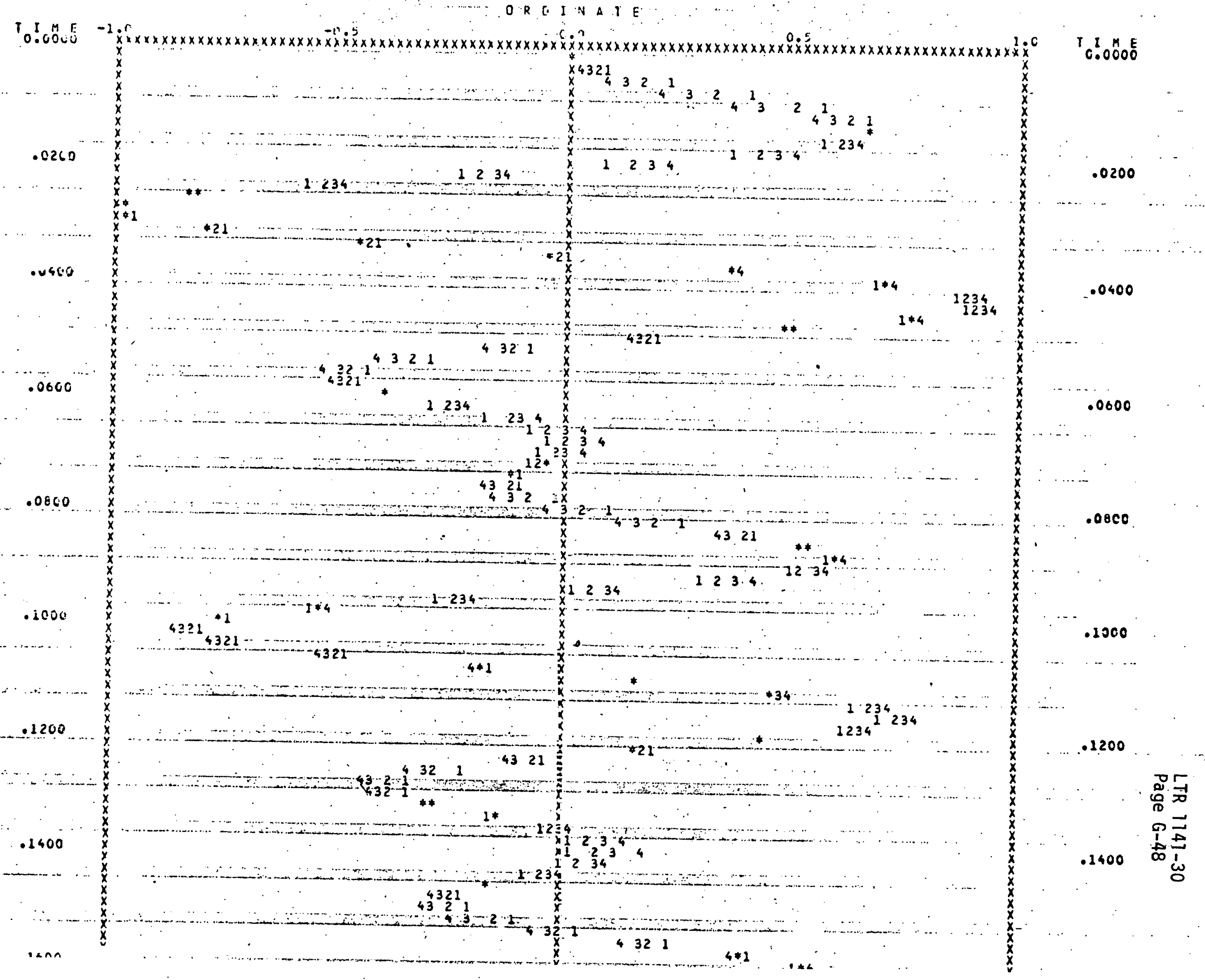




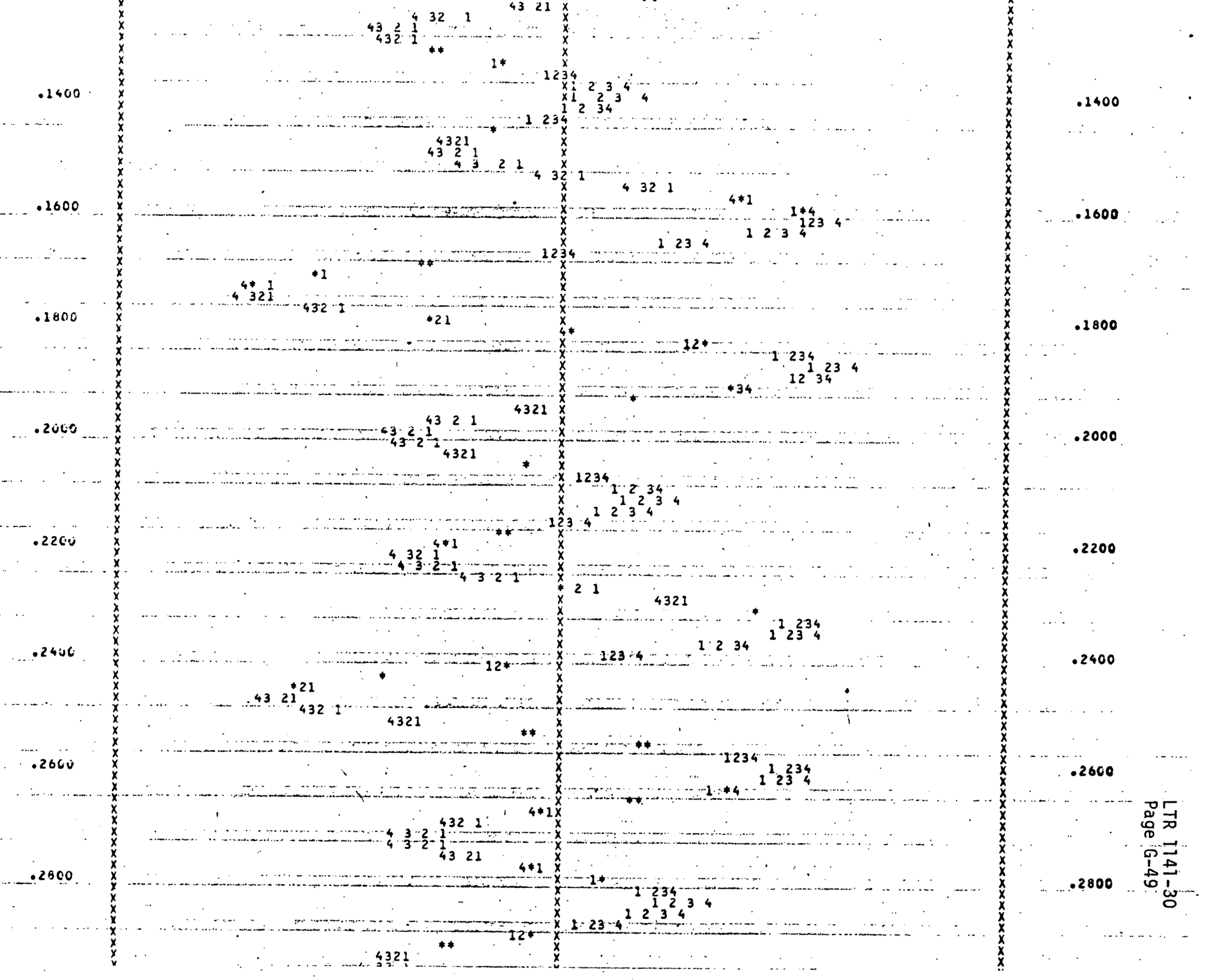




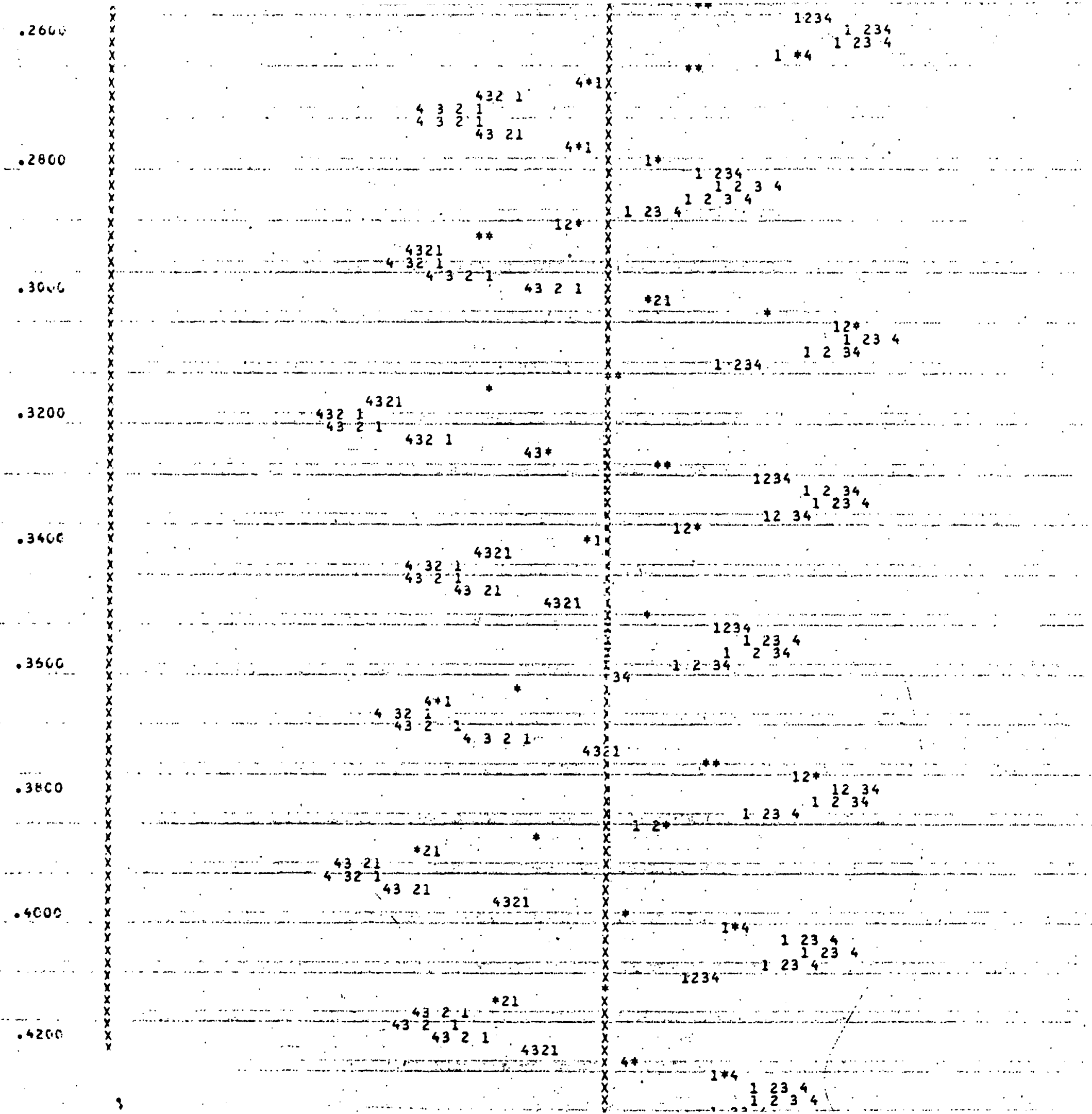

.2600

.2800

.3000

.3200

.3400

.3600

.3800

.4000

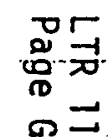

.4200 它志 
APPENDIX H

Flow Parameters for LOFT Steam

Generator Straight-Tube Sections 


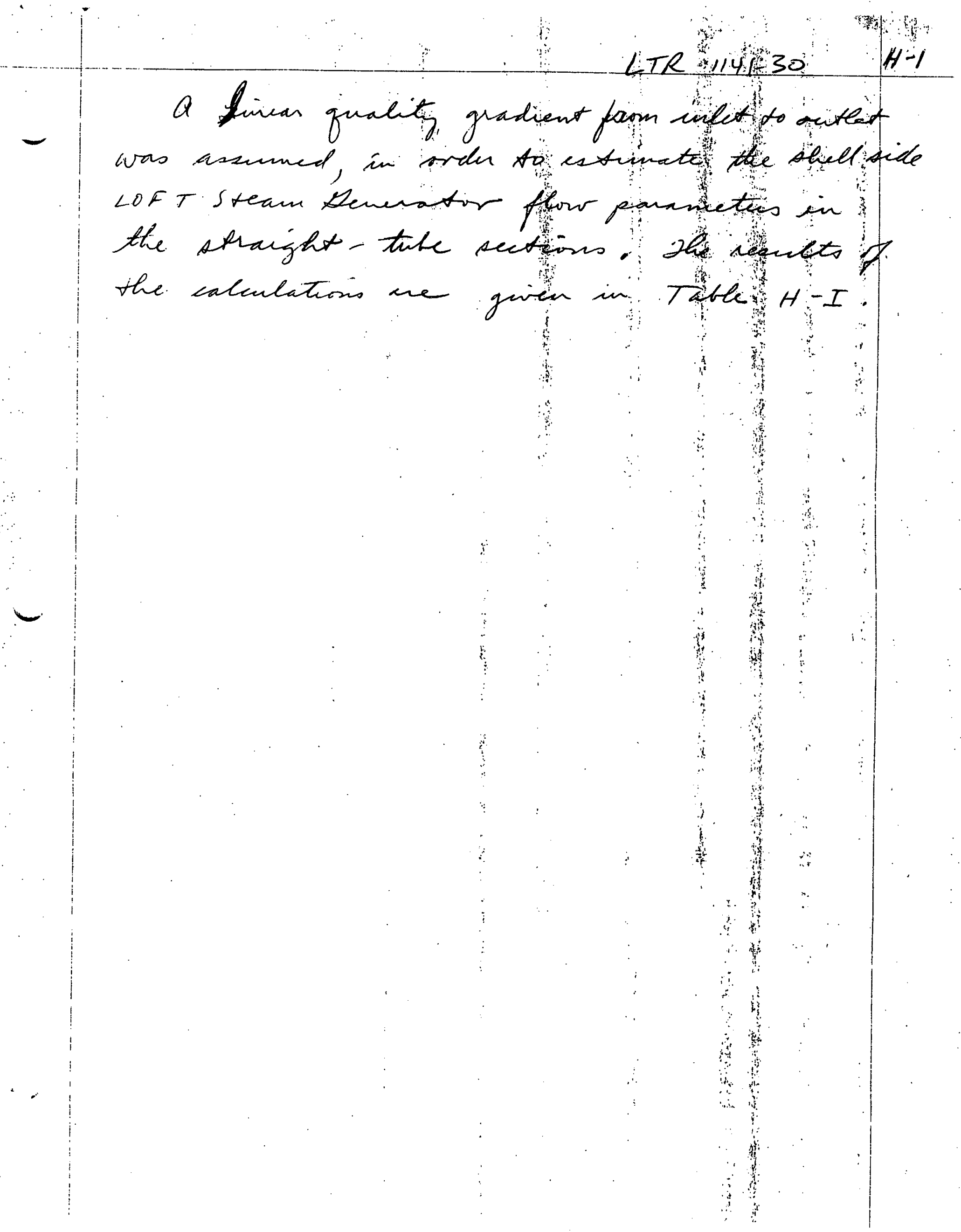




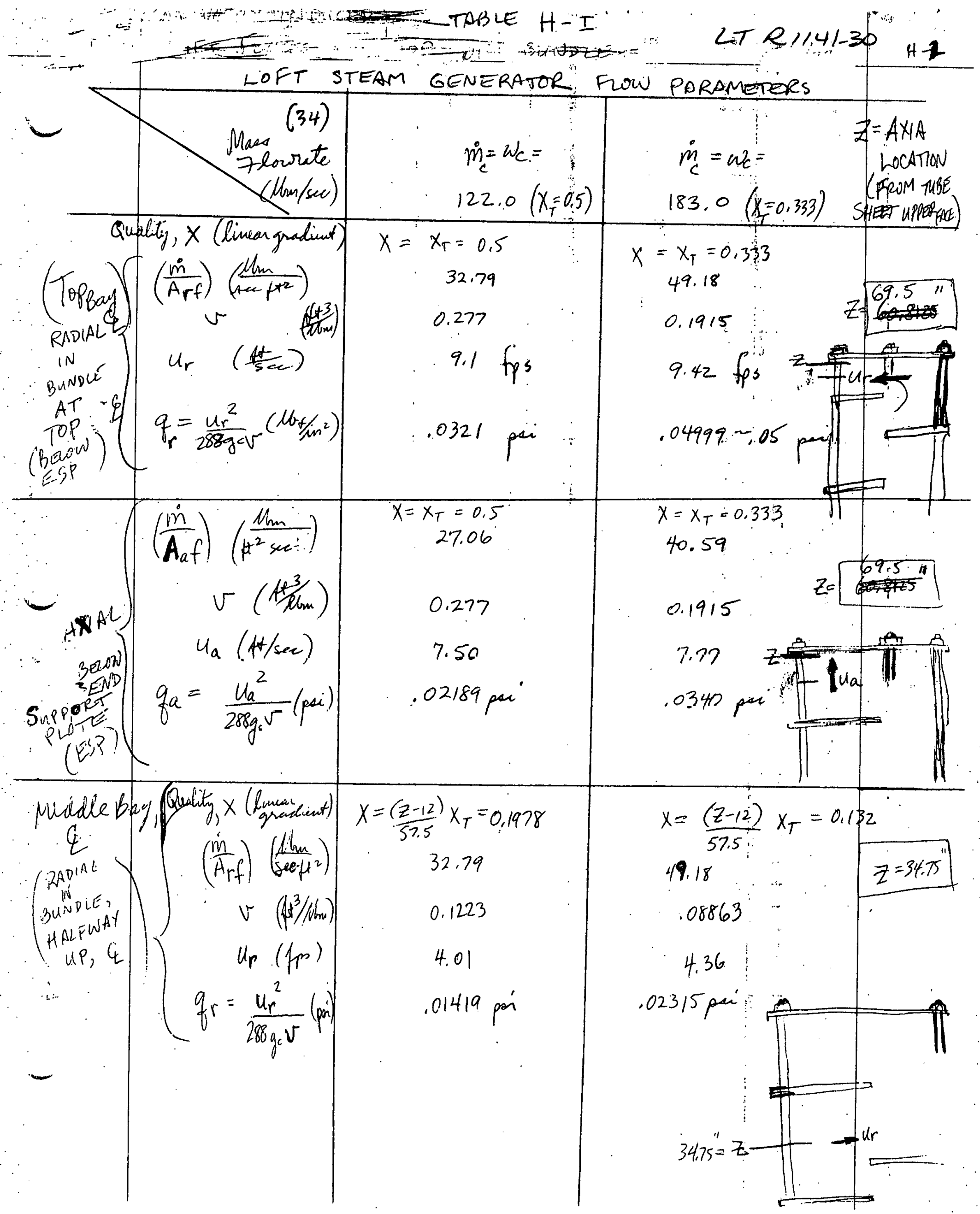




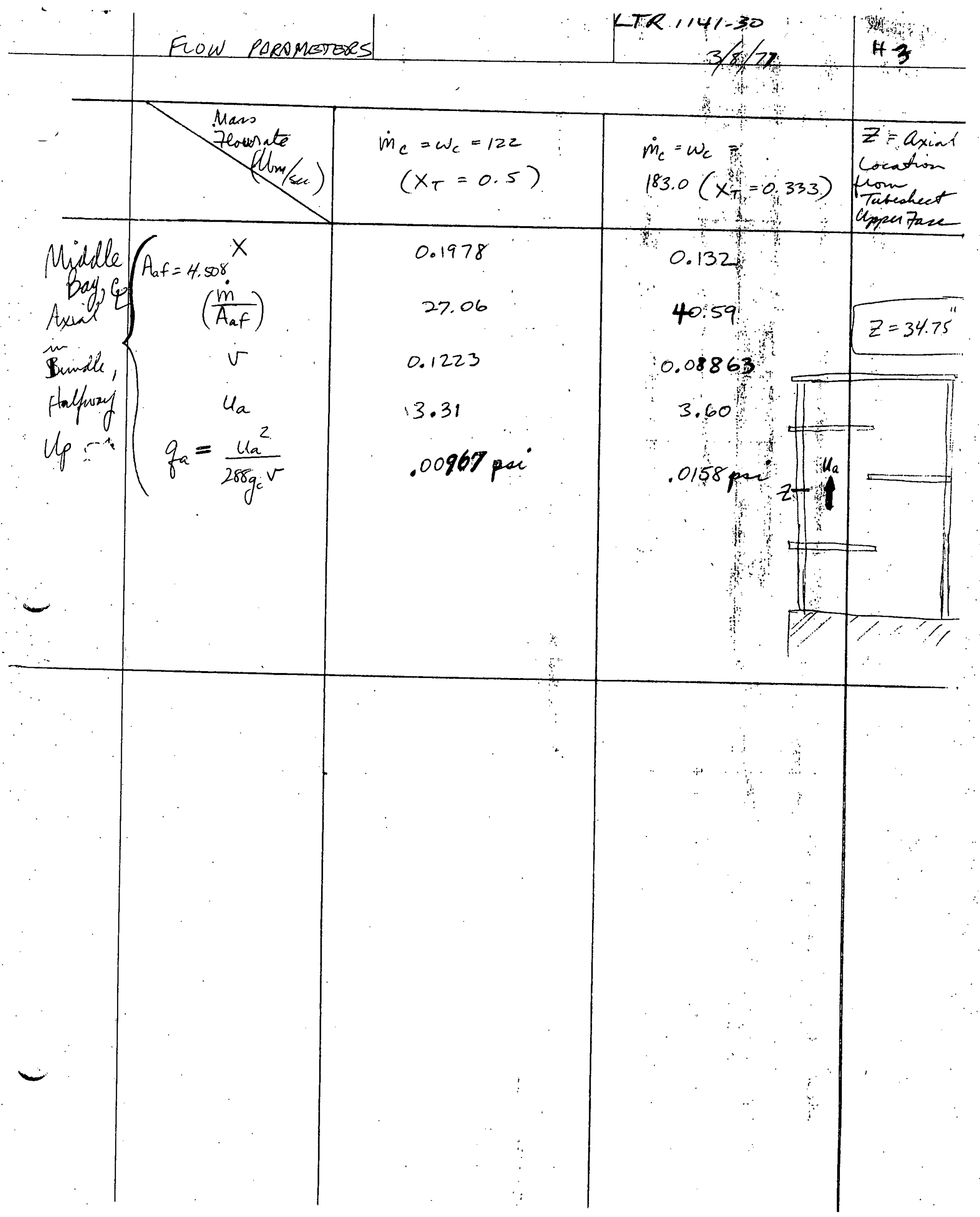




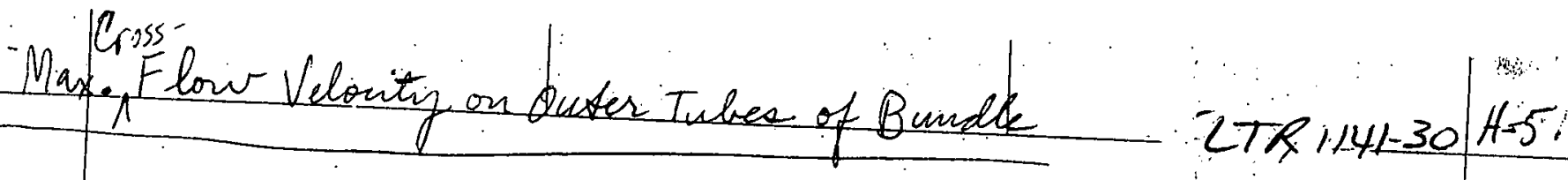

$$
\begin{aligned}
& \text { Assumptions: } 50 \%>x_{\text {top }}>33 \% \\
& \text { 1) } 122<w_{c}<183 \mathrm{um} / \mathrm{sec} \text {. } \\
& \text { 2) Uniform axial velocity profile radially across bufudle } \\
& \text { (Uniform wis flex distinbution) } \\
& \text { - Clinkaze through 3/16" holes in safe pleteo } \\
& \text { helps intake the flows uniform.) } \\
& \text { 3) All mas flow wanined to go around hip if } \\
& \text { brute (leakage thronging 3/16" holes neglectefe } \\
& \text { for vilouty calculations) } \\
& \text { 4) Crossfluiv velocity related to axial velonty } \\
& \text { by ratio of cross-section areas in the } \\
& a_{\text {mine velocity }}=\frac{\dot{m i v}}{\text { A }_{\substack{\text { axial } \\
\text { flow }}}}=\frac{\text { min }}{\text { oaf }} \\
& \text { Axial low area, } A_{\text {af }} \cong 1 / 2\left[\pi / 4(\text { Io } 0)^{2}-3690 \pi / 4(0.5)\right] \\
& A_{a f} \cong 1 / 2\left[\pi / 4(50.75)^{2}-3690 \pi / 4(0.5)^{2}\right] \text {. } \\
& A_{\text {af }} \cong 649.2 \mathrm{in}^{2}=4.508 \mathrm{ft}^{2} \text {. }
\end{aligned}
$$

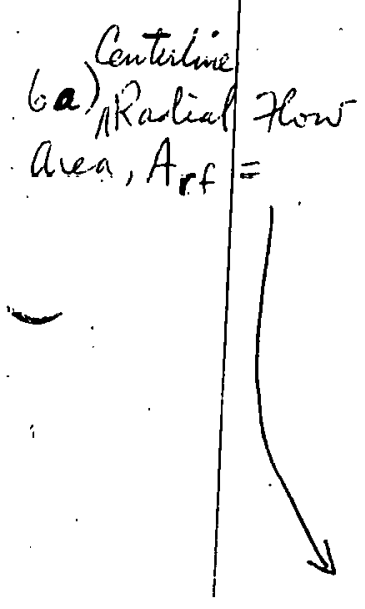

$$
\begin{aligned}
& \text { Illaximum velocity occurs at top if bundle whence } \\
& v^{\prime \prime} \text { are greatest. }
\end{aligned}
$$

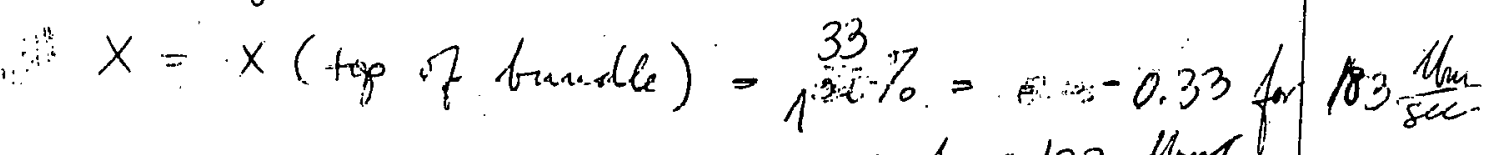

$$
\begin{aligned}
& =0.50 \text { for } 122 \text { Mmpa }
\end{aligned}
$$




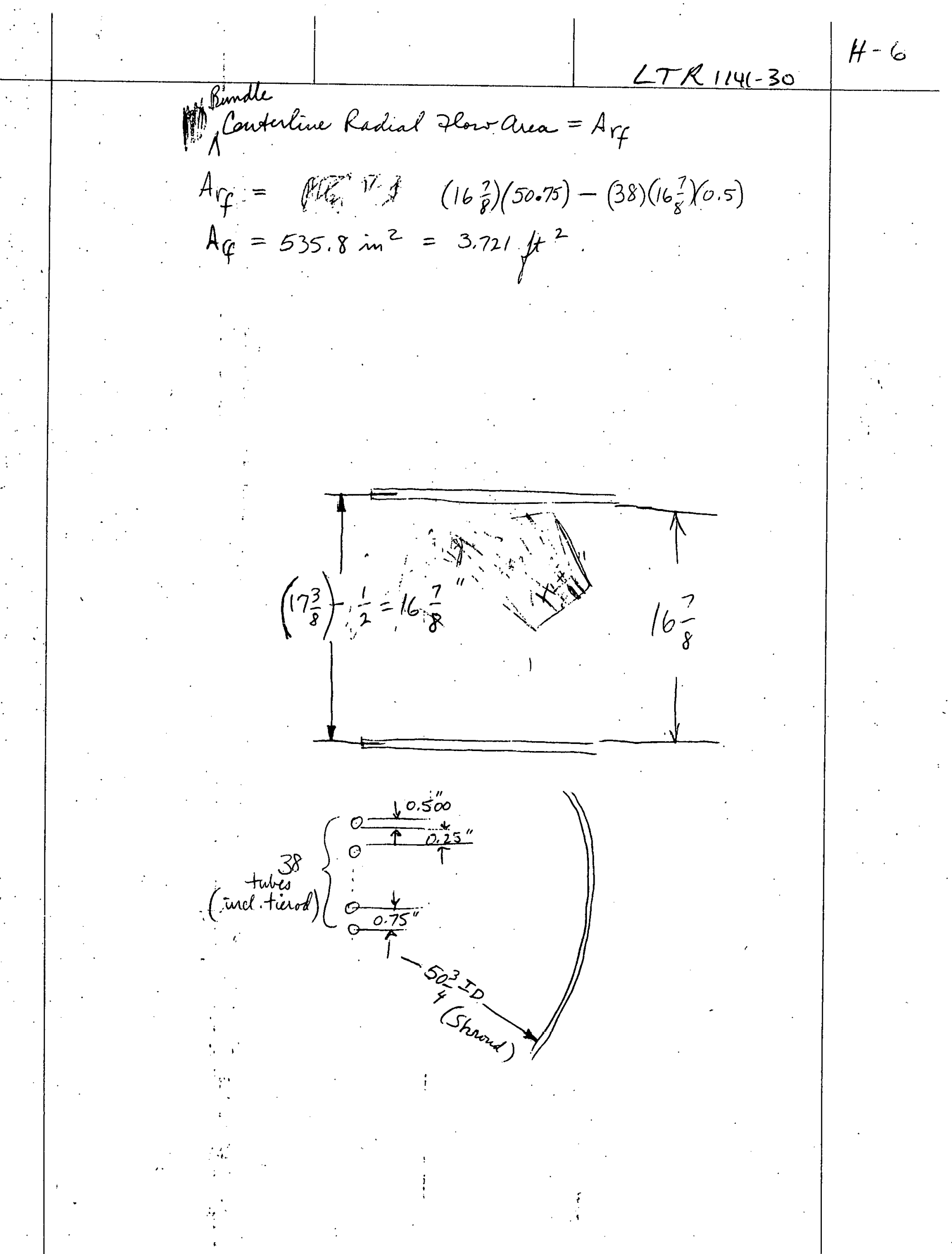


Velocities for $\dot{m}=183 \mathrm{Mm} / \mathrm{sec}$ at top $1 \mathrm{~B}$ LTR 141-30 H-7

$$
\begin{aligned}
\Rightarrow\left(\frac{\dot{m}}{A_{a f}}\right) & =\frac{183 \mathrm{Mm} / \mathrm{sec}}{4.508 \mathrm{ft}^{2}}=40.59 \frac{\mathrm{Mm}}{\mathrm{sec}_{\mathrm{t}}^{2}} \\
\left(\frac{\dot{m}}{A_{\text {rf }}}\right) & =\frac{183 \mathrm{Mm} / \mathrm{me}}{3.721 \mathrm{ft}^{2}}=49.18 \frac{\mathrm{Mhm}}{\mathrm{\mu eff}^{2}}
\end{aligned}
$$

$P=850$ psia

$$
\begin{aligned}
& v=v_{f}(850)+x v_{f g}(850) \\
& V_{183}=0.02105+(0.333)(0.51197)=0.1915443 / 16 m . \\
& u_{a}=u_{\text {axial }}=\frac{\dot{m} v}{A_{\text {af }}}=\left(\frac{\dot{m}}{A_{\text {af }}}\right) v=(40.59)\left(\begin{array}{l}
0.915 \\
\text {.5. }
\end{array}\right.
\end{aligned}
$$

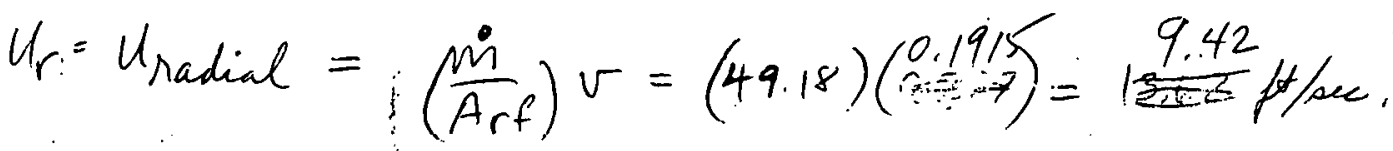




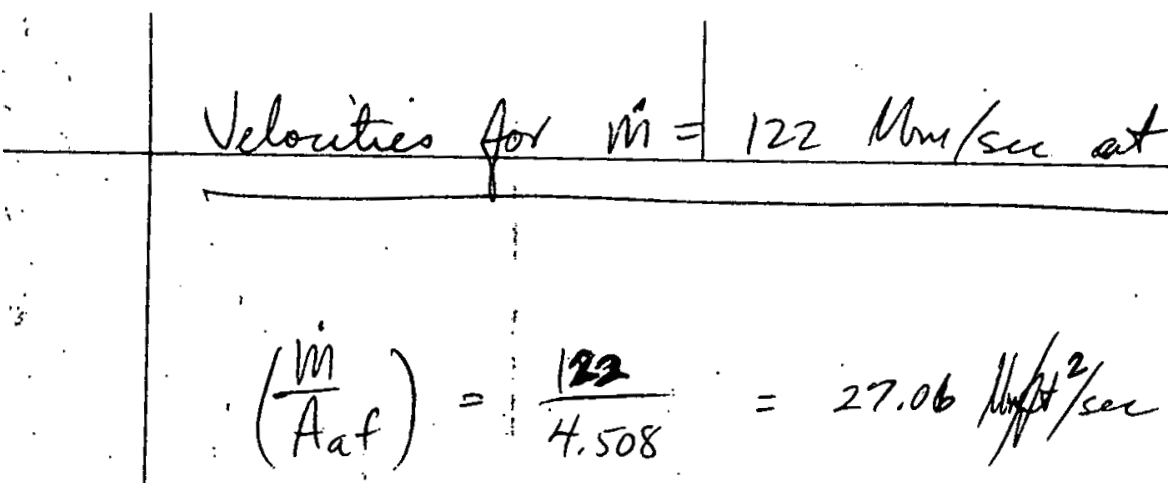

$$
\begin{aligned}
& \left(\frac{i^{\circ}}{\text { Arf }}\right)=\frac{122}{3.721}=32.79 \mathrm{~mm} / \mathrm{pt}^{2} / \mathrm{sec} \\
& P=850 \text { poia } \\
& v_{122}=v_{f}+x v_{f g}=0.277 \\
& u_{a}=\left(\frac{\dot{m}}{A_{a f}}\right) v=(27.06)(0.277)=7.50 \mathrm{fos} \\
& u_{r}=\left(\frac{\dot{m}}{A_{r f}}\right) r=(32.79)(0.277)=9.1 \mathrm{fre}
\end{aligned}
$$


dat1: NOV 199997

to DISTRIBUTION

irom LOFT CDCS, TAN 602, Ext. 6329

subject DOCUMENT TRANSMITTAL

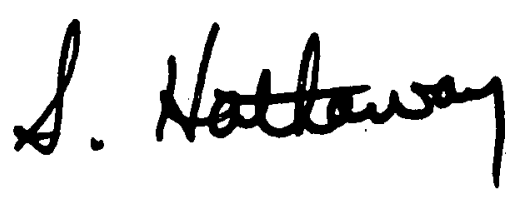

The following documents released by LOFT CDCS, are hereby transmitted for your use and information:

\begin{tabular}{|c|c|c|c|}
\hline DOCUMENT NO. & REV. & CHG. & DATE \\
\hline LTR $1147-30$ & $\emptyset$ & & $10-18-77$ \\
\hline
\end{tabular}

"Flow-Induced Vibration Study in the LOFT Steam Generator"

REMARKS: See attachment 1 for resolution of recommendations.

DISTRIBUTION

E. C. Anderson w/o Attach

S. Matovich

B. 0 . Anderson

G. D. McPherson

J. G. Arendts

L. F. Burdge w/o Attach

H. M. Burton

R. L. Chapman

J. L. Clark

J. C. Commiander

0 . R. Meyer w/o Attach

G. A. Dinneen

B. L. Freed (Original + 7)

R. C. Gottula

C. A. Moore

N. E. Pace

R. G. Rahl

K. Rose - 3

W. A. Spencer

D. H. Stevenson

R. C. Guenzler

R. B. Swartzwelde-

J. C. Haire

G. L. Hunt $w / 0$ Attach

J. A. Hunter $/ j$ i"sumita

R. E. Tiller

W. C. Townsend

j. R. Jones

E. D. Uldrich

D. Engelman

N. C. Kaufman w/o Attach

J. P. Kester

J. L. Li iebentha 1

A. S. Lockhart

L. S. Masson

F. K. Hyer. 
This analysis was performed under WBS 521515, nodes NF 953-957 to determine if tube flow induced vibration was anticipated to be a problem for the LOFT steam generator. The analysis concluded that flow induced tube vibration should not cause tube failure during its in-' tended operational life. Gross flow instabilities within the steam generator could cause tube damage. If such an instability occurred it would be detected during operation and a subsequent investigation would be initiated to assess the effect on the plant at the instability prior to resumption of operation.

The tubes are periodically inspected to detect tube damage utilizing the eddy current technique as part of the LOFT requalification program. A basel ine was obtained in 1976. The next scheduled inspection is tentatively to be performed after the $L 2$ series. Subsequent inspection intervals will be determined from the post 12 series results.

If a tube failure does occur between eddy current testing, the primary to secondary coolant leakage will be detected by routine monitoring of the secondary coolant gross activity. Once such leakage is detected the problem will be assessed and corrected if required prior to resumption of operation. 